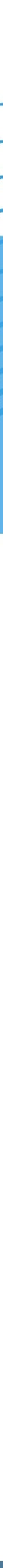

\title{
Connecting the dots
}

Supporting the implementation

of Teacher Design Teams

Floor Binkhorst 


\section{CONNECTING THE DOTS}

\section{SUPPORTING THE IMPLEMENTATION OF TEACHER DESIGN TEAMS}

Floor Binkhorst 


\section{Graduation committee}

Chair

Prof. dr. Th.A.J. Toonen

\section{Supervisors}

Prof. dr. S.E. McKenney, University of Twente

Prof. dr. W.R. van Joolingen, Utrecht University

Co-supervisor

Dr. C.L. Poortman, University of Twente

Members

Prof. dr. P.C. Meijer

Prof. dr. J.M. Voogt

Prof. dr. J.M. Pieters

Dr. K. Schildkamp

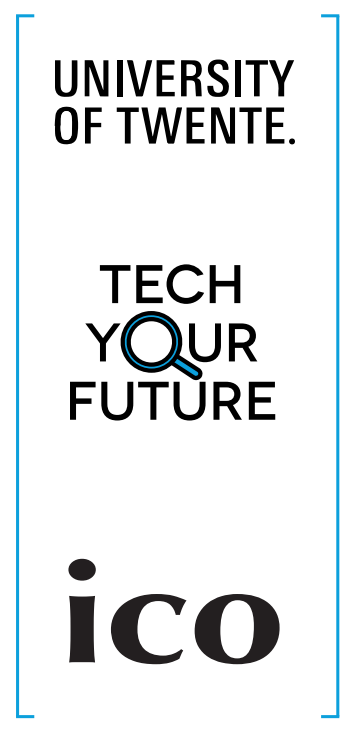

(C) 2017 Floor Binkhorst

Doctoral dissertation, University of Twente

This study was funded by TechYourFuture

Part of the ICO dissertation series

ISBN: 978-90-365-4379-8

DOI: $10.3990 / 1.9789036543798$

Cover: Floor Binkhorst

Layout: Bernard van Gastel \& Floor Binkhorst

Printer: Ipskamp Drukkers B.V. Enschede 


\section{CONNECTING THE DOTS \\ SUPPORTING THE IMPLEMENTATION OF \\ TEACHER DESIGN TEAMS}

PROEFSCHRIFT

ter verkrijging van

de graad van doctor aan de Universiteit Twente,

op gezag van de rector magnificus,

prof. dr. T.T.M. Palstra,

volgens besluit van het College voor Promoties

in het openbaar te verdedigen

op vrijdag 20 oktober 2017 om 14.45 uur

door

\section{Floor Binkhorst}

geboren op 23 april 1985

te Nijmegen 
Dit proefschrift is goedgekeurd door de promotoren en de co-promotor:

\section{Promotoren}

Prof. dr. S.E. McKenney, University of Twente

Prof. dr. W.R. van Joolingen, Utrecht University

\section{Co-promotor}

Dr. C.L. Poortman, University of Twente

(C) 2017 Floor Binkhorst

ISBN: 978-90-365-4379-8

DOI: 10.3990/1.9789036543798 


\section{CONTENTS}

chapter 1

Introduction 1

chapter 2

Understanding Teacher Design Teams: A mixed methods approach to developing a descriptive framework

chapter 3

A qualitative analysis of Teacher Design Teams: In-depth insights into their process and links with their outcomes

chapter 4

Teacher Design Teams for professional development: Guidelines and a nine-step method for coaches

chapter 5

Revealing a balancing act of shared and vertical leadership in Teacher Design Teams

chapter 6

Conclusion and discussion

121

A. References

134

B. Nederlandse samenvatting

143

C. Contributions

152

D. ICO dissertation series

155

E. Dankwoord 

Introduction

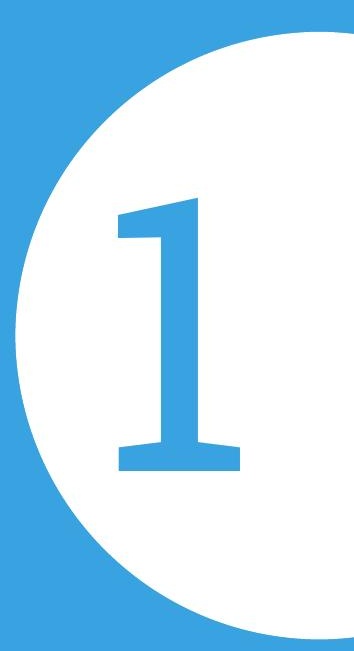


QUOTE "Educational change is just what happens. I mean, I cannot teach the way I was taught when I was a student anymore. Times are changing, society is changing and therefore education is also changing. And as a teacher, I have to move along with these changes... And you can't do this on your own, that's why I joined the Teacher Design Team."

- TDT participant, June 2014.

This quote from a participant in a Teacher Design Team illustrates the context of this dissertation: education that is constantly changing and the important role for teachers who are asked to move along with these changes. This introductory chapter starts by elaborating on the educational context that is changing together with the changing world, with particular attention to the field of science education. Subsequently, the challenges for teachers in (science-related) educational change are described; the importance of actively engaging teachers in educational change is addressed, and teachers' need for professional development to meet the demands of educational change is stressed. After that, essential conditions for engaging teachers in educational change and for effective professional development programs are discussed. Then, the way in which these conditions converge in the concept of Teacher Design Teams (TDTs) is discussed. Subsequently, the potential benefits and the existing challenges for TDTs are described, which give rise to the main aim for this research: supporting the implementation of TDTs. After this, the overall research design of this dissertation is addressed. The four studies that were conducted are described and an overview of the dissertation is given.

\subsection{Context of this study: changing science education}

Today's society is characterized by globalization, information sharing and new technologies (Aikenhead, Orpwood, \& Fensham, 2011; Fisher \& Sugimoto, 2006; Potvin \& Hasni, 2014; Vermunt, 2003), and is often referred to as a 'knowledge society' (Hargreaves, 2003). The knowledge society is based on the acquisition, dissemination and use of information, and is driven by the creativity and ingenuity of its inhabitants. The knowledge society is dynamic in nature, as the speed of changes and innovations increases (Levinsen \& Nielsen, 2011). Learning in the knowledge society therefore comes with many challenges, as students need to learn how to learn and how to keep learning (Aikenhead et al., 2011).

Science education in particular has to deal with two specific issues. First, because the knowledge society is driven by technology and innovation, it heavily relies on people's capacity to deal with science and technology-related situations in their everyday lives (Aikenhead et al., 2011). Thus, to empower students as citizens, there is a specific need to 
familiarize all students with science (Kolst $\varnothing, 2001)$, by developing their scientific literacy (DeBoer, 2000) and their digital literacy (Meyers, Erickson, \& Small, 2013). To give students a more realistic view of what science and technology entail, it is important for teachers to move beyond textbook science and to introduce students to science currently being worked on in laboratories (Kolst $\varnothing, 2001)$.

Second, the innovation-driven knowledge society increasingly calls for educated scientists (DeBoer, 2000) to work on contemporary topics, such as renewable energy, big data and personalized healthcare. However, there have been concerns throughout the world about the low numbers of students that are choosing for a graduate-level education in science, or a career in this field (Aikenhead, 2009; Hampden-Thompson \& Bennett, 2013). Therefore, there have been many efforts to promote students' positive attitude towards science, and their interest in studying science (Osborne, Simon, \& Collins, 2003; Potvin \& Hasni, 2014; van Tuijl \& Walma van der Molen, 2016). Most of these efforts include changes in the science curricula - such as emphasizing contemporary issues and actively engaging students in doing science - to make science more appealing to students (Hampden-Thompson \& Bennett, 2013).

\subsubsection{Changes in science education in the Netherlands}

In response to the demand for changes in science education, new secondary school examination programs for biology, physics and chemistry were introduced in the school year 2013-2014 in the Netherlands. These new programs included a number of ambitions (Boersma, Kamp, Oever, \& van den Schalk, 2010; Commissie vernieuwing Natuurkundeonderwijs havo vwo, 2010; SLO, 2010):

Use of appealing contexts: for example by linking science concepts to students' daily life, society, contemporary science or professions in technology;

Visibility of coherence and connections between the various science subjects: for example by introducing new multidisciplinary topics in the curricula;

Emphasis on scientific literacy for all students: for example by focusing on basic scientific skills and principles;

Motivating and enthusing students for science: for example by strengthening the connections with higher education and technical companies. 
The revised examination programs leave room for teachers to make their own choices. Teachers can, for example, choose to use a general textbook for teaching the basic principles of science, and use additional modules with appealing contexts to teach multidisciplinary topics such as 'biophysics' or 'medicines'. In other words, the new examination programs do not entail one fixed curriculum. This flexibility is intended to leave room for teachers to keep adapting their instruction and for the choice of new topics or contexts.

\subsubsection{Crucial role for teachers in educational change}

The success of educational change largely depends on what teachers do and think (Fullan, 2007; van Driel, Meirink, van Veen, \& Zwart, 2012). As such, there are two main implications related to teachers in the context of educational change. First, successful and sustainable change can never be done to or even for teachers, it can only be achieved by and with teachers (Hargreaves \& Fullan, 2012). In other words, teachers' active participation in decision-making is essential for the successful implementation of educational change (Geijsel, Sleegers, van den Berg, \& Kelchtermans, 2001). Therefore, the current changes in science education can only be successful if teachers are actively engaged.

Second, shifting to new approaches to teaching means that teachers need to learn more about the new priorities, sometimes about new subject-matter content and about how students learn (Garet, Porter, Desimone, Birman, \& Yoon, 2001). Furthermore, teachers need time and practice to understand what educational change implies for their day-to-day activities. Therefore, to meet the demands of educational change, teachers' professional development is essential (Loucks-Horsley, Stiles, Mundry, Love, \& Hewson, 2009). It is widely accepted that professional development can expand teachers' knowledge and skills, which can be used in the classroom to foster changes and improvements in teaching (Desimone, 2009; Guskey, 2002b; Kennedy, 2016). Given that changes are on-going in education, teacher professional development should be a continuous process, starting directly after teacher training and continuing for the teachers' entire professional career (Borko, 2004). 


\subsection{Supporting teachers with educational change}

To support teachers with the aforementioned challenges regarding changes in education, programs aimed at both teachers' engagement in these changes and their professional development are needed. This section first describes conditions that support teacher engagement in educational change and subsequently elaborates on conditions supporting teacher professional development.

\subsubsection{Conditions supporting teacher engagement in educational change}

As educational change often comes with new goals and standards, an effective way to engage teachers in educational change is to involve them in the design of educational materials to meet these goals, which is increasingly considered to be a core aspect of teachers' work (Carlgren, 1999; Cober, Tan, Slotta, So, \& Könings, 2015; Koehler \& Mishra, 2005; McKenney, Kali, Markauskaite, \& Voogt, 2015). Being engaged in the design process can create a sense of ownership of revised curricula (Cviko, McKenney, \& Voogt, 2013; Visser, Coenders, Terlouw, \& Pieters, 2012). When investments are made in adapting new curricula to teachers' own practice, teachers are more likely to be willing to implement educational change (Mooney Simmie, 2007; Wikeley, Stoll, Murillo, \& De Jong, 2005).

However, engaging teachers in the design of educational materials is not automatically successful, as teachers often need to develop their knowledge, skills and confidence in order to enact the design process (Forbes \& Davis, 2010; Huizinga, Handelzalts, Nieveen, \& Voogt, 2013; Stolk, Jong, Bulte, \& Pilot, 2010). Therefore, external support or coaching is an important condition for engaging teachers in educational change. In particular, when teachers are designing educational materials, external support or coaches can help teachers to tackle design challenges and to develop their design expertise (Handelzalts, 2009; Hardré, Ge, \& Thomas, 2006; Huizinga, Handelzalts, Nieveen, \& Voogt, 2014), or can provide subject-matter expertise (Boschman, McKenney, Pieters, \& Voogt, 2016). It is considered important that the support provided is adapted to the teachers' needs (Becuwe et al., 2015).

Furthermore, collaboration is a condition that supports teacher engagement in educational change (Handelzalts, 2009; Johnson, 1993). Collaboration with other teachers creates opportunities to exchange expertise and share reflections with colleagues (Handelzalts, 2009; Havnes, 2009; Huizinga et al., 2013). For example, collaboration can result in a shared understanding of the educational change, which might improve teachers' sense of ownership and their implementation of the change (Elizondo-Montemayor, Hernández-Escobar, Ayala-Aguirre, \& Aguilar, 2008). In particular, teachers' engagement 
in designing educational materials can benefit from collaboration, as a collaborative design process contributes to the quality of the educational materials (Stolk, Bulte, de Jong, \& Pilot, 2009).

\subsubsection{Conditions supporting teacher professional development}

During the past decades, considerable literature has been published about the effectiveness of teacher professional development programs (Desimone, Porter, Garet, Yoon, \& Birman, 2002; Garet et al., 2001; Kennedy, 2016; Penuel, Fishman, Yamaguchi, \& Gallagher, 2007; van Driel et al., 2012; van Veen, Zwart, Meirink, \& Verloop, 2010). This research has led to deeper insight into conditions that are supportive for professional development programs, which are discussed below. One condition considered essential for effective professional development is the focus on teachers' daily teaching practice, or more specifically, the focus on the combination of content knowledge and pedagogical knowledge (Garet et al., 2001; Guskey, 2003; Kennedy, 2016; Penuel et al., 2007; van Veen et al., 2010). Professional development activities that focus on subject-matter and pedagogy have been linked with increases in teacher knowledge, skills, and improvements in practice (Desimone, 2009). In this way, professional development programs that focus on these topics can have positive effects on students' learning (van Veen et al., 2010).

Another condition for effective professional development that is widely recognized is the opportunity for active learning (Desimone, 2009; Garet et al., 2001; Penuel et al., 2007; van Veen et al., 2010). There are many forms of active learning; examples include observation of other teachers followed by interactive feedback and discussions, planning how educational materials can be used in the classroom and engaging in inquiry-based activities (Garet et al., 2001; van Veen et al., 2010). Various studies have indicated links between active learning within a professional development program and positive student achievement outcomes (Fishman, Marx, Best, \& Tal, 2003; Penuel et al., 2007).

Furthermore, consistency is a condition for effective professional development (Desimone, 2009; Penuel et al., 2007; van Veen et al., 2010). First, to prevent a professional development program from becoming isolated, and its effects from disappearing after ending the program, the program should be consistent with school policy and national policy (van Veen et al., 2010). And second, professional development programs should be consistent with teachers' own goals for learning and their goals for students (Penuel et al., 2007), and they should be consistent with teachers' knowledge and beliefs (Desimone, 2009). Professional development programs are more likely to be effective if they form a coherent part of a wider set of learning and professional development opportunities (Garet et al., 2001). 
Substantial duration and intensity are also widely accepted as core conditions of effective professional development programs (Desimone, 2009; Guskey, 2003; van Veen et al., 2010). These terms sometimes refer to the number of contact hours, sometimes to the total timespan over which these hours are distributed and sometimes to the number of learning goals to be reached (Kennedy, 2016). Although research has not indicated a minimum amount of time that is most effective (Desimone, 2009), the general rationale is that the more time teachers spend engaged in professional development, the more likely their teaching practice is to improve (Hunzicker, 2011). However, these characteristics alone are insufficient, and as such, more intensive programs are not always linked with better outcomes (Kennedy, 2016). This could be related to the fact that teachers often already experience a heavy workload, resulting in leaving little time to invest in professional development (van Veen et al., 2010).

There are also two conditions supporting professional development that match the conditions for engaging teachers in educational change. First, external support or coaching is also considered an essential condition for professional development (Kennedy, 2016; van Veen et al., 2010). In professional development programs, coaches can ensure that the quality of the content offered to teachers is adequate, for example, by bringing in expert knowledge (Huizinga et al., 2014; van Veen et al., 2010). Furthermore, coaches are expected to organize the meetings and to provide basic process-support (Becuwe, Tondeur, Pareja Roblin, Thys, \& Castelein, 2016; McKenney, Boschman, Pieters, \& Voogt, 2016).

Second, collaboration is also considered an essential condition for professional development (Avalos, 2011; Kennedy, 2016; Stoll, Bolam, McMahon, Wallace, \& Thomas, 2006). While collaborating, teachers have the opportunity to learn from and with one another by discussing, interacting and working towards shared goals (Hunzicker, 2011; van Veen et al., 2010), which can be a powerful form of teacher learning (Avalos, 2011; Desimone, 2009).

In sum, the previous sections argued that programs aimed at teacher engagement in educational change and teacher professional development should meet certain conditions. The next section will explain how these conditions can be combined.

\subsection{Teacher Design Teams}

The six supportive conditions for teacher professional development can be incorporated in Professional Learning Communities (PLCs). PLCs can be defined as groups of teachers focused on collaborative learning by sharing experiences and critical reflection (Bolam, 
McMahon, Stoll, Thomas, \& Wallace, 2005; Stoll et al., 2006; Vangrieken, Meredith, Packer, \& Kyndt, 2017). As PLCs are aimed at actively discussing teachers' daily teaching practice, they provide opportunities to focus on the combination of content knowledge and pedagogical knowledge, teachers' active learning and collaboration. Furthermore, as PLCs are on-going groups that have meetings on a regular basis, their duration and intensity is usually greater than that of short-term professional development programs (Vangrieken et al., 2017). Teacher authority - defined as the ability to make decisions regarding the PLC and aspects of school governance - is considered an inherent aspect of PLCs (Vangrieken et al., 2017; Vescio, Ross, \& Adams, 2008). Therefore, PLCs are likely to be consistent with teachers' beliefs and school policy. If PLCs are supported by a team coach, or if they have opportunities to call in external support, the PLCs also meet the condition of external support or coaching.

PLCs have received increased attention over the past decades, and are considered to be very effective, as they can build teachers' individual as well as their collective capacities (Kennedy, 2016; Stoll et al., 2006; Vangrieken et al., 2017). As such, well-designed PLCs can improve teaching practice and student achievement (Vescio et al., 2008). There are many types of PLCs, which can vary in focus and type of active learning. Examples of PLCs are: teacher researcher communities (Ermeling, 2010), data teams (Schildkamp, Poortman, \& Handelzalts, 2016) and lesson study teams (Verhoef, Coenders, Pieters, van Smaalen, \& Tall, 2015). Depending on the specific context and professional development goals, these various types of PLCs all can have added value (Brown \& Poortman, in press).

PLCs afford opportunities for teacher learning in the context of educational change. Specifically, PLCs with a specific focus on designing educational materials and implementing them in practice can provide a practical, relevant and rich setting for teacher learning (Voogt et al., 2011; Voogt et al., 2015). PLCs with this focus are often referred to as Teacher Design Team (TDTs). A TDT is a type of PLC in which the participating teachers actively (re)design educational materials. TDTs can vary in the aspects of group composition, goals and type of coaching. Many TDTs include teachers from the same school (e.g. Handelzalts, 2009). However, more and more, scholars have indicated that a shift is needed from teacher teams within schools to teacher teams with participants from different schools (networks) in order to bring about actual school improvement (Chapman, 2014; Hofman \& Dijkstra, 2010; Katz \& Earl, 2010; Stoll, 2010). Teacher networks have the potential to bring professional learning to a level that exceeds what can be achieved within the school (Bryk, Gomez, \& Grunow, 2011; Jackson \& Temperley, 2007). 


\subsection{Problem statement: Implementation of TDTs}

Although several studies have shown that TDTs can contribute to teachers' professional development (Bakah, Voogt, \& Pieters, 2012a; Huizinga et al., 2014; Voogt et al., 2011), as well as to sustainable implementation of educational change by using the educational materials they designed themselves (Handelzalts, 2009; Johnson, Severance, Leary, \& Miller, 2014; Mooney Simmie, 2007), the outcomes of TDT participation are often mixed. These mixed outcomes can be explained by the notion that the effectiveness largely depends on how the program is implemented (Hargreaves \& O'Connor, 2017; Kennedy, 2016).

Several studies have been undertaken to explore ways to support TDT implementation. In a study by Velthuis, Fisser, and Pieters (2014), TDTs followed a highly structured process-guide that prescribed their design activities step-by-step, and positive outcomes were reported regarding teachers' increased self-efficacy. At the same time, Hargreaves (2003) warned that it is necessary to be careful with this type of work, as it could be perceived as a 'prison of micromanagement'. In contrast, other studies have emphasized a more flexible approach, in which participants decide on their design activities and goals (Coenders, Terlouw, Dijkstra, \& Pieters, 2010; Huizinga et al., 2013). Although these studies reported several positive outcomes in terms of teachers' professional development and the designed material, this approach also comes with potential risks, as crucial moments in the process might be overlooked. For example, Huizinga et al. (2013) described a case in which a lack of attention to defining a shared vision during the meetings affected the design activities, which inhibited the TDT's outcomes.

These examples illustrate that variations in the implementation of TDTs can affect the process and hence the outcomes of TDTs. Furthermore, they show that there is not yet consensus on how TDTs can best be implemented. Given that TDTs are increasingly being initiated, there is a need to better understand and facilitate TDT implementation.

\subsection{Research design \\ 1.5.1 TDTs in this dissertation}

This dissertation features research in collaboration with TDTs that were organized by the department of Teacher Education at the University of Twente in the Netherlands. These TDTs were all networked, and included science teachers from various secondary schools in the region. Furthermore, the TDTs were led by team coaches who were experts in their field, in most cases teacher educators from our university. 
The TDTs studied took place between 2010 and 2016. In these years, the teachers were preparing for and implementing the revised science examination programs. All TDTs had meetings on a monthly basis. The team coaches organized these meetings and were responsible for providing the teams with basic resources. Participating teachers taught the same or related science subjects and the TDTs were focused on the design of concrete educational materials or experimentation with new instructional strategies or technologies that were aligned with the ambitions of the revised examination programs However, the exact focus of the TDTs varied over time, as participants decided on their own goals and multiple subject areas were involved.

\subsubsection{Research questions}

This research aimed to develop a theoretical and practical basis for defining and explaining successful support for implementing TDTs. The overarching question that guided this dissertation was: How can the implementation of TDTs be supported?

To address this question, a general understanding of the functioning of TDTs was first needed. This provided insight into which key elements could be influenced to support the functioning of TDTs. Subsequently, an intervention based on these key elements was developed. Enacting this intervention provided insight into how the implementation of TDTs can be supported. Four research questions were formulated as follows:

1 How can the characteristics of TDTs be captured in a descriptive framework?

2. Which key elements of this descriptive framework can be influenced to support TDTs?

3 What are the characteristics of an intervention to support TDTs based on these key elements?

4 How does enacting this intervention support TDT processes?

\subsubsection{Structure of the dissertation}

To address the research questions, four studies were conducted. The first two studies set out to develop a descriptive framework for TDTs, and to obtain in-depth insight into the functioning of TDTs. The third study was aimed at developing an intervention that could support the implementation of TDTs. This intervention was enacted by two TDTs in the fourth study. In addition to brief descriptions of each study, the overall structure of the dissertation is depicted in figure 1.1. 


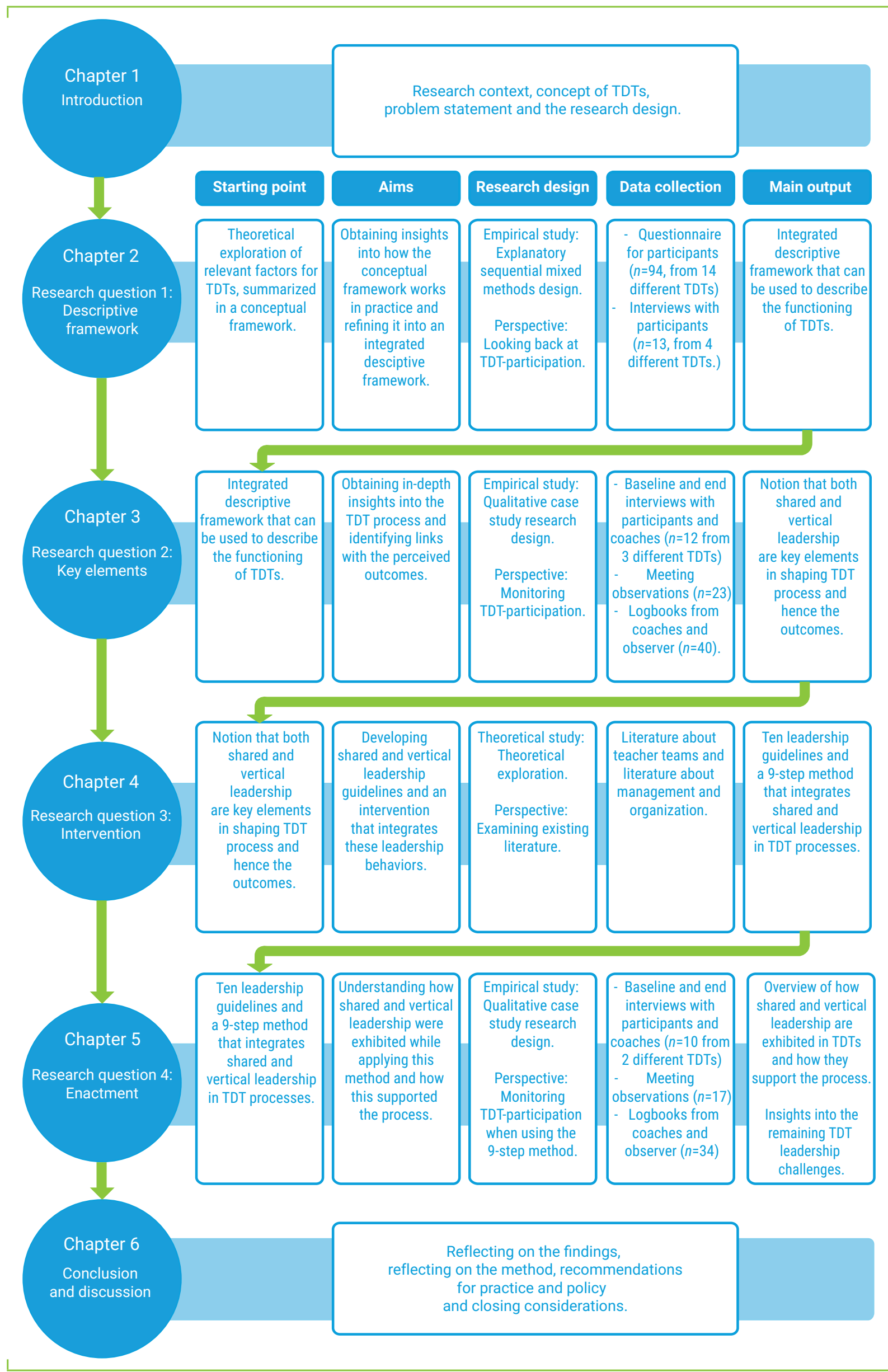


The starting point for the study reported in chapter 2 was a broad theoretical exploration of the factors that promote or interfere with the effectiveness of TDTs. This resulted in a conceptual framework for TDTs based on the core elements of intervention logic: input, process and outcome. The aim of this chapter was to obtain insight into how this conceptual framework works in practice and to refine it into an integrated descriptive framework. An explanatory sequential mixed methods approach was used to explore the perceptions of former TDT-participants regarding the factors in this framework. A questionnaire was administered to obtain general insight, and participants from four different TDTs were interviewed to explain these general findings. These insights from practice were used to evaluate the conceptual framework and to refine it into an integrated descriptive framework. This resulting framework can be applied to describe the functioning of TDTs in practice.

In the study that is described in chapter 3 , the integrated descriptive framework formed the starting point. The aim of this study was to obtain in-depth insight into the TDT process and to identify links with the perceived outcomes. Therefore, the functioning of three TDTs was monitored in detail, zooming in on the processes and outcomes of the descriptive framework. Qualitative data from multiple perspectives were collected by observing the meetings, collecting logbook entries and interviewing participants and coaches. The results indicated that leadership is a key element that can be influenced to support the functioning of TDTs. Both shared and vertical leadership play an important role in shaping the process and hence the perceived outcomes. To support the implementation of future TDTs, team coaches should, on the one hand, provide vertical leadership to promote structure and clarity during the process. At the same time, the coaches should create an atmosphere in which participants can take the initiative.

The notion that shared and vertical leadership are key elements in the functioning of TDTs formed the starting point for the development of an intervention, discussed in chapter 4 . The aim of this study was to develop shared and vertical leadership guidelines and an intervention that stimulates these leadership behaviors. During a theoretical exploration, existing literature about teacher teams and management and organization were examined. This resulted in leadership guidelines and a practical nine-step method that integrates shared and vertical leadership.

Chapter 5 portrays how this nine-step method was enacted in practice by two TDTs, which were monitored over the course of one school year. The aim of this study was to obtain in-depth qualitative insight into how vertical and shared leadership behaviors were exhibited while applying this method in TDTs and how these leadership behaviors supported the process. Similar to chapter 3, qualitative data from multiple perspectives 
were collected by observing the meetings, collecting logbook entries and interviewing participants and coaches. This resulted in in-depth insight into how shared and vertical leadership behaviors were exhibited in TDTs that used the nine-step method and how the leadership behaviors supported the process. Furthermore, the results provided insight into the remaining leadership challenges for TDTs.

Finally, chapter 6 provides summaries and a synthesis of all four studies. Together, these results are used to explain how the implementation of TDTs can be supported. After that, reflections on the methods and directions for future research are provided. Chapter 6 then provides several practical implications of this study, offering guidelines for practitioners and policymakers seeking to initiate and organize TDTs. The dissertation concludes with consideration of how the findings from this research can be used in the context of educational change. 



\section{Understanding Teacher}

Design Teams: A mixed methods approach to developing a descriptive framework

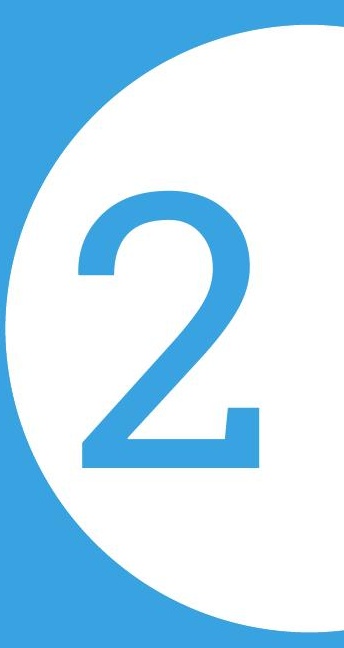

Based on: Binkhorst, F., Handelzalts, A., Poortman, C.L. and van Joolingen, W.R. (2015). Understanding Teacher Design Teams - A mixed methods approach to developing a descriptive framework. Teaching and Teacher Education, 51(C), 213-224. doi:10.1016/j.tate.2015.07.006. 
ABSTRACT Collaboration is a crucial element of effective professional development for teachers. In Teacher Design Teams (TDTs), teachers collaborate on (re)designing educational materials. To optimize their effectiveness, a strong theoretical and practical basis is required. In this study, therefore, we first developed a conceptual framework based on literature. Subsequently, we used a mixed methods approach to explore teachers' perceptions regarding the factors in this conceptual framework. The results reveal detailed insight into the functioning of TDTs, for example, regarding the role of the team coach. The resulting framework can be used to describe the functioning of TDTs and improve future TDTS.

\subsection{Introduction}

One of the most important elements of effective professional development programs for teachers is collaboration among teachers (Avalos, 2011; Crow \& Pounder, 2000; van Veen et al., 2010). A well-known approach to collaborative teacher professional development is the Professional Learning Community (PLC): a group of teachers focused on collaborative learning by sharing experiences and critical reflection. PLCs are considered to be very effective, as they can build teachers' individual as well as their collective capacity (Stoll et al., 2006). In this way, well-designed PLCs can improve teaching practice and student achievement (Vescio et al., 2008).

Most PLCs include participants from the same school (school-based PLCs). Recent studies indicate that a shift is needed from teacher communities within schools to teacher communities with participants from different schools in order to bring about actual school and system improvement (Chapman, 2014; Hofman \& Dijkstra, 2010). Networked communities have the potential to bring professional learning to a level that exceeds what can be achieved within the school (Bryk et al., 2011; Stoll, 2010).

Other factors that are considered to be essential for effective professional development programs are: focus on concrete classroom practices, focus on content knowledge, opportunities for active learning, coherence with teachers' own (learning) goals and that the program is stretched over enough time (Garet et al., 2001; Penuel et al., 2007; van Veen et al., 2010).

One emerging type of professional development program that incorporates these essential factors is the Teacher Design Team (TDT). A TDT is a type of PLC with a specific focus on (re)designing educational materials. Although the term 'TDT' gained popularity the past years - mainly in Ireland and the Netherlands - the idea of engaging teachers in (re)designing educational material is not new. Since the mid-seventies, several scholars 
claimed that teachers should play an active role in curriculum design (Green, 1980; Stenhouse, 1975). Nowadays, there are many types of TDTs, and similar to PLCs, most TDTs are school-based (e.g. Handelzalts, 2009). Also similar to PLCs, some scholars argue that networked design teams have much potential, as they lead to more fluid exchanges across institutional boundaries (Bryk et al., 2011).

The TDTs in this study are all networked, have meetings on a regular basis and are supported by an expert from their field, for instance, a teacher educator from the university. Participants in most of our TDTs teach the same or related subjects and are focused on the design of concrete educational materials or experimenting with new instructional strategies (or technologies) for their own subject. Examples are materials about new topics in the national examination programs, materials about modern scientific insights or materials incorporating innovative instructional practices.

Studies have shown that TDTs can contribute to teachers' professional growth (Voogt et al., 2011). Furthermore, the fact that participants in a TDT produce concrete educational materials themselves creates a feeling of ownership, which increases the probability that teachers will use these materials in their classroom practice (Carlgren, 1999; Mooney Simmie, 2007; Penuel et al., 2007). Therefore, TDTs can contribute to the successful implementation of sustainable educational innovations (Handelzalts, 2009; Mooney Simmie, 2007).

\subsubsection{Aims of this chapter}

From both perspectives - teacher professional development and implementation of educational innovations - TDTs thus have great potential to improve education. To promote the effectiveness of future TDTs, a strong theoretical and practical basis that defines and explains the essential characteristics of TDTs is crucial. Previous studies have indicated many individual factors that can promote or interfere with the effectiveness of TDTs. In this study, we aimed to develop an integrated descriptive framework that connects these individual factors. This descriptive framework will help to understand the functioning of TDTs in both theory and practice.

As a starting point, we developed a conceptual framework for TDTs based on theory (shown in figure 2.1). In the next section we describe how we constructed this conceptual framework. Subsequently, as the main goal of this paper, we explored the perceptions of TDT participants regarding the factors in this framework. Insights into how this 
conceptual framework works in practice were used to evaluate the conceptual framework and to refine it to an integrated descriptive framework. We used two perspectives from practice:

1 Describing the perceptions of all TDT participants to get insight into the input, process and outcome of TDTs and the relations between these factors in general

2. Describing the perceptions of participants in four cases of TDTs to get more detailed insight into the input, process and outcome of TDTs and the relations between these factors in specific situations.

\subsection{Conceptual framework}

In this section we describe how we constructed the conceptual framework for TDTs (shown in figure 2.1), by using literature about team-based professional development programs (such as TDTs, PLCs, Teacher Networks) and literature about teacher involvement in educational innovations. An extensive review article about PLCs (Stoll et al., 2006) and a doctoral dissertation about TDTs (Handelzalts, 2009) were used as key publications. Subsequently, we performed an informal literature search using the snowball method to find relevant cited and citing publications. The factors that we found to be identified as relevant for the effectiveness of such programs were systematically mapped in a framework referring to three stages: input, process and outcome.

The input stage refers to individual teacher characteristics and the characteristics of their schools (contextual characteristics). The process stage refers to factors that describe and influence working processes while the TDT is active. We distinguished three categories within the process stage: characteristics of the team, the activities they perform and organizational features. For the outcome stage, we focus on the two domains that are most important for TDTs: teachers' professional development and (implementation of) the designed material.

\subsubsection{Input}

\section{Teacher characteristics}

The first teacher characteristic included in our framework is motivation to participate in programs aimed at educational reforms such as TDTs. This factor is mainly mentioned in literature about educational reforms, in which there is a debate whether to involve all teachers in educational reform or only the motivated teachers (Erickson, Minnes Brandes, 


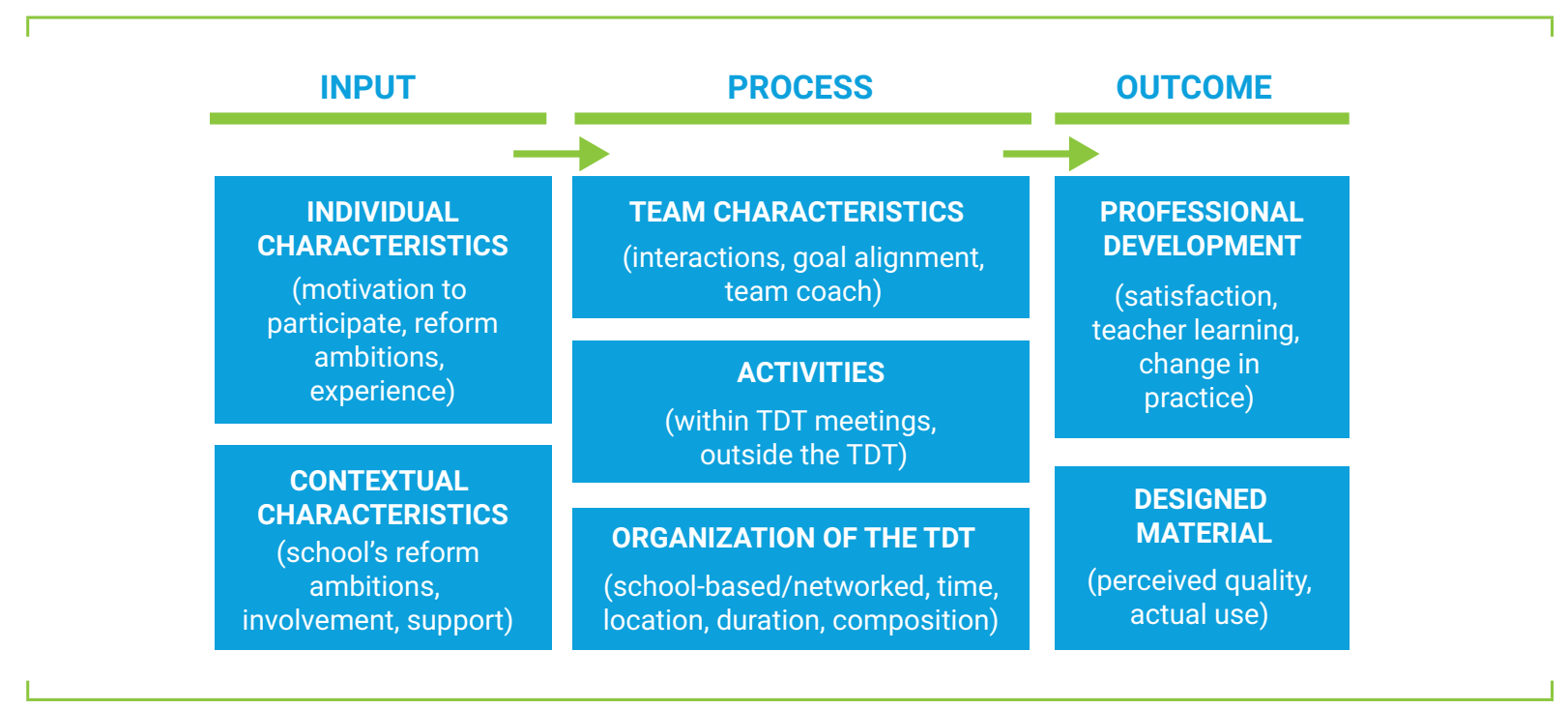

figure 2.1 Conceptual framework for TDTs

Mitchell, \& Mitchell, 2005; Fullan, 1993). In Self Determination Theory, two main types of motivation are distinguished: Autonomous motivation and Controlled motivation (Ryan $\&$ Deci, 2000). Teachers who are autonomously motivated are more likely to participate in professional development programs aimed at reforms, and they are more likely to adopt those reforms (Gorozidis \& Papaioannou, 2014).

Furthermore, teachers' personal reform ambitions play an important role in the effectiveness of professional development and educational innovation. Teachers' uncertainty about educational reforms has a negative influence on implementation of educational innovations (Geijsel et al., 2001). In line with these findings, Handelzalts (2009) states that teachers with clear reform ambitions realize more reform goals by working in a TDT. Thus, positive initial attitude towards educational innovations is essential for sustainable change.

Teachers' design experience also plays a role in TDTs (Huizinga et al., 2013). Teachers are not trained to design curriculum materials, and they often lack crucial design skills (Bakah et al., 2012a). This can affect the design process and the quality of the designed material (Hardré et al., 2006).

The last teacher characteristic that is considered is teaching experience. Working as a teacher is often perceived to be a very isolated job (Little, 1990). New teachers may feel the need to share their experiences as a teacher with colleagues and to be able to learn from them. Professional development programs with a focus on collaboration can 
be beneficial for them (Thomas, Wineburg, Grossman, Myhre, \& Woolworth, 1998). On the other hand, experienced teachers who have clear ideas about their own classroom practice can perceive collaboration as difficult and threatening (Thomas et al., 1998).

\section{Contextual characteristics}

Similar to personal reform ambitions, the school's reform ambitions can affect the outcomes of a TDT (Handelzalts, 2009). Schools with great reform ambitions might have more potential to actually change.

The role of the teaching staff in the school is of special interest as a contextual characteristic. To what extent does the school involve teachers in the reform? Involving teachers in the school's decision-making process related to educational reform can affect their feeling of ownership of the reform, and results in shared co-constructed decisions (Geijsel et al., 2001; Smylie, Lazarus, \& Brownlee-Conyers, 1996).

Furthermore, the school's conditions for supporting teachers' participation are included in the framework. Studies have shown that emotional supportiveness (Geijsel et al., 2001; Wikeley et al., 2005), as well as providing practical conditions, such as adequate time and space (Stoll et al., 2006), have positive effects.

\subsubsection{Process}

\section{Team characteristics}

Regarding team characteristics, team interaction is important. Team interaction is most effective if there is an open atmosphere, and teachers are willing to share ideas and information with each other (Stoll et al., 2006). In such open atmosphere, it is also important that teachers support each other, by giving feedback and by openly discussing differences in visions or potential conflicts (Grossman, Wineburg, \& Woolworth, 2001; Hord, 2004; Kuusisaari, 2014). A shared feeling of responsibility and equal contributions also promotes the effectiveness of the group work, as it strengthens the commitment to the team (Stoll et al., 2006). Furthermore, it is important that the individual members feel as if they belong to the group (Stoll et al., 2006).

In our definition of TDTs there is always a team coach to organize and structure the process. In most cases the team coach is an expert from their field, e.g., a teacher educator from the university. Support from an expert can improve the effectiveness of TDTs, as he or she brings new knowledge into the team (Cordingley, Bell, Rundell, \& Evans, 2003; Huizinga 
et al., 2013). Besides knowledge transfer, team coaches have two main tasks: organizing and structuring the process towards a specific (and shared) goal (Erickson et al., 2005; Grossman et al., 2001) and stimulating group interaction, including dealing with conflicts (Thomas et al., 1998).

Finally, the individual group members can have different expectations of the TDT, which can affect the perceived outcomes (Gregory, 2010). It is important to have a clear focus or goal (Hord, 2004; Little, 2002). Having shared goals, or goal alignment, is especially important in teacher collaboration programs (Meirink, Imants, Meijer, \& Verloop, 2010; Stoll et al., 2006). There should be coherence between the individual goals, the team goals and the overall goals of the program, in this case, the TDT (Penuel et al., 2007).

\section{Activities}

The participants can perform various activities within TDT-meetings. During the meetings, teachers can share information and experiences with each other, but external expertise is also considered to be crucial (Cordingley et al., 2003). External experts present 'formal knowledge' and up-to-date developments to the group (Erickson et al., 2005). TDTs can also perform design activities. Being involved in the actual design of educational material contributes to teachers' professional competencies, as opposed to teachers who are only involved in implementation of new educational materials (Shawer, 2010). Teams with clear goals and ambitions tend to start directly with the actual design task, while teams with less clear goals need more structure and clarification of what is expected of them (Handelzalts, 2009).

Furthermore, teachers can perform activities outside of TDT meetings. One of the essential characteristics of teacher professional development programs is that they must be coherent with teachers' own classroom practices (van Driel et al., 2012; van Veen et al., 2010). Long-term programs in which teachers have the chance to test their new knowledge or designed materials in practice (such as TDTs) therefore have great potential to be effective. Implementation activities are thus of great importance in TDTs.

\section{Organizational characteristics}

Many organizational characteristics are already fixed by our definition of TDTs, which is limited to networked TDTs instead of school-based TDTs. Furthermore, the duration of the TDTs in this study is always an academic year, and the location of the meetings is at the university. We describe two additional organizational characteristics that can vary within the scope of this definition. 
First the composition of the group as a whole can vary. Effective teams are small enough to know everyone in the team and large enough to bring a variety of knowledge and ideas into the team (Thousand \& Villa, 1993). Many other aspects of group composition could be considered, such as mono-disciplinary versus multidisciplinary teams, the amount of previous experience as a group, et cetera. Important features for group composition are: teachers need each other to succeed, teachers inspire each other with new ideas and there is a balance between natural teacher relationships and the artificial setting of the TDT (Handelzalts, 2009; Hargreaves, 2003; Little, 1990).

The second organizational characteristic, which can vary between participants, is time. In general, professional development programs that extend over a longer period of time such as TDTs - are considered time-consuming. As described in the section on contextual characteristics, it can be helpful if participants' schools are supportive, and if they give their teachers enough time and space (Stoll et al., 2006), but teachers also need to make time for the TDT activities themselves. Studies have shown that it is useful to organize meetings on a regular basis (Handelzalts, 2009), but there should also be enough time between the meetings so that participants can perform implementation or design activities outside of the TDT meetings.

\subsubsection{Outcome}

\section{Professional development}

The first outcome domain that is included in the conceptual framework is the participants' professional development. The evaluation levels described by (Guskey, 2002b) can be used in order to determine the results in terms of professional development. Guskey states that there are five levels of evaluation for professional development programs: 1. Participants reaction; 2. Participants' learning; 3. Organization support and change; 4. Participants use of new knowledge; 5. Student learning outcomes. Each level is based on the previous levels. In other words, success at the lower levels is necessary for success at higher levels.

The first evaluation level is focused on the participants' initial satisfaction with the experience. The second level is the teachers' learning: the new knowledge and skills that the participants gained, such as pedagogical knowledge, content knowledge, design skills or professional skills such as networking. The focus of the TDT determines the kinds of knowledge teachers can gain. The third evaluation level, organization support and change, is already included in the contextual characteristics (input). Therefore, in this study the participants' use of the new knowledge (change in practice) is the third 
level of professional development. At this level, one can examine the extent to which the participants perceive their classroom practice to have changed due to their new knowledge and skills. The last evaluation level for Guskey concerns improvements in student learning outcomes, which is always the ultimate goal of teachers. However, in this paper we only focus on the previous evaluation levels, as they are prerequisites for improvement in student learning outcomes.

\subsubsection{Designed material}

Because teachers (re)design educational material in TDTs, the designed material itself is also an important outcome domain. This domain can be divided into two variables: the perceived quality of the designed material and the actual use of the designed material. Similarly to Guskey's evaluation levels, the second level is based on the first level. In other words, sufficient perceived quality of the designed material is a requirement for implementing it in practice.

\subsection{Method}

\subsubsection{Context}

Our mid-sized university in the Netherlands has been organizing networked TDTs since 2010. This study was held with participants in these TDTs. TDTs were led by a team coach; in most cases a teacher educator from the university. The team coaches recruited TDT-participants by sending an open invitation to teachers in their field. The TDTs typically had 7-11 teachers from various secondary schools in the region of the university as members. Each TDT held ten 3-hour meetings during an academic year. During these meetings, they collaborated to design educational material. Most TDTs were focused on one school subject. These TDTs were aimed at designing new educational materials or experimenting with new instructional strategies (or technologies) for their own subject. But some TDTs had a more general theme, for example, dealing with gifted students. These TDTs were multidisciplinary, with teachers from different subjects. The TDT participants always registered for one academic year (from September to June), but teachers could decide to reregister for several years 
The perceptions of TDT participants were explored with an explanatory sequential mixed methods design (Creswell, 2013). This type of design starts with a quantitative phase to gain general insight and is complemented by a qualitative phase to gain in-depth explanations.

In this study, we first administered a questionnaire to all previous participants in TDTs. Subsequently we collected qualitative data by interviewing participants from four different TDTs. For the first perspective in our research, the perceptions of all TDT participants, the quantitative data from the questionnaire were used to identify general perceptions of TDTs and provide initial insight into the relations between the factors. The qualitative data helped to explain the general perceptions about TDTs and the relations between input, process and outcome factors, as a complement to the quantitative data. For the second perspective in our research, the perceptions of participants in four cases of TDTs, we also used both the quantitative and the qualitative data. The questionnaire results of the four selected TDTs were first used to detect notable differences between the TDTs. The qualitative data gave us insight into the different relations between the input, process and outcomes in the four TDTs. The results from both perspectives were combined to convert the conceptual framework to an integrated descriptive framework. The ethical committee of our university approved the design of this study.

\subsubsection{Instruments}

\section{Questionnaire development}

In order to measure participants' perceptions of TDTs in retrospect, we developed a questionnaire based on our conceptual framework for TDTs. The questionnaire incorporated existing validated scales and instruments where available (although they had to be translated into Dutch). Some scales were constructed in collaboration with the TDT coaches. The questionnaire included all of the factors in the conceptual framework (figure 2.1) except for a number of the organizational factors, most of which could be determined from background documentation or were the same for all TDTs in this context (i.e., networked TDTs with coach from the university).

In order to enhance the reliability and validity of the questionnaire, we performed a small pilot study. The pilot questionnaire was completed by 7 teachers. The last question was an open-ended question in which we asked the respondents for remarks and identification of possible ambiguities in the questionnaire. As some items appeared to be multi-interpretable, we made some adjustments to the formulation of the statements. 
table 2.1 Questionnaire scales and examples of items.

\begin{tabular}{|c|c|c|c|c|}
\hline & Scale & Items & $\mathbf{a}$ & Example \\
\hline \multicolumn{5}{|l|}{ INPUT } \\
\hline \multirow{4}{*}{$\begin{array}{l}\text { Individual } \\
\text { characteristics }\end{array}$} & Autonomous motivation $^{\text {a }}$ & 4 & .78 & $\begin{array}{l}\text { "I participated in a TDT because it seemed interesting to } \\
\text { me" }\end{array}$ \\
\hline & Controlled motivation $^{a}$ & 4 & .70 & $\begin{array}{l}\text { "I participated in a TDT because my school obliged me } \\
\text { to" }\end{array}$ \\
\hline & $\begin{array}{l}\text { Personal reform } \\
\text { ambitions }\end{array}$ & 4 & .87 & "I'm open to educational innovations" \\
\hline & Education experience & 1 & - & "I have ... years of teaching experience" \\
\hline \multirow[t]{3}{*}{$\begin{array}{l}\text { Contextual } \\
\text { characteristics }\end{array}$} & $\begin{array}{l}\text { School's reform } \\
\text { ambitions }\end{array}$ & 3 & .82 & "My school is open to educational innovations" \\
\hline & Teacher involvement & 3 & .78 & $\begin{array}{l}\text { "My school thinks it is important to involve teachers in } \\
\text { educational reforms" }\end{array}$ \\
\hline & School support & 4 & .72 & $\begin{array}{l}\text { "I felt supported by my school during my TDT } \\
\text { participation" }\end{array}$ \\
\hline
\end{tabular}

\section{PROCESS}

Team Team interaction ${ }^{\mathrm{b}}$ :

characteristics

- Communication

- Mutual support

- Effort/participation

- Cohesion

Team coach $^{c}$

Personal goals ${ }^{\mathrm{d}}$

Perceived team goals ${ }^{a}$

(calculated value for goal alignment)

$\begin{array}{ll}3 & .83 \\ 3 & .83 \\ 3 & .73 \\ 3 & .80 \\ 7 & .94 \\ 9 & - \\ 9 & - \\ 1 & -\end{array}$

\section{"Relevant information was shared openly"}

"Suggestions of team members were respected"

"Each team member gave the TDT the same priority"

"All team members felt involved in the TDT"

"The support of the team coach contributed to the results of the TDT"

"My goal was to improve my classroom practice"

"The goal of our team was to improve our own classroom practices"

This value is calculated as the sum of the absolute differences between the nine personal and team goals.

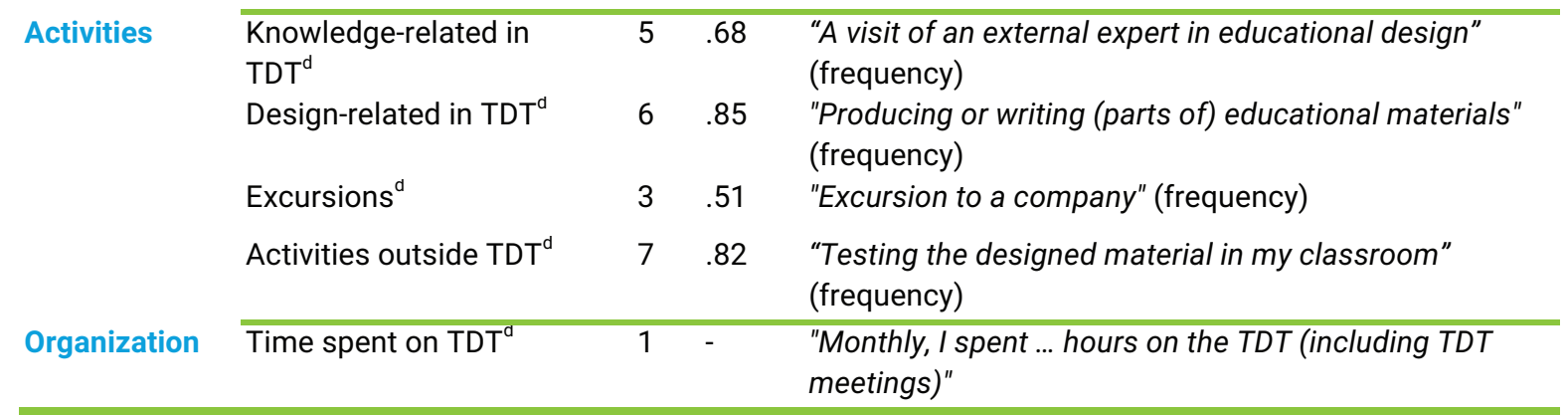

\section{OUTCOME}

\begin{tabular}{|c|c|c|c|c|}
\hline \multirow{3}{*}{$\begin{array}{l}\text { Professional } \\
\text { development }\end{array}$} & Satisfaction & 2 & .91 & "I was satisfied about the results of the TDT" \\
\hline & Teacher learning & 6 & .84 & $\begin{array}{l}\text { "Through my participation, I gained new pedagogical } \\
\text { insights" }\end{array}$ \\
\hline & Changes in practice & 5 & .90 & $\begin{array}{l}\text { "Through my participation, I experiment more with new } \\
\text { teaching strategies in my classroom" }\end{array}$ \\
\hline \multirow[t]{2}{*}{$\begin{array}{l}\text { Designed } \\
\text { material }\end{array}$} & Perceived quality ${ }^{c}$ & 4 & .91 & $\begin{array}{l}\text { "We adopted modern pedagogical insights in the } \\
\text { material" }\end{array}$ \\
\hline & Actual use & 3 & .85 & "I actually use the designed material in my classroom" \\
\hline
\end{tabular}

a: Derived from (Fernet, Senecal, Guay, Marsh, \& Dowson, 2008; Gorozidis \& Papaioannou, 2014);

b: Derived from (Hoegl \& Gemuenden, 2001);

c: Derived from (Huizinga et al., 2013);

d: Constructed in collaboration with TDT team coaches. 
The final questionnaire consisted of 20 (sub)scales with a total of 101 items (excluding a few background questions such as age, gender, name of the school). Most items were measured with a 5 -point Likert scale ( $1=$ completely disagree; $5=$ completely agree). To calculate a value for goal alignment, the questionnaire included nine statements with 5-point Likert scales for possible personal goals and the same nine statements with perceived team goals. A value for goal alignment was calculated as the mean of the absolute differences between the nine personal and team goals. A summary of the questionnaire with some examples of the statements is shown in table 2.1.

\section{Questionnaire respondents}

The questionnaire was provided to the 176 secondary school teachers who participated in one of the TDTs that have run at our university since 2010. Participants who were still active in one of the TDTs received the questionnaire on paper and filled it in manually. The other participants received a digital version of the questionnaire by email.

In total, 94 respondents from 14 different TDTs completed the questionnaire (53.41\% response rate). Because teachers can participate in a TDT for several years, they were asked to give their most recent year of participation. Information about the respondents is shown in table 2.2.

\section{Questionnaire data analysis}

For the statements about activities, we had no prior assumptions for categorization. Therefore, an exploratory factor analysis was performed for the activity statements. Four categories of activities were found: Knowledge-related activities in the TDT (5 statements, e.g. discussions about educational innovations, or guest lectures by external experts), Design-related activities in the TDT (6 statements, e.g. discussions about the design process, or writing/producing material), Activities outside TDT (7 statements, e.g. searching for relevant information, or testing the material in the classroom) and Excursions (3 statements, e.g. company visits).

The reliability of all questionnaire scales was tested with Cronbach's Alpha calculations. All Cronbach's Alphas were above .70 (Table 2.1), except the activity scales of Knowledgerelated activities in TDT $(\alpha=.68)$ and Excursions $(\alpha=.51)$. The means, standard deviations and correlations of all scales with the outcome scales were calculated. For the four TDTs that were selected for the qualitative analysis, we also calculated group means and standard deviations for all factors. 
table 2.2 Information about questionnaire respondents

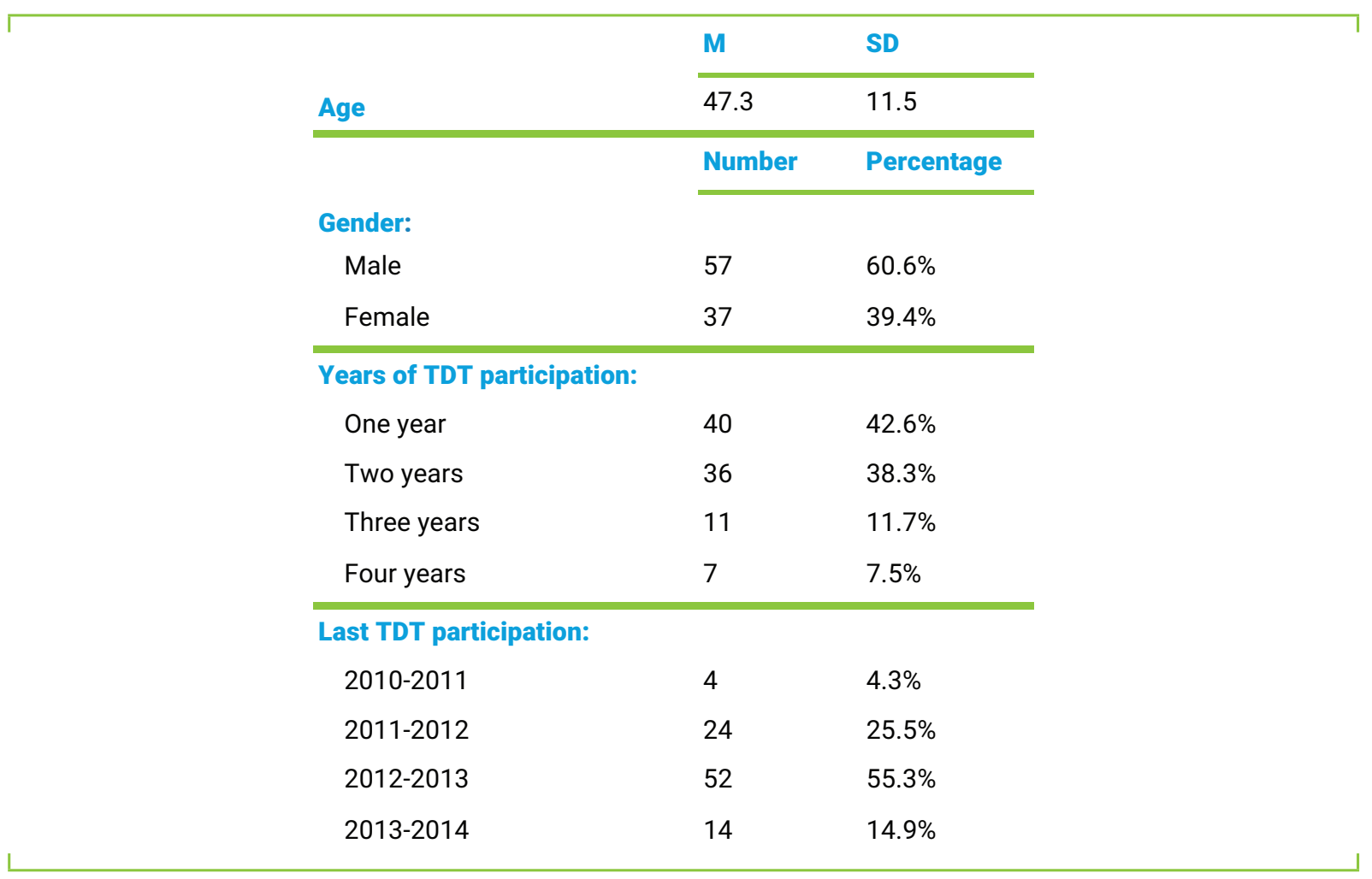

\section{Interview content}

The qualitative phase of this study was aimed at developing more in-depth explanations about the perceptions of TDTs. Each interview started with the perceived outcomes of the TDT and the respondents were asked to reason backwards in order to determine which factors contributed to this outcome. The interviewer tracked whether all factors of the conceptual framework were mentioned. If not, the interviewer brought it up. The interviews took between 30 and 50 minutes.

\section{Interview case selection}

The TDTs for the qualitative phase of this study were selected based on the following selection criteria that resulted from the preliminary results of the quantitative phase:

The TDT was active in the school year 2012-2013 (this year has the most questionnaire respondents);

The TDT had between 7 and 11 participants in 2012-2013 (the average is 9 participants) 
table 2.3 Information about interview respondents

\begin{tabular}{|c|c|c|c|c|}
\hline TDT & $\mathbf{A}$ & B & C & D \\
\hline $\begin{array}{l}\text { Focus of TDT } \\
\text { (in 2012-2013) }\end{array}$ & $\begin{array}{l}\text { Designing new } \\
\text { course modules, } \\
\text { experiments and } \\
\text { practical tools } \\
\text { for teaching. }\end{array}$ & $\begin{array}{l}\text { Designing new } \\
\text { course } \\
\text { modules and } \\
\text { experiments. }\end{array}$ & $\begin{array}{l}\text { Experimenting with } \\
\text { remotely teaching } \\
\text { using video- } \\
\text { conferencing }\end{array}$ & $\begin{array}{l}\text { Developing } \\
\text { school policy for } \\
\text { excellent and } \\
\text { highly gifted } \\
\text { students. }\end{array}$ \\
\hline When active? & 2010-2014 & 2010-2014 & 2010-2014 & 2011-2013 \\
\hline $\begin{array}{l}\text { Number of } \\
\text { questionnaire } \\
\text { respondents }^{a}\end{array}$ & $N=11$ & $N=15$ & $N=7$ & $N=10$ \\
\hline $\begin{array}{l}\text { TDT-participants in } \\
\text { 2012-2013 }\end{array}$ & $\begin{array}{l}9 \text { teachers with } \\
\text { same science- } \\
\text { related subject }\end{array}$ & $\begin{array}{c}7 \text { teachers } \\
\text { with same } \\
\text { science-related } \\
\text { subject }\end{array}$ & $\begin{array}{l}9 \text { teachers with } \\
\text { same science- } \\
\text { related subject }\end{array}$ & $\begin{array}{c}9 \text { teachers with } \\
\text { various subjects } \\
\text { (mostly science- } \\
\text { related) }\end{array}$ \\
\hline \multicolumn{5}{|l|}{ Respondents } \\
\hline $\begin{array}{l}\text { Number of interview } \\
\text { respondents }\end{array}$ & 3 & 3 & 4 & 3 \\
\hline Male/female & $1 m / 2 f$ & $3 m / 0 f$ & $4 \mathrm{~m} / 0 \mathrm{f}$ & $2 m / 1 f$ \\
\hline $\begin{array}{l}\text { One year/two or more } \\
\text { years of participation }\end{array}$ & 1 one/2 more & 0 one $/ 3$ more & 0 one/4 more & 2 one/ 1 more \\
\hline
\end{tabular}

The TDT had at least 6 questionnaire respondents for 2012-2013 (the aim was to interview at least 3 teachers from each TDT; the expected response rate was about $50 \%)$

Four TDTs met these criteria and were thus selected for the case studies.

\section{Interview respondents}

All questionnaire respondents from the selected case studies who had participated in 2012-2013 were contacted for an interview. In total, thirteen teachers agreed to participate. The interviews took place at the participants' schools. Background information about the selected TDTs and individual participants is shown in table 2.3. 
The interviews were audiotaped and transcribed verbatim. The transcripts were first coded by labeling text sections based on all factors in the conceptual framework. After that, more detailed codes were given to topics that needed further specification. For example, a section about the team coach was first coded as "Team coach". In the second stage, sequences were coded as "Team coach as organizer" or "Team coach as team motivator". A PhD student who was not involved in this study independently double-coded $12 \%$ of the fragments with the same coding scheme. Calculations of inter-rater reliability based on Cohen's kappa revealed that the reliability was .82. All fragments were sorted in a large table and were analyzed by interpreting the perceptions of each individual respondent and by interpreting the overall perceptions of the four groups.

\subsection{Results}

The results of this study are presented in two parts. First we explain the general perceptions of the TDT participants and the relations between input, process and outcome (first perspective). Subsequently we use the framework to describe the four selected TDTs in more detail (second perspective). We used quantitative as well as qualitative data in both parts.

\subsubsection{General perceptions of TDTs and relations between factors}

Table 2.4 shows the average perceptions of all questionnaire respondents, and the correlations with the outcomes. We begin by elaborating on the outcomes of the TDTs, to get an overview of the perceived successfulness of the TDTs. In the following sections, the results of the input and process factors and the relations with the outcomes will be discussed. 
table 2.4 Perceptions on all framework factors and correlations with outcomes

\begin{tabular}{|c|c|c|c|c|c|c|c|c|}
\hline \multirow[b]{2}{*}{$\mathbf{N}=94$} & \multirow[b]{2}{*}{ Scale/topic: } & \multirow[b]{2}{*}{ M } & \multirow[b]{2}{*}{ SD } & \multicolumn{2}{|c|}{ Correlations } & \multirow[b]{2}{*}{$\begin{array}{l}\text { Changes } \\
\text { practice }\end{array}$} & \multirow[b]{2}{*}{$\begin{array}{l}\text { Perc. } \\
\text { quality }\end{array}$} & \multirow[b]{2}{*}{$\begin{array}{l}\text { Actual } \\
\text { use }\end{array}$} \\
\hline & & & & $\begin{array}{l}\text { Satis- } \\
\text { faction }\end{array}$ & $\begin{array}{l}\text { Teacher } \\
\text { learning }\end{array}$ & & & \\
\hline \multicolumn{9}{|l|}{ INPUT } \\
\hline \multirow{4}{*}{$\begin{array}{l}\text { Individual } \\
\text { characteristics }\end{array}$} & Autonomous motivation & 4.0 & .63 & $.40 * *$ & $.43 * *$ & $.39 * *$ & $.38 * \star$ & $.29 * *$ \\
\hline & Controlled motivation & 1.8 & .71 & -.17 & -.03 & -.15 & -.11 & -.12 \\
\hline & Personal reform ambition & 4.3 & .57 & $.26 *$ & .19 & $.22 *$ & $.25 *$ & $.27 * \star$ \\
\hline & Education experience $^{a}$ & 15.5 & 9.95 & -.13 & -.18 & $-.29 \star \star$ & -.14 & -.19 \\
\hline \multirow{3}{*}{$\begin{array}{l}\text { Contextual } \\
\text { characteristics }\end{array}$} & School's reform ambitions & 3.9 & .61 & .17 & .08 & .07 & .15 & $.24^{\star}$ \\
\hline & Teacher involvement & 3.7 & .71 & .09 & .05 & -.01 & .12 & .15 \\
\hline & School support & 3.7 & .77 & -.06 & -.03 & .09 & -.08 & .13 \\
\hline \multicolumn{9}{|l|}{ PROCESS } \\
\hline \multirow{7}{*}{$\begin{array}{l}\text { Team } \\
\text { characteristics }\end{array}$} & Team interaction: & & & & & & & \\
\hline & - Communication & 4.0 & .68 & $.70 * *$ & $.58 * \star$ & $.45 * \star$ & $.64^{\star \star}$ & .42 ** \\
\hline & - Mutual support & 3.9 & .72 & $.77 * *$ & $.58 * *$ & $.48 * *$ & $.71 * *$ & $.49 * *$ \\
\hline & - Effort/participation & 3.5 & .75 & $.53^{\star \star}$ & $.48 * *$ & $.40 * *$ & $.51 * \star$ & $.42 * \star$ \\
\hline & - Cohesion & 3.3 & .70 & $.69 * *$ & $.58 * *$ & $.44 * *$ & $.60 * *$ & $.52^{\star *}$ \\
\hline & Team coach & 3.7 & .78 & $.73 * \star$ & $.61 * *$ & $.45^{\star \star}$ & $.66 * \star$ & $.44^{\star \star}$ \\
\hline & Goal alignment $^{\mathrm{b}}$ & .57 & .44 & $-.28 * \star$ & $-.25 *$ & $-.40 * \star$ & $-.24 *$ & $-.38 * *$ \\
\hline \multirow[t]{4}{*}{ Activities } & Knowledge-related in $\mathrm{TDT}^{\mathrm{C}}$ & 2.8 & .77 & $.35 * \star$ & $.46 * \star$ & $.34^{\star \star}$ & .28 ** & $.21 *$ \\
\hline & Design-related in $\mathrm{TDT}^{\mathrm{c}}$ & 3.4 & .88 & $.68 \star \star$ & $.65 \star *$ & $.43 * *$ & $.70 * *$ & $.60 * *$ \\
\hline & Excursions $^{c}$ & 1.8 & .79 & .08 & .16 & .13 & .17 & .08 \\
\hline & Activities outside TDT $^{c}$ & 3.1 & .75 & $.32 * \star$ & $.42 \star \star$ & $.34^{\star \star}$ & $.37 * \star$ & $.52 \star \star$ \\
\hline Organization & Time spent on TDT ${ }^{d}$ & 6.7 & 2.4 & .08 & .05 & -.05 & .08 & .05 \\
\hline \multicolumn{9}{|l|}{ OUTCOME } \\
\hline \multirow{3}{*}{$\begin{array}{l}\text { Professional } \\
\text { development }\end{array}$} & Satisfaction & 3.5 & .92 & - & & & & \\
\hline & Teacher learning & 3.3 & .78 & $.66 * \star$ & - & & & \\
\hline & Changes in practice & 2.9 & .88 & $.56 \star \star$ & $.68 * *$ & - & & \\
\hline \multirow{2}{*}{$\begin{array}{l}\text { Designed } \\
\text { material }\end{array}$} & Perceived quality & 3.4 & .84 & $.79 * \star$ & $.72 \star \star$ & $.58 * *$ & - & \\
\hline & Actual use & 2. 8 & 1.1 & $.64^{\star \star}$ & $.59 \star \star$ & $.60 * *$ & $.70 * *$ & - \\
\hline \multicolumn{9}{|c|}{$\begin{array}{l}\text { Note: all items are measured with a 5-point Lik } \\
\text { a. Education experience in years; } \\
\text { b. Calculated goal alignment value ( } 0=\text { persona } \\
\text { and perceived team goals are completely oppo } \\
\text { c. Frequencies ( } 1=\text { never; } 5=\text { very often); } \\
\text { d. Hours spent on TDT per month. } \\
\text { * } p<0.05 ;{ }^{\star *} p<0.01\end{array}$} \\
\hline
\end{tabular}


On average, the questionnaire respondents scored above the middle of the scale (3) on the outcome factors of Satisfaction $(M=3.5, S D=.92)$, Teacher learning $(M=3.3, S D$ $=.78)$ and Quality of material $(\mathrm{M}=3.4, \mathrm{SD}=.84)$. The interviews also showed that the participants experienced learning gains, for example: "New content knowledge about our subject. [...] And sometimes knowledge about education. Every now and then the team coach came up with something new in the field of pedagogy", or "I learned some practical things. How can you shape a series of lessons? That was very informative, designing the material". The other two outcome factors, which both concern actual change or use in practice, had lower average scores (Changes in practice: $\mathrm{M}=2.9, \mathrm{SD}=.88$; Actual use: $\mathrm{M}=2.8, \mathrm{SD}=1.10$ ). The interview participants found it difficult to indicate real changes in practice due to their TDT participation: "Well, I don't know how the practice would have been if I had not been participating in the TDT. So it's difficult to show the concrete changes in practice."

\section{Input factors}

Regarding motivation, respondents perceived more autonomous motivation than controlled motivation to participate $(\mathrm{M}=4.0, \mathrm{SD}=.63 ; \mathrm{M}=1.8, \mathrm{SD}=.71$, respectively). Autonomous motivation correlated with all outcome factors, in contrast to controlled motivation, which did not correlate significantly. In general, the same relation emerged from the interviews, although the participants in team $\mathrm{C}$ experienced more controlled motivation, which will be explained in section 2.4.2. Personal reform ambitions were above the middle of the scale ( $M=4.3, S D=.57)$. In the interviews, participants explained that being open to innovations is in the nature of TDT participants. For example: "In general, they [TDT participants] are persons who want to innovate and dare to broaden their views." Furthermore, interview participants explained that having a group of ambitious teachers is essential to the success of TDTs: "Enthusiasm is the key. You need teachers who are willing to do something, to achieve something and to try something. Otherwise it doesn't work."

Table 2.5 shows the questionnaire respondents' design experience prior to their TDT participation. The majority of the respondents had experience in designing material for their own classes or schools, but for most respondents this experience did not go beyond the school level. This topic was barely mentioned in the interviews. Some interview participants thought that it might have helped if they had had a little more design experience, like this participant: "If I had been more experienced, it would probably have gone easier. It is quite difficult to develop new material and to write things". 
table 2.5 Design experience prior to TDT participation

\begin{tabular}{|lcc|}
\hline Experience: & Frequency & Percentage \\
\cline { 2 - 3 } No experience & 9 & $9.6 \%$ \\
Designed material for own classes & 61 & $61.9 \%$ \\
Designed material for own school & 55 & $58.5 \%$ \\
Designed material for external party & 12 & $12.8 \%$ \\
\hline
\end{tabular}

There was a range of years of educational experience $(M=15.5$ years, $S D=9.95)$, but all teachers had some degree of educational experience (2 years experience was the minimum reported). A negative correlation was found between educational experience and the outcome of Changes in practice. However, in the interviews participants explained there was no relation between experience and willingness to change: "There are people with 20 years of experience who think, I have been teaching like this for 20 years, why would I change? There are also people with 20 years of experience who really like the reforms. It depends on the person."

The quantitative results for the contextual input characteristics show that the respondents on average scored on the positive end of the scale. The TDT participants were positive about their school's reform ambitions, teacher involvement and the support provided $(\mathrm{M}=3.9, \mathrm{SD}=.61 ; \mathrm{M}=3.7, \mathrm{SD}=.71 ; \mathrm{M}=3.7, \mathrm{SD}=.77$, respectively). Few significant correlations were found between contextual characteristics and the outcome variables. In the interviews, none of the participants mentioned these topics spontaneously, but in general they were positive about their school's reform ambitions and the way the school involved teachers in it. For example: "I think we are an ambitious school, in terms of innovations. When you look at the possibilities here, I think that's very important. [...] Teachers are involved in the process, yes". Furthermore, in general the interview participants were satisfied with their schools' support during the TDT. Although most participants mentioned that their schools did not ask about the progress of their participation very often, they did not experience a lack of support: "Sometimes they asked me about what I did in the TDT, but they never asked what I really learned and how the school could benefit from my TDT participation. [...] I didn't miss that. If it's useful I will tell them myself." This participant also explained that the TDT is focused on a specific subject. Results or products from the TDT are therefore not always relevant for the whole organization, but only for a select group. 
With regard to team characteristics, all questionnaire scales correlated with the outcomes. Under team interaction, the subscales of communication and mutual support had the highest average scores $(\mathrm{M}=4.0, \mathrm{SD}=.68 ; \mathrm{M}=3.9, \mathrm{SD}=.72)$. The interview participants also reported that the team members communicated quite well and openly with each other: "The people in the TDT liked to share information. [...] The willingness to exchange information was very great." Likewise, most participants stated in the interview that the team members were willing to support each other, listen to each other and give each other feedback. Questionnaire respondents were slightly less positive about the team effort and cohesion in the group. Mean scores for these subscales were just above middle of the scale $(\mathrm{M}=$ $3.5, \mathrm{SD}=.75 ; \mathrm{M}=3.3, \mathrm{SD}=.70)$. In the interviews, the participants from all TDTs noted that participation in the TDT was not equally distributed among the members. However, in most cases, this was not seen as a problem: "That is very different, the effort. But if you just say you have no time, the group is OK with that." The perceptions of cohesion in the group differed between TDTs, which will be further explained in section 2.4.2.

On average the respondents were positive about their team coach $(\mathrm{M}=3.7, \mathrm{SD}=.78)$. The interview participants explained their expectations of the team coach. According to the interviewees, the coach (should have) played a role in structuring the activities, stimulating the team interactions and mediating between the members to find a shared team goal. The coach was mentioned in a positive sense, for example: "The coach made an inventory of all personal goals to find a shared goal", as well as in a negative sense: "I missed a clear structure in the activities, the coach could have given more structure".

The average value for goal alignment was .57 (where $0=$ personal goals and perceived team goals are the same; 4 = personal goals and perceived team goals are completely opposite; $\mathrm{SD}=.44$ ). This value means that in general, the questionnaire respondents reported that they strived for the same goal as their fellow team members. The value for goal alignment correlated with all outcome variables in the sense that closer alignment of goals correlated with higher outcome scores. The interviews revealed that there was a broad consensus that TDTs should have a clear and shared goal. There were differences in how and when this goal was formulated. In two TDTs, the goal was pre-defined and known before enrolling the TDT. In the other two TDTs the team members defined the goal during the first meetings. Differences between those approaches are further explained in section 2.4.2.

The most frequent activities were design related activities inside the TDT $(M=3.4$, SD $=.88$; where 1 = never and 5 = very often) and activities outside of the TDT $(\mathrm{M}=3.1$, $\mathrm{SD}=.75)$. Knowledge-related activities within the TDT were somewhat less frequent 
$(\mathrm{M}=2.8, \mathrm{SD}=.77)$. The category of Excursions had the lowest frequency score $(\mathrm{M}=$ $1.8, \mathrm{SD}=.79$ ). This is not surprising, because company visits or visiting other schools cannot take place as often as activities such as discussing educational reforms, or writing (parts of) new educational materials. The frequency of design-related activities within the TDT showed the strongest correlations with the outcome factors. In the interviews, participants described this kind of activity as most useful: "We made a lesson plan that teachers could actually use. In small groups of two or three, we picked a part and we worked that out. How can you teach this topic? What kinds of experiments are possible?" They also mentioned knowledge-related topics such as exchanging experiences with each other and external guest speakers. Furthermore, participants mentioned that it is essential to have the possibility of immediately implementing or testing the designed material in practice: "When we come up with something, we can immediately implement it in the classroom. [...] It is the same with visiting conferences. When do I actually learn something at a conference? If I can use something the next day in my class." The frequency of activities outside of the TDT correlated with all outcome factors, especially the outcome Use of material (.52; $\mathrm{p}<$ $.01)$.

Most factors regarding the organization of the TDT were the same for every TDT in this study. All TDTs included teachers from different schools (networked TDTs), and held ten monthly 3-hour meetings at the university during an academic year. The number of participants in TDTs varied between 2 and 19, with an average of 9.1. Most TDTs consisted of teachers from the same or related topics, except team $D$, which will be further described in section 2.4.2. On average, the participants spent 6.7 hours (SD $=2.4$ ) on the TDT per month. Taking into account that the duration of the monthly meetings was 3 hours, the participants spent 3.7 hours per month on the TDT of their own or their school's time. No correlations were found between time spent on the TDT and the outcome variables. Some interview participants explained that participating in a TDT felt like a huge time investment. On the other hand, some participants mentioned that participating in a TDT saves time in the long term, because the designed material can be used year after year. The participants explained that the TDT should be a more continuous process. "Directly after the meeting you think, the next time will be next month, that's a pretty long time. So you go on with your daily practice, and before you know it, three or four weeks have passed, and you should have done something for the TDT". 


\subsubsection{Case descriptions of four TDTs}

This section gives an overview of the differences in the four TDTs and of the relations between the framework factors. Although the main focus of this part of the study is on the qualitative interview data, we also used the questionnaire results of the four selected TDTs to detect notable differences between the TDTs (table 2.6).

\section{Team A - Positive and implementing}

Team A consisted of teachers from the same subject, and was aimed at designing educational modules. Table 2.6 shows that team A is the only team in which all outcome scores are above the middle of the scale. The interview participants from this team also reported the greatest learning gains and actual implementation of the gained knowledge. For example: "Yes, the idea with the logbooks, which we used in that module. I picked that up to use in my daily practice, and that clearly came from working in the TDT."

In general, the participants from team A were autonomously motivated to participate ( $\mathrm{M}$ $=4.4)$ and they were ambitious concerning educational reforms $(M=4.6)$. The contextual characteristics were perceived as positive; the schools also had reform ambitions, they involved teachers and they were perceived as supportive during TDT participation. The group work was perceived as positive; all team interaction subscales had an average score above 3.5. One of the interview participants explained about the team interaction: "Everything goes very naturally. Because we are all similar and like-minded people". The respondents were satisfied with the team coach ( $M=4.2)$. In the interviews they explained that the team defined a shared goal together, coordinated by the team coach. They performed activities within as well as outside of the TDT meetings. Parts of the designed material were directly tested in practice between the TDT meetings. Team members were positive about this approach.

\section{Team B - Positive but not implementing}

Similar to team A, this team had teachers from the same subject, and aimed at designing educational modules. Team B was positive about most outcome factors. However, table 2.6 shows that the outcome factor Actual use of material had an average score below the middle of the scale $(M=2.6)$. The interview participants explained that they were satisfied with their TDT participation and the learning gains, but they were somewhat cautious in their opinion about the material: "Well, the problem is, I haven't tested it yet. Now there is material that I can grab at the moment that I'm going to teach that lesson. And only then I can tell whether it matches with my students. Or that I have to do it in a different way." They 
table 2.6 The perceptions on all framework factors for four selected TDTs

\begin{tabular}{|c|c|c|c|c|c|}
\hline & Scale/topic & $\begin{array}{l}\text { TDT } \mathbf{A} \\
\mathrm{N}=11^{*} \\
\mathrm{M}\end{array}$ & $\begin{array}{l}\text { TDT } B \\
\begin{array}{l}N=15^{\star} \\
M\end{array}\end{array}$ & $\begin{array}{c}\text { TDT C } \\
N=7 * \\
M\end{array}$ & $\begin{array}{l}\text { TDT D } \\
\begin{array}{c}\mathrm{N}=10 * \\
\mathrm{M}\end{array}\end{array}$ \\
\hline \multicolumn{6}{|l|}{ INPUT } \\
\hline \multirow{4}{*}{$\begin{array}{l}\text { Individual } \\
\text { characteristics }\end{array}$} & Autonomous motivation & 4.4 & 4.1 & 3.4 & 4.1 \\
\hline & Controlled motivation & 1.3 & 1.5 & 2.9 & 1.7 \\
\hline & Personal reform ambitions & 4.6 & 4.1 & 4.1 & 4.5 \\
\hline & Education experience $^{a}$ & 16.3 & 14.9 & 24.9 & 18,0 \\
\hline \multirow{3}{*}{$\begin{array}{l}\text { Contextual } \\
\text { characteristics }\end{array}$} & School's reform ambitions & 4.1 & 4.0 & 3.8 & 4.1 \\
\hline & Teacher involvement & 4.1 & 3.5 & 3.7 & 3.9 \\
\hline & School support & 3.8 & 3.7 & 3.7 & 3.9 \\
\hline \multicolumn{6}{|l|}{ PROCESS } \\
\hline \multirow{7}{*}{$\begin{array}{l}\text { Team } \\
\text { characteristics }\end{array}$} & Team interaction: & & & & \\
\hline & - Communication & 4.5 & 4.2 & 3.6 & 3.5 \\
\hline & - Mutual support & 4.2 & 3.8 & 3.6 & 3.1 \\
\hline & - Effort/participation & 4.0 & 3.4 & 3.3 & 2.6 \\
\hline & - Cohesion & 3.6 & 3.3 & 2.9 & 2.6 \\
\hline & Team coach & 4.2 & 4.0 & 3.2 & 2.6 \\
\hline & Goal alignment ${ }^{\mathrm{b}}$ & .50 & .74 & .75 & .64 \\
\hline \multirow[t]{4}{*}{ Activities } & Knowledge-related in $\mathrm{TDT}^{\mathrm{C}}$ & 3.2 & 3.3 & 1.9 & 3.0 \\
\hline & Design-related in $\mathrm{TDT}^{\mathrm{C}}$ & 4.2 & 3.3 & 3.1 & 2.5 \\
\hline & Excursions $^{c}$ & 1.4 & 1.2 & 1.9 & 1.1 \\
\hline & Activities outside TDT ${ }^{c}$ & 3.8 & 3.0 & 3.0 & 2.7 \\
\hline Organization & Time spent on $\mathrm{TDT}^{\mathrm{d}}$ & 8.8 & 7.3 & 5.9 & 5.9 \\
\hline \multicolumn{6}{|l|}{ OUTCOME } \\
\hline \multirow{3}{*}{$\begin{array}{l}\text { Professional } \\
\text { Development }\end{array}$} & Satisfaction & 4.2 & 3.5 & 2.6 & 2.6 \\
\hline & Teacher learning & 4.1 & 3.6 & 2.7 & 2.3 \\
\hline & Changes in practice & 3.4 & 3,0 & 2.1 & 2.5 \\
\hline \multirow{2}{*}{$\begin{array}{l}\text { Designed } \\
\text { material }\end{array}$} & Perceived quality & 4.0 & 3.3 & 2.8 & 2.5 \\
\hline & Actual use & 3.6 & 2.6 & 2.4 & 1.8 \\
\hline \multicolumn{6}{|c|}{$\begin{array}{l}\text { Note: all items are measured with a 5-point Likert scale }(1=\text { completely disagree; } 5=\text { completely agree), except: } \\
\text { a. Education experience in years; } b \text {. Calculated goal alignment value ( } 0=\text { personal goals and perceived team } \\
\text { goals are the same; } 4=\text { personal goals and perceived team goals are completely opposite); } \\
\text { c. Frequencies }(1=\text { never; } 5=\text { very often); } \\
\text { d. Hours spent on TDT per month. } \\
\text { *: N represents the total number of questionnaire respondents from this team. Year of participation was not } \\
\text { necessarily 2012-2013. }\end{array}$} \\
\hline
\end{tabular}


did not actually use the material in the classroom, therefore they were unsure about its quality. In contrast to team A, none of the participants from team B reported about testing the material in practice during TDT participation. This is reflected in their different frequencies for activities outside of the TDT (Team A: M = 3.8; Team B: M=3.0).

The input factor and process factor scores for team B were similar to those of team A. Members of Team B were also autonomously motivated, they were open to educational reforms, just as their schools were, and they perceived the team interactions as positive (mean scores on all questionnaire factors were above the middle of the scale). Furthermore, like team A, this team formulated a shared team goal during the first sessions. The team coach led this process.

\section{Team C - Controlled motivation and skepticism}

Team C consisted of teachers of the same science-related subject and aimed at experimenting with video conferencing technologies. The goal was to teach two classrooms in two different schools at the same time. Table 2.6 shows that all mean outcome scores were on the negative end of the scale in this team. The interview participants explained they gained some knowledge about new technologies, but on average they agreed that the main insight was that it is not profitable to use video conferencing in classes: "Our group has come to the conclusion that it doesn't work. A normal lesson is always more effective than a video lesson". Therefore, the negative perceptions of the outcomes could be explained in part by the fact that the main goal of the TDT failed.

But insight about the input factors reveal more explanations. Table 2.6 shows that the average score for autonomous motivation was more than .5 point lower than the other teams, and the score for controlled motivation was more than a full point higher. This was clarified in the interviews: "I think this TDT is top-down. My school leader comes to me and says: 'our school has signed up for a video conferencing project, now we need teachers to participate in a TDT, do you want to participate?' We did not directly see the usefulness of the project." Formally, the teachers were asked whether they wanted to participate in the TDT, but they felt as if they were more or less forced. The other input factors show similar results as those for team $A$ and $B$.

The interview participants explained that the controlled motivation to participate affected some process factors. The TDT had a clear pre-defined goal (experimenting with video lessons), but although this was the goal of the project, it did not feel like their own goal: "We had a clear goal, but that doesn't mean that we thought that this would be the solution. From the very beginning there was skepticism in the group." Although the participants explained 
they really tried to make it work most of the time, sometimes it was hard to stay positive: "Sometimes I thought, come on guys, try to think more positively. Try to think more about the solutions instead of only looking at the problems. [...] The positive attitude was missing." The team coach could have played a role in improving the atmosphere: "As a team coach you have the difficult task of making something out of it. And then I think you can better spare your energy to improve the atmosphere instead of [looking at the problems of] the TDT itself."

\section{Team D - Diverse group and hard to find shared goal}

The aim of team D was to develop school policies for how to deal with excellent and gifted students. The TDT consisted of teachers from different subjects, although most teachers taught science-related subjects. The participants had different roles in their schools; some teachers were 'excellence coordinators' and other teachers were just interested in this topic. Table 2.6 shows that the averages scores for all outcome factors were on the negative end of the scale for this team. Some interview participants reported some small learning gains, for example, some new insights and perspectives on this topic, but the overall tendency was not to really use these new insights in practice. Team D initially had a clear concrete goal, but at the end of the year there was no shared product: "The original intent was to create a booklet with guidelines for excellence. But we didn't do that."

The reasons for team D's lower outcome values differ from those for team C. Table 2.6 shows that team D's mean questionnaire scores for the input variables are all above the middle of the scale, similar to the positive scores of teams A and B. The interview participants also reported that they were autonomously motivated to participate and they were positive towards educational reforms. However, team D had some issues during the process. Due to the diverse group composition it was hard to find cohesion in the group: "Although it is an interesting topic and you can learn a lot from each other, it is hard to find cohesion in the group. I can imagine that TDTs with teachers from the same subject, they have a shared view. We knew beforehand that that wasn't going to work." Table 2.6 also shows that the value for cohesion in team $\mathrm{D}$ was lower than in the other teams $(\mathrm{M}=2.6)$. The participants experienced difficulties in finding a way to incorporate all of the different views and opinions into a shared end product: "On the one hand, I think that we as participants clearly brought up what we wanted. [...] But some teachers came with features of which I thought, this is not exactly what I want." So although the team had a clear pre-defined goal, it was difficult to find a shared interpretation of this goal. Consequently, it was difficult to carry out design-related activities that were perceived as relevant for all participants. The interview participants explained that they did some knowledge-related activities, but they did not use the new knowledge to actually develop something with the group: "There 
were guest speakers, who told us quite interesting things, but after that we didn't do anything with it. Normally I criticize my students for that, for starting with something, and not doing anything with it. It's a missed chance."

Similar to team $\mathrm{C}$, the interview participants from team D mentioned that the team coach could have played a role in solving the issues: "I missed a real plan. This is our goal, what steps should we take to reach that goal? [...] If I coach a process like this, I always take a look at what we have to do, where are we going, what do I need?"

\subsection{Conclusion and discussion}

This study started with a conceptual framework for TDTs that was based on theory. The perceptions of TDT participants regarding the factors in this framework were explored with a mixed methods approach. We gained insight into general perceptions on TDTs and relations between those factors. Furthermore, we found several relations in four particular TDTs that help us understand how this framework can be applied in practice.

\subsubsection{General perceptions of TDTs and relations between factors}

The first perspective in this study was to gain insight into the general perceptions on TDTs and relations between factors. Both the quantitative and qualitative data showed that in general, participants in the TDTs were satisfied with the TDT's outcomes. Teachers mentioned clear learning outcomes and most were pleased with the quality of the designed material. However, teachers in this study did not perceive their classroom practice to have improved after the TDT-participation and they did not often use the designed material. The educational innovation thus was not implemented in practice, as we did expect from literature (Carlgren, 1999; Mooney Simmie, 2007; Penuel et al., 2007) Therefore, we can argue that despite the potential of TDTs, the performance remains only partially optimized. Another explanation for the lack of reported change is related to the measurement of perceptions in retrospect. Maybe the participants did not realize that their practice had changed in small increments. Future research can include a pre- and posttest to draw more conclusions about changes in practice.

In general, TDT participants formed a homogeneous group of motivated and ambitious teachers (input factors). There is an ongoing debate in the literature about involving all teachers in educational reforms or only involving the motivated teachers. On the one hand, one could argue that voluntary participation is desirable so that the group is committed and stable (Erickson et al., 2005) and teachers are inclined to implement 
the reforms (Gorozidis \& Papaioannou, 2014). On the other hand, most innovation projects that only involve volunteers have less long-term effects (Hargreaves, 2003). With that argument, future TDTs should focus more on involving all teachers to support the sustainability of the reform.

The participants were positive about their own schools and the degree of involvement. But both the quantitative and qualitative data show that there is almost no relation between the contextual characteristics and the outcomes. This might seem to contradict the existing literature that states that the conditions in the school context are very important (Stoll et al., 2006; Wikeley et al., 2005). This can be explained in two ways. First, in this study, all TDTs were networked. There was not one specific school (leader) that had a direct interest in the outcomes of the TDTs. School leaders looked at the TDTs from a little distance, which increased the feeling of autonomy of the participating teachers. Second, teachers in the Netherlands are relatively autonomous in planning their own lessons. Therefore, they do not need their schools to be very involved in the process of designing materials for their own subject.

The process factors appear to be the most important in this study. The quantitative data show that all process factors correlated with almost all outcome variables. This is in line with the existing literature: positive team interaction, a good balance of activities, a good team coach and clear alignment of the team goals contribute to the effectiveness of the TDT.

\subsubsection{Case descriptions of four TDTs}

In the second perspective we aimed to describe different situations in particular TDTs using the framework. Analyzing the perceptions from four selected TDTs in more detail revealed differences between those groups and some relations between input, process and outcome factors in particular TDTs. Teams A and B reported the greatest gains in professional development and they were the most positive about the designed material. The perceptions of the input and process factors in these teams were positive and similar to the average perceptions of all respondents. The main difference between these teams is that the participants from team A performed more Activities outside TDTs and also reported more Actual use of the material than team B. Participants from the other two TDTs were less positive about the outcomes, but they mention different reasons.

Participants from team $C$ reported more controlled motivation to participate. In the interviews they explained that they were more or less forced to participate. In the process, these participants mentioned skepticism regarding the pre-defined goal, which 
affected the positive atmosphere in the group. The participants stated that the team coach could have played a role in improving the atmosphere. The negative perceptions of the outcomes can partly be explained by the fact that the participants experienced controlled motivation to participate. This is in line with motivation theory (Gorozidis \& Papaioannou, 2014). Furthermore, the participants experienced many practical and technical difficulties with teaching two classes with video conferencing. Eventually, the main insight was that it is not profitable to use video conferencing in classes. Therefore, part of the negative perceptions of the outcomes could be explained by the fact that the main goal of the TDT failed.

Team D was a heterogeneous group with teachers from different subjects. The participants explained that it was hard to find cohesion, due to this diverse group composition. Although this group had a clear pre-defined goal, the participants struggled to find a shared interpretation of this goal. They explained that the coach could have done more to define a clear goal and structure the activities.

One overall difference between the positive teams (A and B) and the more negative teams

( $C$ and $D$ ) is that the latter both had clear pre-defined goals. This does not necessarily mean that having a pre-defined goal has a negative effect on the outcomes. We argue that it could be explained by the fact that teams A and B explicitly took time to define a shared team goal. The team coach led this process. In teams $C$ and $D$ the goal was given, and possible differences in expectations and interpretations were not extensively discussed during the first meetings.

\subsubsection{Integrated descriptive framework}

The perceptions of the TDT participants could all be interpreted in terms of the conceptual framework; no new factors were mentioned. This means that the conceptual framework is a useful starting point to describe the individual factors that are present in TDTs. The aim of this study was to use insight from practice to adjust the conceptual framework to yield an integrated descriptive framework in which these individual factors are connected.

Findings from practice revealed some relations between the input, process and outcome factors. Both quantitative and qualitative data showed that most significant relations occur between the process factors and the outcomes. Team interaction, the process of defining a goal together and the type of activities (within the meetings as well as outside of the meetings) were all perceived as important for the outcomes. More specifically: the interview participants indicated specific actions the team coach took or could have taken during the process to better support the team process. These actions always 


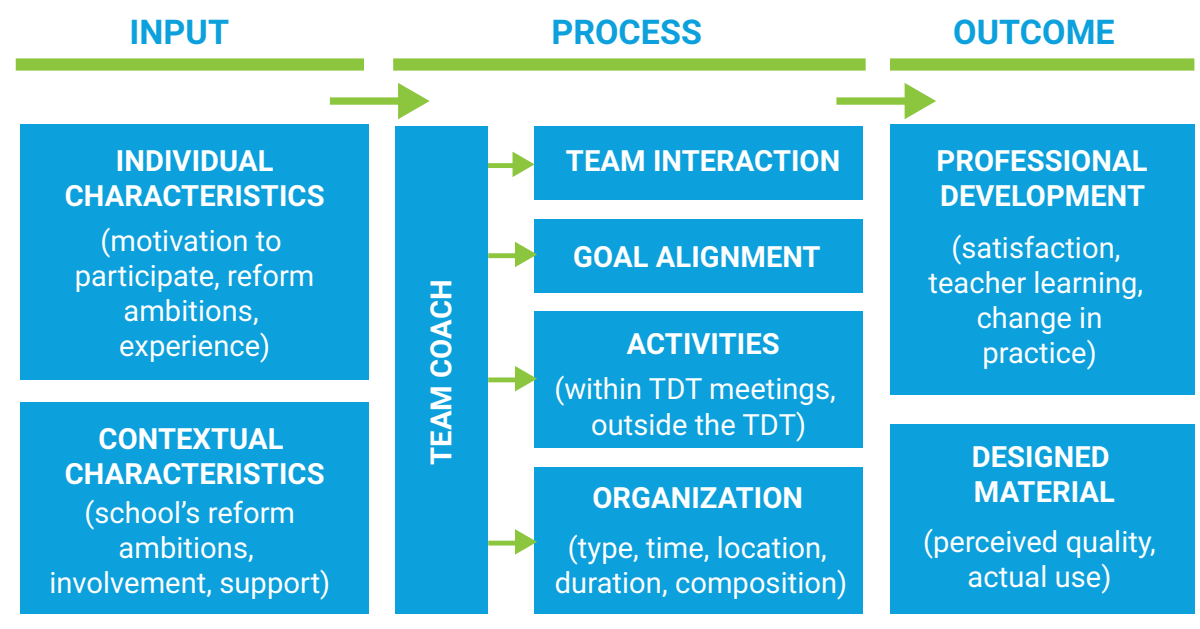

figure 2.2 Integrated descriptive framework for TDTs

concerned other process factors: the coach could structure the activities, stimulate the team interaction and mediate the team goals to find a shared goal. The integrated descriptive framework therefore has more focus on the process factors, compared to the conceptual framework, and the team coach is placed as a central actor in this process.

In general, participants were autonomously motivated to participate in the TDT, but the participants from team $\mathrm{C}$ also mentioned controlled motivation. This affected process factors in this team, such as team interaction and ownership of the team goal. For the other input factors, all participants in this study were very similar. In general, the participants were positive about educational reforms and they perceived their schools as ambitious and supportive. This means that this study only revealed one example of how input factors can affect the process. But the fact that we did not find any other relations does not mean they are not possible. Therefore, all input factors are still taken into account in the integrated descriptive framework, as they could affect the process.

The integrated descriptive framework is depicted in figure 2.2. This framework is based on both literature and practice and can therefore be considered the fundamental first step in the further development of a theoretical and practical basis for TDTs.

\subsubsection{Limitations and future research}

The main limitation of this study is that we only included TDTs in one specific context. Other types of TDTs might reveal other relations that we did not find in our context. For example, we expect that school-based TDTs might show more relations between 
the contextual characteristics and the process than our networked TDTs. To make the integrated descriptive framework suitable for all types of TDTs, we kept it as broad as possible. Findings on school-based TDTs could therefore still be interpreted in terms of this framework. We encourage TDT-researchers to use this descriptive framework in different contexts to gain deeper understanding of how various types of TDTs work in practice.

The results of this study give reason to investigate the process of networked TDTs in more detail, as the process stage had most significant effects on the TDT outcomes. This will be presented in the next chapter. 



\section{A qualitative analysis}

of Teacher Design Teams: In-depth insights into their process and links with

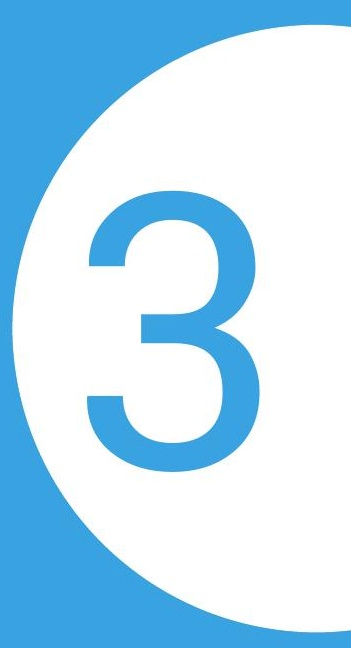

\section{their outcomes}

Based on: Binkhorst, F., Poortman, C.L, and van Joolingen, W.R. (under review). A qualitative analysis of Teacher Design Teams: in-depth insights into their process and links with their outcomes. 
ABSTRACT Teacher Design Teams (TDTs) are professional learning communities in which teachers collaborate to (re)design innovative educational materials. TDTs can contribute to teachers' professional growth. Furthermore, engaging teachers in the design process could create ownership, increasing the likelihood that teachers actually use the innovative materials in practice. In this study, we aimed to obtain in-depth insights into the TDT process and to identify possible links with the outcomes. We studied three cases of TDTs, collecting qualitative data from multiple perspectives. We found that the perceived outcomes of the TDTs were mixed. The leadership style of team coaches appeared to play an important role in shaping the process and hence the perceived outcomes. To improve the outcomes of future TDTs, findings from this study suggest that team coaches should provide more structure and clarity during the process. At the same time, the coaches should create an atmosphere in which participants can take the initiative.

\subsection{Introduction}

Professional development programs for teachers involving collaboration are considered to be highly effective, as they can build teachers' individual and collective capacities (Avalos, 2011; Crow \& Pounder, 2000; Hardré et al., 2013; Stoll et al., 2006; van Driel et al., 2012; van Veen et al., 2010). Therefore, the concept of Professional Learning Communities (PLCs) - which are groups of teachers focused on collaborative learning through sharing experiences and critical reflection - has received much attention in many countries (Stoll et al., 2006). Well-designed PLCs can contribute to improved teaching practice and student achievement (Vescio et al., 2008). PLCs can either have participants from the same school (school-based PLCs) or participants from various schools (networked PLCs). Various studies have indicated that networked PLCs are needed for actual school improvement, as they have the potential to move beyond the knowledge that is available within a single school (Bryk et al., 2011; Chapman, 2014; Hofman \& Dijkstra, 2010).

A Teacher Design Team (TDT) is a specific type of PLC that can be defined as 'a group of at least two teachers, from the same or related subjects, working together on a regular basis, with the goal to (re)design and enact (a part of) their common curriculum' (Handelzalts, 2009). As with other types of PLCs, TDTs can be either school-based or networked. Studies have shown that TDTs can contribute to teachers' professional development (Bakah et al., 2012a; Kafyulilo, Fisser, \& Voogt, 2014; Voogt et al., 2011). By sharing expertise and experiences while designing educational materials, teachers can gain new knowledge and skills and can use these to improve their overall teaching practice. Additionally as teachers who participate in a TDT are engaging in designing specific educational materials, they are not only exposed to new teaching practices, but also actively shape 
their teaching practice (Voogt et al., 2011). This is crucial for teachers, as designing materials is considered to be a core aspect of teachers' work (Carlgren, 1999). In particular, this is important in the case of educational innovations. The success of educational innovations largely rests on the shoulders of teachers, as they are expected to put the innovative ideas into practice (Huizinga et al., 2013; Fullan, 2007). Designing concrete educational materials in TDTs could create a sense of ownership of these innovations, which increases the likelihood that teachers would actually adapt their classroom practice accordingly (Bakah, Voogt, \& Pieters, 2012b; Visser et al., 2012; Wikeley et al., 2005). Therefore, TDTs can also contribute to sustainable implementation of educational innovations (Handelzalts, 2009; Johnson et al., 2014; Mooney Simmie, 2007).

\subsubsection{Problem statement}

As TDTs can yield both professional development and innovative educational materials, they can be very valuable to teachers. Although several studies have indicated how individual characteristics of TDT can influence part of their outcomes (e.g. Boschman, McKenney, \& Voogt, 2015; Huizinga, Handelzalts, Nieveen, \& Voogt, 2014), there is little empirical research available that evaluates how the complete process of TDTs works and how aspects of the process are linked with their perceived outcomes in terms of both professional development and the designed material. More thorough, in-depth understandings of the TDT process and outcomes are required to evaluate how TDTs could best be organized to promote the outcomes of TDTs in the future. Therefore, the aim of the present study is to obtain in-depth insights into the TDT process and to explore potential links with the perceived outcomes of TDTs.

\subsection{Theoretical framework}

Several studies about TDTs and other types of (networked) PLCs have indicated essential characteristics and potential outcomes. In the previous chapter, we aggregated these findings and developed a descriptive framework that includes all key elements that are important for understanding the TDTs' process and outcomes.

To address how the key elements of the process are related to the outcomes, the following theory of action for professional development can be used (Desimone, Smith, \& Philips, 2013): (1) teachers experience professional development with effective features; (2) the professional development increases teachers' knowledge and skills and/or changes their attitudes and beliefs; (3) teachers apply their new knowledge, skills, attitudes and beliefs to improve their instruction, their pedagogy or both; and (4) these instructional changes 


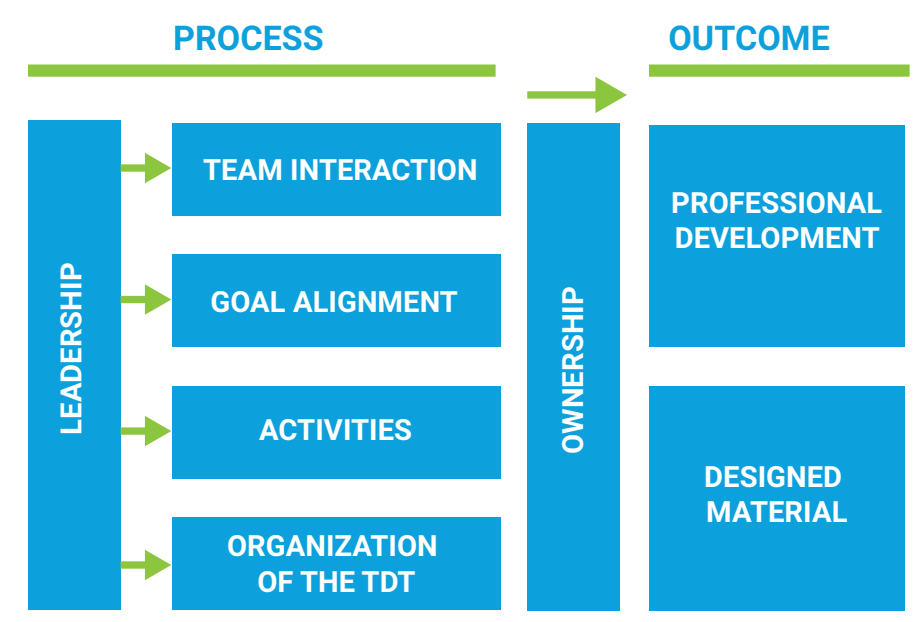

figure 3.1 Processes and outcomes of TDTs

foster increased student learning. In the context of TDTs, this means that teachers who participate in a TDT that includes effective features during the process can gain new knowledge and skills and use them to improve their teaching practice, which can foster increased student learning. Additionally, as TDTs are also focused on designing concrete educational materials, we use an analogous theory of action: TDTs that include effective features can also result in new educational materials that can be used in practice.

In this section, we will use the descriptive framework from the previous chapter, and zoom in further on the process and outcome stage. We first discuss the potential outcomes of TDTs in terms of professional development, the designed material and the sense of ownership of the TDT. Subsequently, we will address the key elements of the TDT process, including the process features (i.e., team interaction, goal alignment, activities and organization of the TDT) and the leadership style. This framework is depicted in figure 3.1.

\subsubsection{Professional development}

As explained in the introduction, teachers' professional development is one of the main objectives for TDTs. Teachers who participate in a TDT can gain new knowledge and skills, such as pedagogical knowledge, content knowledge, design skills or professional skills such as networking (Bakah et al., 2012a; Huizinga et al., 2014; Kafyulilo et al., 2014; Voogt et al., 2011). As Desimone et al.'s (2013) theory of action suggests, students can only benefit from this new knowledge and skills if teachers use them in practice. 
To assess the professional development of TDT participants, we use three levels (Desimone et al., 2013; Guskey, 2002a; Kirkpatrick \& Kirkpatrick, 2006). The first level concerns the teachers' initial reaction regarding the TDT. How was their experience of it and were they happy with the TDT? The second level is the teachers' learning: did the participants gain new knowledge and skills? The third level is when teachers actually apply these new understandings and skills and change their behavior in the classroom. An example of such application could be when teachers change the way they teach by applying new strategies for instruction.

\subsubsection{Designed material}

The second main objective for TDTs is developing educational materials. The type of material the participants develop depends on the focus of the TDT. For example, they can choose to design a complete educational module that takes several weeks to teach, or they can design several smaller instructional units, such as experiments, digital quizzes or tests.

To evaluate the designed material, its perceived quality can be assessed. As with the professional development, we also evaluate a further level: the actual use of the designed material after it was designed. Here we need to note that schools in the Netherlands are characterized by great autonomy (OECD, 2014): schools and their teachers are highly autonomous on matters regarding curriculum planning and assessment, as compared to other countries. For example, schools and teachers can choose which teaching methods or textbooks they use. Therefore, participants from our TDTs can choose whether they actually use the designed material or not.

\subsubsection{Sense of ownership}

Although professional development and the designed materials are the main objectives for TDTs, to reach the higher levels of the outcomes (change of behavior in classroom and actual use of the material), a sense of ownership is desired. As we explained in the introduction, a sense of ownership of the innovation is likely to develop in TDTs, as teachers are engaged in designing innovative educational material (Bakah et al., 2012b; Cviko et al., 2013; Visser et al., 2012). In this way, the professional development and the designed materials are adapted to teachers' own practice, which increases the chance that teachers will implement the innovations (Wikeley et al., 2005). 
However, previous research indicated that TDT participants do not always implement innovations in practice (Chapter 2). This implies that designing materials in TDTs might not automatically lead to ownership of the innovation and hence implementation. Other studies conceptualized ownership as 'ownership of an organization', or 'ownership of a community' (Avey, Avolio, Crossley, \& Luthans, 2009; Buchem, 2012; Lee \& Suh, 2015). These studies indicate that ownership of a community can lead to positive attitudes and behaviors (Avey et al., 2009; Lee \& Suh, 2015). Applying this broader definition of ownership to TDTs might explain why certain participants do change their teaching practice and use the designed material and others do not.

Ownership of the TDT can be described along four dimensions (Avey et al., 2009). First, self-efficacy is a person's belief that he can succeed at a specific task and that he can make a substantial contribution. Second, accountability is the feeling that everyone in the team can be held accountable for their actions and for the eventual results. Third, belongingness is defined as the feeling that a place or object (in our case, the TDT) feels like 'home'. It is the feeling that an individual is attached to, or belongs in the TDT. Finally, self-identity is slightly different from belongingness. It occurs when the TDT, or specific targets of the TDT, become classified 'as an extension of the self', or in other words, when they become part of the individual's identity.

\subsubsection{Process features}

Studies of TDTs and other (networked) PLCs have shown that a well-designed process including effective interaction, clear goals and relevant activities is essential for achieving the desired outcomes (Chapter 2; Handelzalts, 2009; Stoll et al., 2006). We distinguished four process features that will be addressed: Team interaction, Goal alignment, Activities and Organization.

\section{Team interaction}

Team interaction is crucial for teacher teams (Gast, Schildkamp, \& van der Veen, 2017), and is considered most effective if there is an open atmosphere of communication, in which teachers are willing to share ideas and information with each other (Dickerson, Jarvis, \& Levy, 2014; Hoegl \& Gemuenden, 2001; Stoll et al., 2006). Furthermore, mutual support by giving each other feedback and by openly discussing different views or potential conflicts is a vital aspect of team interaction (Grossman et al., 2001; Hord, 2004). Equal participation and effort from the team members also promotes the effectiveness of the group's work, 
as it strengthens their commitment to the team (Stoll et al., 2006). Furthermore, it is important that the team members feel coherence in the group (Gast et al., 2017; Hoegl \& Gemuenden, 2001; Stoll et al., 2006).

\section{Goal alignment}

Goal alignment is an essential process feature for professional communities such as TDTs (Hord, 2004; Meirink et al., 2010; Stoll et al., 2006). Studies have indicated that there should be coherence between the individual goals, the team goals and the overall goals of the program (Meirink et al., 2010; Penuel et al., 2007). In other words, it is important that goals are shared among team members (Stoll et al., 2006).

Furthermore, discussing the goals explicitly is crucial for the outcomes (Chapter 2). Teams that do not discuss their goals explicitly often have varying and even conflicting interpretations and therefore misconceptions of the goals (Johnson et al., 2014). Participants need to engage in collaborative sense-making to understand and work through these misconceptions (Allen \& Penuel, 2015).

\section{Activities}

Activities the team carries out are the third feature of the process. In the previous chapter, we identified three categories of activities that regularly take place in TDTs. The first type of activities consists of knowledge-related activities within meetings. During the meetings, teachers can share information and discuss experiences with each other, but external expertise is also considered to be crucial (Cordingley et al., 2003). External experts present 'formal knowledge' and up-to-date developments to the group (Erickson et al., 2005).

TDTs can also perform design-related activities within the meetings, for example, designing an overall structure for a lesson or writing texts for educational materials. Being involved in the actual design of educational material develops teachers' professional competencies, as opposed to only involving teachers in the implementation of new educational materials (Shawer, 2010).

Finally, teachers can perform activities outside of TDT meetings. Such activities could include searching for relevant articles to discuss in the next meeting, writing parts of the educational material or implementing (parts of) the educational material in the classroom. Implementation of materials in class between the TDT meetings is particularly important, as professional development programs are most effective if they are coherent with teachers' own classroom practices (van Driel et al., 2012; van Veen et al., 2010; Vescio et al., 2008). 


\section{Organization of the TDT}

Furthermore, it is important how TDTs are organized. For example, the duration, the frequency and the location where the meetings take place all can affect the outcomes (Handelzalts, 2009; van Veen et al., 2010, van Driel et al., 2012). In this study, we zoom in on three aspects of organization.

First, the method for planning the TDT meetings is important. Some teams meet on a regular basis, for example, every second Monday of the month. Other teams have to choose a new date every time they plan a meeting. Studies have shown that it is beneficial for teams to organize meetings on a regular basis (Handelzalts, 2009).

Second, although formally the time investment for our TDTs is 60 hours, because some of the activities take place outside the TDT meetings the actual time investment varies for each participant. It can be helpful if participants' schools are supportive, and if they give their teachers designated time and space (Stoll et al., 2006), but teachers themselves also need to make time for the TDT activities outside the meetings.

Third, the composition of the group as a whole can vary. Variables such as team size, previous experience as a group or professional backgrounds could all be considered.

\subsubsection{Leadership}

Leadership style is crucial in all types of team work, as it can directly influence the work process (Cordingley et al., 2003; Grossman et al., 2001; Scribner, Sawyer, Watson, \& Myers, 2007). Although in theory, TDTs are self-regulating teams in which participants have the autonomy to make decisions for the team (Handelzalts, 2009), various studies have emphasized the importance of support from a team coach. The team coach is expected to organize the TDT meetings, to provide basic process-support and to bring in expert knowledge about pedagogy (Becuwe et al., 2016; Huizinga et al., 2013; McKenney et al., 2016).

There are two main types of leadership: vertical leadership and shared leadership (Pearce, 2004; Pearce \& Sims, 2002). Vertical leadership is the traditional form for leading teams; one person guides his or her followers. Shared leadership occurs when team members show leadership behavior themselves, for example, by guiding or inspiring fellow team members, or by taking the lead in planning activities. Over recent decades, the overall consensus has become that teams tend to perform better if leadership is shared (Bergman, Rentsch, Small, Davenport, \& Bergman, 2012; Hoch, Pearce, \& Welzel, 2010; Pearce \& Sims, 
2002; Scribner et al., 2007). However, some studies have suggested that we should strive for a hybrid form of leadership, incorporating a mix of both vertical and shared leadership (Gronn, 2009; Pearce, 2004).

In this study, we examined the extent to which the leadership of TDTs was shared, by exploring both the team coach's and the team members' influence on shaping the process. If the team coach mainly steers the process, it can be categorized as vertical leadership and if participants take the lead it can be categorized as shared leadership. We expected that in teams in which the leadership was primarily shared, teachers would experience a strong sense of ownership. However, we also expected that some degree of vertical leadership is needed to give the process a clear structure.

\subsubsection{Research questions}

In the problem statement, we explained that there is little empirical research available that evaluates how the complete process of TDTs works and how aspects of the process are linked with their perceived outcomes. Therefore, the aim of this study was to obtain in-depth insights into the TDT process and to explore possible links with the TDTs' outcomes through exploration of multiple perspectives in three case studies. The theoretical framework was used to address the following research questions:

1 What are the perceived outcomes of the TDT, in terms of professional development, designed material and sense of ownership?

2. How is the TDTs' process, in terms of leadership and the four process features, linked with the TDT's perceived outcomes?

\subsection{Method}

A qualitative case study approach was used to find explanations and in-depth insights into the functioning of specific cases (Yin, 2013). We selected three TDT case studies to monitor for a year by collecting qualitative data from multiple perspectives. We observed the TDT meetings, collected logbook entries after each meeting and interviewed both the TDT participants and the team coaches. The ethical committee of our university approved the design of this study. 


\subsubsection{Case descriptions}

The University of Twente has been organizing networked TDTs since 2010. The duration of a TDT at our university is always one academic year. After each year, teachers can decide to extend their participation for another year. The TDTs have monthly 3-hour meetings at the university.

Most of these TDTs have focused on secondary school science subjects, because science teachers always need to find new ways to teach in stimulating, imaginative and creative ways to develop students' curiosity (Mooney Simmie, 2007). Furthermore, it is considered important for teachers to move beyond textbook science and to introduce students to science currently being worked on in laboratories, as this gives students a more realistic view of what science entails (Kolstø, 2001).

In this study, we monitored three TDTs during the 2014-2015 academic year. We refer to these teams as TDT A, TDT B and TDT C. These specific TDTs were selected because they all had a team coach with experience in leading TDTs since the TDTs started in 2010. The three team coaches all worked as teacher educators at the university's school of education, and they were not involved as researchers or authors of this paper. The team coaches were responsible for recruiting participants from various schools in the region, chairing the meetings and providing expert knowledge about pedagogy and designing educational materials. The first author of this paper observed the meetings, but she was not involved in the organization of the TDTs.

The aim of the three TDTs was to design new educational materials or experiment with new instructional strategies for the teachers' own subjects, but the exact focus of the TDT and the strategy for formulating the goal differed. We will briefly describe the three TDTs.

TDT A did not have a pre-defined goal, but the participants could set the goal. Although the TDT did not specifically articulate a team goal, the general theme could be summarized as: digital tools in education. The TDT had nine participants, who had a meeting every month. In these meetings they enacted collaborative activities that were related to the general theme. In total, TDT A had nine meetings.

TDT B included six teachers, who set the team goal during the first meetings. Their goal was articulated as: constructing practical assignments for technical design projects, including assessment tools. In total, TDT B held seven meetings, in which they worked towards these goals. 
table 3.1 Information about the three cases

\begin{tabular}{|c|c|c|c|}
\hline & TDT A & TDT B & TDT C \\
\hline Focus of the TDT & $\begin{array}{c}\text { General theme: digital } \\
\text { tools in education. Various } \\
\text { sub-goals, e.g.: } \\
\text { redesigning a digital } \\
\text { lesson series, exploring } \\
\text { computer simulations for } \\
\text { chemical experiments, } \\
\text { digital quizzes }\end{array}$ & $\begin{array}{l}\text { Constructing practical } \\
\text { assignments for } \\
\text { technical design } \\
\text { projects, including } \\
\text { assessment tools. }\end{array}$ & $\begin{array}{l}\text { Redesigning a complete } \\
\text { 10-week thematic module } \\
\text { about a multidisciplinary } \\
\text { science topic. }\end{array}$ \\
\hline $\begin{array}{l}\text { Strategy for } \\
\text { formulating the goal }\end{array}$ & Team set the goal & Team set the goal & Goal was fixed beforehand \\
\hline $\begin{array}{l}\text { Number of } \\
\text { participants }\end{array}$ & 9 & 6 & $6^{\mathrm{a}}$ \\
\hline Number of meetings & 9 & 7 & 7 \\
\hline
\end{tabular}

In TDT C, the team goal was pre-defined: redesigning a complete 10 -week thematic module about a multidisciplinary science topic. This TDT initially had 6 participants, but during the year, two more participants joined the team. TDT C held 7 meetings in total.

The characteristics of the TDTs are summarized in Table 3.1.

\subsubsection{Respondents}

The TDTs consisted of six to nine teachers from different schools who all taught the same science-related school subject; either Chemistry, Physics or the multidisciplinary subject Nature, Life and Technology (NLT). At the start of the first meeting, two or three participants from each TDT were selected as interview respondents on a voluntary basis. Representativeness of the respondents in terms of age, gender and prior TDT experience was checked with the team coach. Furthermore, the three team coaches also acted as respondents.

\subsubsection{Instruments}

The three TDTs were monitored over one academic year. The data collection consisted of three stages, as depicted in table 3.2. 
The first stage was setting a baseline. After the first meeting, we held semi-structured interviews with the team coaches and the selected participants. The interviews were aimed at uncovering expectations for the process and the outcomes. Each interview took between 20 and 45 minutes.

During the year, all TDT meetings were audiotaped and if possible, the first author of this paper observed the meetings. However, as some TDTs were held simultaneously, the observer was not able to attend all meetings. After each meeting, both the team coach and the observer completed a logbook entry about the meeting. When the observer missed a meeting, the logbook entry was completed after listening to the audio recording. The logbook addressed explicit open questions about the key elements of the process.

In the final stage, after the last meeting, we again held semi-structured interviews with the team coaches and the same respondents from each TDT. During these interviews, the respondents reflected on the process and perceived outcomes. Each interview took between 30 and 60 minutes.

table 3.2 Schematic overview of the collected data

\begin{tabular}{|c|c|c|c|c|}
\hline Stages in the research & & TDT A & TDT B & TDT C \\
\hline \multirow{2}{*}{$\begin{array}{l}\text { Baseline stage } \\
\text { Aim: Insights into } \\
\text { expectations about process } \\
\text { and outcomes. }\end{array}$} & $\begin{array}{l}\text { Number of interviews with } \\
\text { participants }\end{array}$ & 3 & 3 & 2 \\
\hline & $\begin{array}{l}\text { Number of interviews with } \\
\text { coaches }\end{array}$ & 1 & 1 & 1 \\
\hline \multirow{4}{*}{$\begin{array}{l}\text { Process stage } \\
\text { Aim: Detailed insights into } \\
\text { process, including process } \\
\text { features and leadership style }\end{array}$} & $\begin{array}{l}\text { Number of audio recordings of } \\
\text { meetings }\end{array}$ & 9 & 7 & 7 \\
\hline & $\begin{array}{l}\text { Number of meetings observed by } \\
\text { researcher }\end{array}$ & 4 & 4 & 6 \\
\hline & $\begin{array}{l}\text { Number of logbook entries } \\
\text { completed by coaches }\end{array}$ & 9 & 1 & 7 \\
\hline & $\begin{array}{l}\text { Number of logbook entries } \\
\text { completed by researcher }\end{array}$ & 9 & 7 & 7 \\
\hline \multirow{2}{*}{$\begin{array}{l}\text { Final stage } \\
\text { Aim: Looking back at the } \\
\text { process and insights into } \\
\text { perceived outcomes }\end{array}$} & $\begin{array}{l}\text { Number of interviews with } \\
\text { participants }\end{array}$ & 3 & 3 & 3 \\
\hline & $\begin{array}{l}\text { Number of interviews with } \\
\text { coaches }\end{array}$ & 1 & 1 & 1 \\
\hline
\end{tabular}




\subsubsection{Data analysis}

All interviews were audiotaped and then transcribed verbatim. The transcripts were coded by labelling text sections, based on all aspects that are shown in bold in the theoretical framework (e.g., professional development: learning). For the sections about leadership, we coded for both which part of the process was led (i.e., shaping goal alignment, stimulating team interaction, planning activities, organizing the TDT) and whether the leadership was vertical, shared or mixed. Some examples of codes are shown in table 3.3. A PhD student who was not involved in this study independently double-coded 10\% of the codes. The inter-rater reliability based on Cohen's kappa was .79.

Subsequently, all codes from the interviews were sorted in a table for each case. We summarized the perceptions of each individual respondent per code and we searched for similarities and differences between the individual respondents. This resulted in a summary per code for each case.

The logbook entries completed by the team coaches and observers included explicit questions about the aspects that are shown in bold in the theoretical framework. Therefore, the logbooks were already pre-coded, and could be directly structured in a table similarly to the interview data. Examples of the pre-coded logbook entries are shown in table 3.3. Again, we developed a summary per code for each of the three cases.

Next, the three cases were analyzed by comparing the logbook summaries and the interview summaries. We mapped the variables from the descriptive framework and searched for links between them by looking for patterns. For example, when found a cluster of respondents that reported a strong sense of ownership, we looked how the process factors or outcome factors of this group differed from the other respondents. Furthermore, sometimes respondents indicated links between factors themselves. In these cases, we searched the data to confirm these perceived links. 
table 3.3 Examples of codes and logbook entries

\begin{tabular}{|c|c|c|}
\hline Code & Example from interview & Example from logbook \\
\hline $\begin{array}{l}\text { Professional } \\
\text { development - } \\
\text { learning }\end{array}$ & $\begin{array}{l}\text { "I gained new knowledge and skills about } \\
\text { how to use digital tools in the classroom" } \\
\text { (Participant TDT A) }\end{array}$ & - \\
\hline $\begin{array}{l}\text { Ownership - } \\
\text { accountability }\end{array}$ & $\begin{array}{l}\text { "I felt accountable for my specific tasks. } \\
\text { For the rest of the TDT as well of course, } \\
\text { but I specifically wanted my part to } \\
\text { succeed" (Participant TDT C) }\end{array}$ & - \\
\hline $\begin{array}{l}\text { Team interaction - } \\
\text { mutual support }\end{array}$ & $\begin{array}{l}\text { "We supported each other and we asked } \\
\text { each other to provide feedback" } \\
\text { (Participant TDT A) }\end{array}$ & $\begin{array}{l}\text { "The participants who brought an } \\
\text { assignment received feedback from the } \\
\text { others" (Observer TDT B, meeting 4) }\end{array}$ \\
\hline $\begin{array}{l}\text { Leadership - } \\
\text { shaping goal } \\
\text { alignment - mixed }\end{array}$ & $\begin{array}{l}\text { "We mentioned ideas for the team goal } \\
\text { and the coach wrote it down. He } \\
\text { searched for a central theme in our } \\
\text { ideas" (Participant TDT B) }\end{array}$ & $\begin{array}{l}\text { "I played a central role by leading the } \\
\text { discussion about the team goal. I tried } \\
\text { to incorporate everyone's ideas and } \\
\text { input" (Team coach TDT C, meeting 1) }\end{array}$ \\
\hline
\end{tabular}

\subsection{Results}

The descriptive framework, depicted in figure 3.1, is used to describe the functioning of the three cases. We begin with addressing the first research question by presenting the perceived outcomes of the TDTs in terms of professional development, designed material and sense of ownership. Then we address the second research question, by describing the features of the process and the leadership style, and their links with the TDTs' perceived outcomes.

\subsubsection{Professional development}

In the baseline interviews, the respondents in all TDTs indicated that they hoped to gain new knowledge and skills, but they were not sure what type of new knowledge and skills they could expect. They hoped to "get new ideas from others", to "become more aware of their own didactic approach", or to "learn more about designing materials". Furthermore, most respondents stated that they thought their teaching practice would improve in small steps, mainly by trying new things in the classroom, but they were not sure what type of improvements to expect. The team coach from TDT A explained that although he expected that participants would learn new things, it was difficult to predict exactly what type of new knowledge and skills they will gain when the main focus of the TDT was still undecided: "I expect they will learn new things. But what they learn depends on what 
will happen. Right now, I'm not able to predict that properly." This illustrates that teacher professional development is not perceived as a linear rational process, but as a more complex development.

In the final interview, as a first reaction the respondents stated that they were fairly satisfied with the TDT. Most of them also indicated that they had learned: they gained some new knowledge and skills. In TDTs A and B, the respondents explained they mainly gained new pedagogical insights, by sharing knowledge and experiences with each other. One respondent from TDT B explained: "I gained more insight into how other teachers view education and pedagogy. It's good to learn that from others". In TDT C the teachers also indicated that they gained new content knowledge about the topic of the material they worked on. Some teachers reported actual change in behavior, as they perceived their classroom practice to be improved. However, they were not sure whether this improvement was due to the TDT, or due to the fact that they always improve incrementally.

\subsubsection{Designed material}

In the baseline interviews, respondents from TDT A did not have very clear expectations for the designed material. However, they all hoped and expected to design concrete materials that could be applied in the classroom. In the final interviews, the respondents from TDT A explained that they worked on various educational materials; therefore, all respondents mentioned different end products. One respondent redesigned a digital lesson series herself, tested it in practice and shared her experiences during the TDT meetings. She was very satisfied with this end product and she was determined to use it in the future. The other two respondents mainly mentioned smaller end products, such as interactive quizzes and working with computer simulation tools. They were less satisfied with the quality; in the final interview they mentioned that the TDT was less productive than they had expected: "It was a bit chaotic and not productive. We invested our energy in many different things. [...] I think we should and could have achieved more." These respondents did not mention clear plans to use the designed material in the future.

In TDT B, the respondents also had no clear expectations for the designed material in the baseline interviews. In the final interviews, the respondents all mentioned an assessment tool for technical design projects as the end product. In general, the respondents were satisfied with the quality of this end product and they all planned to use it in the future. However, two respondents mentioned that it was still work in progress and that the tool was not completely finished yet. 
The respondents from TDT C had a clear view of what to expect beforehand and what the module should look like by the end of the year. In the final interviews the three respondents and team coach indicated that they were satisfied with the quality of the module they designed; however, it was not yet finished at the end of the year. The team coach explained during the interview that they worked on many separate facets, and it still had to be brought together into a single module: "We mainly developed some new experiments. [...] But we still have to bundle it into one module and make a guideline for [other] teachers with tips and tricks on how to use this module." All respondents mentioned that they planned to use at least some parts of the module in their classroom practice, but only one respondents mentioned plans to use the complete module.

\subsubsection{Sense of ownership}

In each TDT, there were respondents who had a strong sense of ownership, and respondents who felt less ownership. We did not find differences regarding sense of ownership between the teams in general.

Four of the nine TDT respondents who were interviewed after the TDT mentioned high self-efficacy regarding ownership of the TDT. They believed they had made substantial contributions to the team and the product. The other respondents felt less certain about their ability to make a substantial contribution. They mentioned different reasons, for example: "When I tried to work with it, I encountered many technical problems, so I couldn't move forward to the pedagogy of the material" (Respondent TDT A) or "From the start, I was a bit unsure about the process... What is the division of roles, what can I contribute?" (Respondent TDT C).

Three respondents (one from each TDT) felt that they could be held accountable for the work in the TDT. Four respondents only felt accountable for their own tasks that they initiated themselves, not for the TDT as a whole. The other two respondents did not feel any accountability. One of them explained: "I think we could have achieved more in the TDT but I don't blame myself for that. I think I didn't feel enough engaged in the TDT" (Respondent TDT A).

All respondents felt belongingness with the team. They explained that it felt good to be a part of a team, and that it was a relief compared to other programs for professional development. 
Furthermore, all respondents mentioned that the TDT had become part of their identity as a teacher to some extent. They argued that what they did in the TDT - collaboration with colleagues and working on educational innovations - are also important aspects of being a teacher. They explained that doing these actions, rather than the TDT itself, felt like part of their identity.

There were three respondents (one from each TDT) who felt a strong sense of ownership, on all four dimensions. These three respondents were also positive about their professional development and the designed material. In particular, they mentioned the most plans to use the designed materials and the new knowledge in practice. The converse was also true: the three respondents with the least sense of ownership were less satisfied with the professional development and designed material. This illustrates how sense of ownership may well be linked with perceived outcomes in terms of professional development and designed material and is a hypothesis worthy of further research and consideration.

\subsubsection{Process features}

\section{Team interaction}

The team coaches from all TDTs mentioned in their logbooks that the team discussed actively and openly. The interview respondents reported the same impression regarding the team's communication. However, one respondent from TDT C mentioned some struggle related to communication, as every participant worked on isolated tasks. This was also mentioned in the observer's logbook about TDT C: "The participants all work on their own tasks, the communication mainly goes through the team coach."

The interview respondents and the logbooks indicated that the participants in TDTs A and B supported each other. They tried to help each other and gave each other feedback. The interview respondents from TDT C mentioned it was difficult to support each other, because everyone had their own specific tasks.

The interview respondents from TDT A mentioned that the participation and effort from the individual team members was perceived to be equally distributed, although not every participant was equally active for the different topics. In TDTs B and C some participants did more than others. 
The respondents from TDTs A and B indicated there was clear coherence in the group. A respondent in TDT B explained: "We are all teachers from the same subject striving for the same passion, yes, I definitely felt coherence." In TDT C, the respondents said it did not really feel like a team. The team coach explained in the final interview that every participant had his or her own specific tasks and that he was the connecting factor as a team coach.

All respondents and the team coaches indicated that good team interaction is important for the TDTs' outcomes. The respondents from TDTs A and B were positive about their team interaction, and they explained that the team's outcomes in terms of professional development and designed material benefited from their effective team interaction. In TDT C, the respondents were less positive about the team's interaction. They explained that the outcomes could have benefited from better team interaction.

\section{Goal alignment}

As indicated in table 3.1, there were different strategies for formulating a team goal: in TDTs A and B, the team was responsible for setting the goal, and in TDT C, the goal was fixed beforehand.

The observer's logbook indicated that TDT A did not explicitly discuss the team goal in any meeting. In the first meetings, they talked about possible activities, but they did not formulate a goal. The interview respondents from TDT A also stated that they did not discuss the team goal explicitly. In TDT B, both the team coach's and the observer's logbooks indicated that the team explicitly discussed the team goal during the meetings. In TDT $C$, the goal was fixed beforehand, and the team discussed the requirements during the first meeting. During the final two meetings they returned to these requirements, but the goal was not discussed explicitly in between, according to the logbooks.

The interview respondents from TDT A indicated that they did not have one shared goal, but they had various smaller goals. One respondent explained that a shared goal was lacking: "I missed some structure and an explicit goal that everyone supports. Some clearness about what we are actually going to do together." In TDTs B and C, all respondents indicated there was a shared goal. However, the team coach from TDT $\mathrm{C}$ explained that there were differences in interpretations of the goal: "We had a shared goal, but the interpretations of the goal, and in particular the views of what we had to do to reach that goal varied".

Overall, we found a link between goal alignment and perceived outcomes. Seven out of nine teachers explicitly mentioned in the final interviews that clear goals and corresponding activities are essential to provide focus in the designed material. Some of 
them felt that these features were missing, as a respondent from TDT A explained: "We did many small things, and a bigger product is not completed. A bit more to the point; that would be an idea [to promote the TDT's outcomes] I think."

\section{Activities}

The observer's and team coach's logbooks indicated that all teams spent the most time on knowledge-related activities during the meetings. Such activities included: discussions about pedagogical strategies, discussions about the use of digital tools, sharing experiences from the classroom and sometimes lectures from external experts.

The three TDTs also did some design-related activities during the meetings. These included: developing an online inquiry learning space for a computer simulation (TDT A), constructing an assessment tool together (TDT B) or editing a draft version of a module (TDT C). In the baseline interviews, most respondents indicated that they expected that the focus would be on these design-related activities rather than knowledge-related activities.

The activities outside of the TDT meetings varied from person to person. In TDTs A and $\mathrm{B}$, some participants tested the designed material in the classroom, while others did not. This enactment was always discussed and evaluated with the other participants in the next meeting of the TDT. Respondents who did implement the materials in practice during the design process explained that this was valuable for the TDTs' progress and the outcomes. In TDT C every participant had his or her own specific tasks to perform outside of the TDT meetings. However, the team coach mentioned in the logbook that the objective of these activities was not always achieved: "Apparently the task was not clear. They just provided small pieces of text, not a complete document."

Respondents from all TDTs indicated that the practical activities, such as writing, producing or brainstorming were most valuable for the TDT's outcomes. In particular, testing (parts of) the designed material in practice was seen as an essential activity for bringing the designed material to a higher level.

\section{Organization of the TDT}

In the final interviews, all respondents explained that they were positive about the organization of the TDTs. The respondents appreciated that the TDT were networked, as they had the chance to become acquainted with teachers from other schools. Furthermore, the respondents were positive about the interval of one month between the meetings. 
TDT A and TDT B planned the meetings on a regular basis: every second Monday of the month. The team coach from TDT C planned each meeting separately. This resulted in more cancellations from participants.

The time investment varied from person to person. All respondents knew that they had signed up for a 60-hour professional development program, but most respondents spent less time than that.

In TDT C, the participants perceived some inconsistencies in the team composition. During the year, two more teachers joined the TDT, and some experts on the topic joined the meetings now and then. This inconsistency in team composition led to some confusion among team members.

Overall, the respondents and team coaches from TDTs A and B were satisfied with the existing organizational structure. In TDT C, the respondents indicated that the outcomes would have benefited if the meetings were planned on a regular basis and if the team composition had been fixed.

\subsubsection{Leadership}

In this section we describe how vertical, shared and mixed leadership behaviors were enacted, with respect to the four features of the process: team interaction, goal alignment, activities and organization.

\section{Stimulating team interaction}

For all TDTs, most respondents provided examples of how they stimulated team interaction themselves. For example, a respondent from TDT A stated: "The team coach didn't have to stimulate our team interaction. Mainly because many ideas came from the participants themselves." This can be categorized as shared leadership. However, the logbooks also indicated a few examples in which the team coaches played a vertical leadership role by leading discussions in the right direction, or by making sure that every member had his or her turn in the discussion. In TDT C, where the team interaction was perceived as less effective, the team coach often felt that he had to enact vertical leadership to stimulate and motivate his participants: "Often I had the feeling I had to motivate and coach all members individually to get something done". 
As mentioned above, TDT A did not explicitly discuss a team goal. The team spontaneously planned the activities they came up with. This strategy evoked shared leadership behavior, as many participants pitched their ideas. However, the respondents explained that this also led to some confusion about the mission of the TDT: "I think it would be better to check what everybody wants to achieve by the end of the year. [...] It should be clear what we are aiming for. Then we are more motivated to actually do something."

In TDT B, the team coach asked all members to pitch ideas for the end goal during the first meeting. Subsequently, the team voted democratically to choose one of the goals. The participants appreciated the fact that the team coach took the lead in this process. At the same time, there was room for their own input. This leadership behavior can be categorized as a mix between vertical and shared leadership.

In TDT C, the goal was fixed beforehand. The team coach explained that it was difficult to find the right balance between vertical and shared leadership in clarifying this team goal: "If I would have put all my energy into clarifying the goals, then I'm only describing my own expectations. Instead of describing the needs from the entire team."

Respondents perceived that a mix between vertical and shared leadership is most effective in shaping goal alignment. Shared leadership was considered crucial to adjust the goals to participants' own needs. At the same time, vertical leadership could create clarity, which is needed to actually achieve something.

\section{Planning activities}

In TDTs $A$ and $B$, both the team coach and the participants took the initiative for activities. However, the perceived degree of shared leadership differed from person to person. This is illustrated by these two quotations from respondents in TDT B: "We can decide everything; if you want to turn left, we turn left. The team is free in that sense, we can initiate all activities" versus "Our coach chose the activities. He came with ideas and possible approaches."

In TDT C, both the team coach's and observer's logbooks indicated that the team coach initiated most activities. The team coach and each participant agreed upon the specific tasks and the coach kept an overview of what activities were needed to reach the team goal. This method for planning the activities could be categorized as vertical leadership. In the final interviews, two of the three respondents from TDT C described similar examples 
of vertical leadership regarding planning the activities. However, one of the respondents explained that she could initiate, plan and enact all activities that she wanted, which can be considered shared leadership behavior.

Both team coaches from TDTs A and B explicitly explained that shared leadership in planning activities was important for the team's outcomes. TDT B's coach explained: "I appreciate initiative. If someone comes up with something and wants to share it. Then you get feedback from others and you can bring it to a higher level." Respondents from all TDTs agreed that shared leadership regarding planning activities was important. Overall, the respondents who perceived the leadership regarding planning the activities to be shared had a stronger sense of ownership of the TDT. However, respondents also explained that it was not desirable to have only shared leadership. One respondent from TDT A explained that too many initiatives could lead to reduced quality of the activities: "Some activities just came by and had nothing to do with our goals. This resulted in reduced quality, and activities were not always well aligned." Respondents explained that more vertical leadership could ensure that the activities corresponded with the team goals. For example, the team coach could have stimulated them to test (parts of) the designed material in practice, and to reflect on this enactment within the meetings.

\section{Organizing the TDT}

In all TDTs, the team coaches organized the meetings. The team coaches set the dates for the meetings, arranged the rooms to meet in and sent the participants an invitation for each meeting. These managerial tasks can be categorized as vertical leadership.

\subsection{Discussion}

In this study, we aimed to obtain a deeper understanding of the process features and leadership styles in TDTs and their possible links with the TDTs' perceived outcomes. We studied three cases of TDTs, addressing the following research questions: What were the perceived outcomes of the TDTs? How was the TDTs' process linked with the perceived outcomes? In this section we will discuss our main findings and the implications for future TDTs. 


\subsubsection{What were the perceived outcomes of the TDTs?}

All respondents indicated that they gained new knowledge and learned some new things, which is in line with previous research about TDTs (Bakah et al., 2012a; Huizinga et al., 2014; Voogt et al., 2011). However, teachers found it difficult to indicate whether these learning gains would lead to improved classroom practice.

The three TDTs all designed educational materials. These materials were seen as useful, and some respondents were determined to use them in the future. However, most respondents indicated that they had higher expectations about the end product beforehand. Furthermore, in some cases the designed material was not yet finished. Therefore, some teachers found it difficult to predict whether they would use it in the future. These findings about the perceived outcomes suggest that one year of participation in a TDT might not be enough to realize professional growth, to design materials and to implement them in practice.

According to the literature, engaging teachers in the process of designing innovative educational material could lead to a sense of ownership of the innovation (Cviko et al., 2013; Voogt et al., 2015). In this study, all respondents felt ownership related to the TDT in terms of belongingness and self-identity. However, only some of the participants felt a sense of ownership in terms of self-efficacy and accountability. Therefore we can state that engaging teachers in designing educational materials does not automatically lead to a sense of ownership.

Furthermore, we found a possible link between sense of ownership and the outcomes of the TDT: respondents who expressed a strong sense of ownership tended to actually use the designed material in practice and to change their classroom practice. This is in line with literature that states that ownership can contribute to sustainable implementation of educational innovations (Carlgren, 1999; Mooney Simmie, 2007).

To summarize, although the main objectives for TDTs were achieved to some extent, not all respondents had yet achieved the higher levels of the outcomes (change of behavior in classroom and actual use of the material). The perceived outcomes of the TDTs differed not from case to case, but from person to person. 


\subsubsection{How was the TDTs' process linked with the perceived outcomes?}

In the results section, we described the process features (i.e., team interaction, goal alignment, activities and organization of the TDT) and the leadership styles in the TDTs in detail. We found several links between these processes and the perceived outcomes of TDTs.

All teachers and the team coaches indicated that team interaction was essential for the TDTs' outcomes, which is in line with other research (Dickerson et al., 2014; Gast et al., 2017). In general, the participants communicated openly and they supported each other. Respondents and team coaches indicated various examples of shared leadership regarding team interaction. They all explained that shared leadership regarding team interaction was desirable, as this can stimulate openness and better feedback. However in TDT C - in which the team interaction was perceived as less effective - the team coach felt he had to enact vertical leadership to motivate and coach every participant individually.

We also found a possible link between the goal alignment and the perceived outcomes of the TDT. Respondents who indicated that the goals were shared and discussed explicitly were also more positive about the TDT's outcomes. The approach regarding the team goal differed for each TDT. In TDT A, there was a high level of shared leadership regarding goal alignment, as participants could pitch their ideas. However, they never explicitly discussed the team goal, which led to a lack of clarity about the team goal. In TDT B, there was also shared leadership regarding goal alignment, as participants could pitch their ideas. But in TDT B this was combined with vertical leadership, as the team coach led the process of choosing a goal and ensured that the team chose a focus. They discussed the team goal regularly and all respondents felt the goal was shared. In TDT C, the goal was fixed beforehand and was perceived as shared. However, the exact requirements for the end product were not clear to all members, as they did not often explicitly discuss the team goal. Based on our findings, we cannot state which strategy for formulating a team goal is best. However, we can conclude that pitching ideas for the team goal can ensure that the goals are aligned with participants' own needs, and that explicitly discussing the team goal can improve clarity. This was also demonstrated in other studies (Allen \& Penuel, 2015; Johnson et al., 2014). Therefore, a mix between shared and vertical leadership regarding goal alignment appears to be needed to promote the outcomes of the TDT. 
The practical design-related activities, such as writing, constructing and designing were considered the most valuable activities for the TDT's outcomes. However, all TDTs mainly performed knowledge-related activities during the meetings. Not all respondents carried out activities outside of the TDT meetings. The respondents who tested the designed materials in practice stated that such testing is essential to the success of a TDT, which was also found in other studies about TDTs (Coenders et al., 2010; Cviko et al., 2013). In TDTs $A$ and $B$, both team members and the team coach initiated and planned activities. In TDT C, the team coach mainly took the lead in planning activities. The perceived degree of shared leadership regarding planning the activities varied from person to person, rather than from team to team. Respondents who mentioned the most examples of shared leadership had a stronger sense of ownership, and were more positive about the outcomes of the TDT. This finding is in line with literature that suggests that motivating leadership behaviors enhance the sense of ownership (Avey et al., 2009). However, respondents also explained that vertical leadership was needed to ensure that the activities corresponded with the TDT's goals, and to stimulate participants to carry out activities outside the meetings, as this could improve the quality of the designed material.

The organization of TDT A and B was perceived as efficient. Both the team coach and the team members of TDT $C$ mentioned that it would have been better to have meetings on a regular basis, as the other teams did.

To summarize, we found that the process of TDTs is largely shaped by the leadership style. Shared leadership can ensure that the formulated goals of the TDT and activities during the process are adapted to participants' own needs, which can strengthen the sense of ownership and hence promote the outcomes of the TDT. Furthermore, the respondents also indicated that vertical leadership was needed to provide structure and clarity in the process, which is essential for actually achieving something. Therefore, we conclude that a hybrid form of leadership, with a mix of both shared and vertical leadership (Binci, Cerruti, \& Braganza, 2016; Ensley, Hmieleski, \& Pearce, 2006; Gronn, 2009; Pearce, 2004) appears to be most effective for TDTs.

\subsubsection{Implications: directions for future TDTs}

This study provided in-depth insights into the outcomes of TDTs and how the process is linked with these outcomes. These insights can be useful for teacher educators who are planning to establish TDTs or other types of (networked) PLCs, or who want to improve the outcomes of existing teacher teams. 
We showed that leadership plays a vital role in shaping the process of the TDTs and hence their outcomes. To improve the outcomes of future TDTs, shared leadership is essential. Participants need to feel that they can take the initiative themselves to shape and lead the program in order to enhance the sense of ownership and hence improve the likelihood that high quality materials will be designed and incorporated into teachers practice. However, we found that the perceived degree of shared leadership varied from person to person, as not all participants felt they could take the initiative. Therefore, in future TDTs it is important that team coaches clearly explain that shared leadership is expected, to ensure that all participants feel that the leadership is to some degree in their hands.

At the same time, this study showed that team coaches play an important role in providing clarity and focus during the process. They need to ensure that clear goals are formulated and that the participants carry out the corresponding activities. Therefore, clear vertical leadership is also needed.

However, how to provide a mix of vertical and shared leadership is not self-evident, and is sometimes even described as paradoxical (Binci et al., 2016; Elloy, 2006; Meirink et al., 2010). There is no literature yet on how team coaches can effectively combine these seemingly contradictory tasks in TDTs or other (networked) PLCs. Therefore, more research is needed to design a new approach that supports team coaches of teacher communities in balancing vertical and shared leadership in an effective way, to support the process and hence the outcomes.

\subsubsection{Limitations and future research}

We chose an in-depth qualitative research design that deepened our understandings about how TDTs work in practice. Although the generalizability of our findings is limited, in-depth understandings could be relevant for teacher teams in various contexts. As a next step, more research in different settings is needed to obtain a broader understanding of the links between process and outcomes in teacher teams.

Furthermore, a limiting factor in this study is that the research is mainly based on self-report of a selection of the participants. However, we used various sources of evidence in terms of data and methods (i.e., interviews, observations, logbooks), to reduce bias (Poortman \& Schildkamp, 2011). Furthermore, the representativeness of the selected respondents was checked with the team coach. 
Furthermore, a limitation of the study could be that concepts such as ownership were only measured by the end of the TDT. Future research could investigate how the sense of ownership develops over time.

To conclude, as stated above, more research is needed to see whether the directions suggested by the present study actually lead to better outcomes of future TDTs. Therefore, we need to design a new approach to organizing and leading TDTs that incorporates aspects of both shared and vertical leadership. This new approach could then be implemented and evaluated to see whether it leads to improved performance. 



\title{
Teacher Design Teams
}

\author{
for professional \\ development: \\ Guidelines and a \\ nine-step method for \\ coaches
}

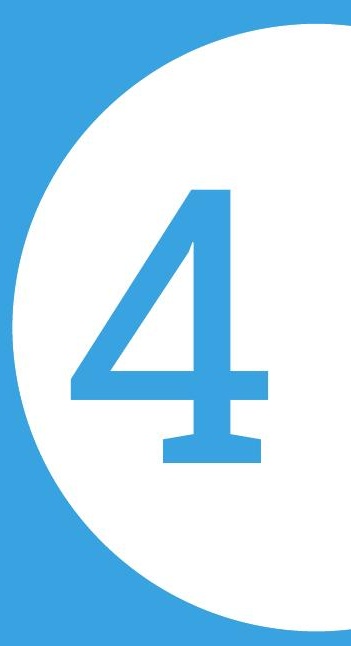

Based on: Binkhorst, F., Poortman, C.L., McKenney, S. and van Joolingen (under

review). Teacher Design Teams for professional development: Guidelines and a nine-step method for coaches. 
ABSTRACT Teacher Design Teams (TDTs) are professional learning communities in which teachers collaborate to (re)design innovative educational materials. By voluntary participation in the creation of educational materials that can be used in their classrooms, TDT members own and actively engage in the design process. When appropriately supported, TDT work stimulates the explication and use of pedagogical content knowledge, thus providing important opportunities for teachers to learn from one another. However, providing appropriate support is especially challenging, because TDT coaches not only must provide vertical leadership through the structure, clarity and quality of the team process, but also must provide for shared leadership that creates an environment in which leadership is distributed among participants. This paper proposes a set of guidelines and describes a stepwise method, both of which can support team coaches in combining these seemingly contradictory tasks. As a starting point, we investigate the features associated with productive TDT processes. Then we identify leadership behaviors that can foster these productive process features and summarize them in leadership guidelines. Next, we describe a method that supports team coaches with enacting these leadership guidelines in an integrated way. We conclude by discussing the conditions needed for this method to be fruitful.

\subsection{Introduction}

Professional development programs for teachers are increasingly team-based (Avalos, 2011). Teacher collaboration in professional learning communities (PLCs) is considered to be very effective, as such communities can build on teachers' individual capabilities as well as their collective capacity (Crow \& Pounder, 2000; Stoll et al., 2006; van Driel et al., 2012). In this way, PLCs can contribute to improved teaching practice and student achievement (Vescio et al., 2008).

PLCs can include teachers at a single school (school-based) or they can include teachers from various schools (networked). Studies have indicated the potential for networked PLCs to achieve a higher level of professional development than can be accomplished within the school (Bryk et al., 2011; Jackson \& Temperley, 2007).

Teacher Design Teams (TDTs) are a specific type of networked PLCs that consist of secondary school teachers who collaborate to (re )design educational materials. In TDTs, teachers engage in the creation of materials that can be used to make their lessons more attractive and to address immediate concerns in each other's classrooms (Handelzalts, 2009; Johnson et al., 2014; Mooney Simmie, 2007). Active participation can offer a rich context for developing and clarifying pedagogical content knowledge (Boschman McKenney, \& Voogt, 2015; Boschman et al., 2016), increasing knowledge and skills related to the integration of technology (Kafyulilo et al., 2014), or fostering teachers' design expertise 
(Huizinga et al., 2014). Therefore, TDTs provide important opportunities for teachers to learn from one another and thereby contribute to teachers' professional development (Bakah et al., 2012a; Voogt et al., 2011).

Although there are many types of TDTs, this paper focuses on TDTs with teachers from various secondary schools as participants and a team coach who facilitates the meetings.

\subsubsection{Problem statement}

Chapters 2 and 3 of this dissertation indicated that the team coach plays a vital role in shaping how the team works and hence the effectiveness of the TDT. However, it is challenging to provide adequate support (Gendole, Coenders, Voogt, \& Pieters, 2015; Huizinga et al., 2013). On the one hand, team coaches need to enact top-down or vertical leadership, as they are expected to organize the TDT meetings, to provide basic support for the team's work process and to supply expert knowledge about designing and pedagogy (Becuwe et al., 2016; Huizinga et al., 2013; McKenney et al., 2016). In this way, vertical leadership can foster structure, clarity and quality in the team's process. On the other hand, as TDTs are self-regulating teams, team coaches are expected to create an environment in which participants take the lead themselves by sharing ideas, initiating activities and enacting them. This type of horizontal, distributed or shared leadership can result in fruitful conditions for teachers' professional learning (Admiraal et al., 2015). Chapter 3 indicated that team coaches struggle to establish a productive balance between vertical and shared leadership. And while research-based guidelines for TDT coaching methods might be able to help, they are lacking in the literature.

\subsubsection{Goal and approach}

The aim of the present chapter is to develop research-based guidelines and a stepwise method that supports team coaches in leading TDTs, particularly with their challenging task of blending vertical and shared leadership. We started by summarizing the findings of chapters 2 and 3 and exploring additional literature on TDTs. This yielded a set of ten features that are consistently associated with the work process of productive TDTs. Then we searched for literature about vertical and shared leadership behaviors related to these features, both within and outside the field of education. We considered which leadership behaviors could be supportive for each of the ten process features. This resulted in a set of ten leadership guidelines for coaches. 
Next, we searched for proven approaches related to productive teamwork that included aspects of both vertical and shared leadership. These insights were used to develop a nine-step method that supports team coaches in enacting these leadership guidelines in an integrated way. Two team coaches and six former participants in TDTs provided expert feedback on the method, which prompted refinements.

\subsection{Process features in productive TDTs}

In chapter 2 , in which a descriptive framework for TDTs was developed, four categories were distinguished that describe key aspects of the process engaged in by TDTs: goal alignment, activities, team interaction and organization of the TDT. For this chapter, we used literature about teacher teams and teacher professional development to identify features within these categories that are crucial for the effectiveness of TDTs. This resulted in ten features that are associated with a productive TDT process. These are summarized in table 4.1 (second column).

\subsubsection{Process features related to goal alignment}

\section{Shared team goals}

Having a shared vision or a shared sense of purpose is considered a central aspect of effective teacher teams (Hord, 2004; Stoll et al., 2006). Working towards goals that are relevant for teachers' own practice promotes ownership (Cviko et al., 2013). This increases the likelihood that teachers will actually improve their teaching practice (Handelzalts, 2009; Voogt et al., 2015).

\section{Interpretation of the team goals}

Furthermore, clarity regarding the team goals and shared interpretations of these goals are also associated with team effectiveness (Meirink et al., 2010; Penuel et al., 2007; Stoll et al., 2006). If the team goal is too broad, or too open, participants could be overwhelmed by the number of possibilities (Scribner et al., 2007). 


\subsubsection{Process features related to activities}

\section{Relevance of the activities}

Collaborative activities within teacher teams, such as brainstorming, discussing and evaluating practice, can be relevant for teachers and thus have a positive impact on their teaching practice (Vescio et al., 2008). In addition, as indicated in chapter 3, individual activities outside of the TDT meetings could also be relevant for teachers. In particular, participants can have the opportunity to carry out activities within their own classroom practice, such as testing the designed material with their students; professional development programs that are coherent with teachers' own classroom practice are the most effective (van Driel et al., 2012; van Veen et al., 2010; Vescio et al., 2008).

\section{Clarity of tasks}

Task clarity is a significant predictor of team effectiveness; ambiguity about the tasks can result in the loss of valuable meeting time (Conley, Fauske, \& Pounder, 2004). In the previous chapter, we also indicated that not all participants knew what was expected of them. These participants explained that this led to unstructured meetings and reduced productivity.

\section{Quality of the activities}

The quality of the activities is considered one of the core characteristics for effectiveness in professional development programs (van Veen et al., 2010). Therefore, participants should always have access to expertise within and outside of the team (Little, 2006). Chapter 3 indicated that if participants feel that the quality of the activities is high, they are more likely to be positive about the outcomes, and they are more likely to actually improve their teaching practice.

\subsubsection{Process features related to team interaction}

\section{Openness of the climate}

A climate of open communication, in which teachers share their ideas and experiences with each other, is vital for team effectiveness (Chapter 2; Stoll et al., 2006). In such open climate, it is essential that teachers provide feedback to each other and that different viewpoints are discussed openly (Grossman et al., 2001; Hord, 2004; Stoll et al., 2006). 


\section{Engagement in team interactions}

Furthermore, equal participation and effort can strengthen the commitment to the team (Stoll et al., 2006). An imbalance in team members' input or participation can affect team efficiency (Crow \& Pounder, 2000). This means that all participants should be engaged in team interactions, not only the ones who are the most outgoing.

\section{Relevance and meaningfulness of discussions}

The previous chapter showed that a major pitfall in team interactions is that discussions are too long and sometimes end up going nowhere. Meaningful, relevant discussion is therefore a significant process feature.

\subsubsection{Process features related to the organization of the TDT}

\section{Organizational structure}

Literature about the organizational structure of teacher teams emphasizes the importance of the time element (Hord, 2004; Kruse \& Louis, 1997). To permit teams to have time to work together, meetings can take place on a regular basis, for example every first Monday of the month, as this provides participants with the opportunity to plan meetings in advance (Handelzalts, 2009). However, the meetings should also have a time limit, as participants always have other obligations and the types of activities within the meetings are usually very demanding (Handelzalts, 2009).

\section{The work process during meetings}

Regarding the work process during meetings, long-term planning should be flexible, as teams should be open to new insights. However, chapter 3 also showed that clarity about the process and purpose of the meetings is highly appreciated by participants.

The key message from this section is that a team process that involves engagement by all participants and in which participants perform meaningful activities and work towards goals that are relevant for their own practice helps support the effectiveness of TDTs. Therefore, we need to specify a set of leadership guidelines in which shared leadership is central, allowing participants to make decisions that suit their own needs. At the same time, the process needs to be clear and structured. Therefore, top-down or vertical leadership is also needed. 


\subsection{Types of leadership in teams}

Before we identify guidelines for leadership behavior for TDTs, we first provide an overview of the most common types of leadership in teams. To do this, we broadened our perspective from educational science to include the field of management and organization. These insights about leadership behaviors will be integrated with the ten process features that we described in the previous section. This will result in a set of ten guidelines for leadership behavior that could support the work process of TDTs.

\subsubsection{Vertical versus shared leadership}

When broadening our perspective to include the field of management and organization, we found a trend of increased emphasis on team-based work. Knowledge work in general shifted from hierarchical top-down organizational structures towards more shared team-based structures (Mohrman, Cohen, \& Morhman Jr, 1995). Given this shift towards team-based structures, scholars have questioned whether traditional leadership styles are still appropriate (Pearce, 2004; Gronn, 2008). Traditionally, leadership was construed as involving one appointed leader who guides his followers, which is termed vertical leadership (Pearce \& Sims, 2002). Together with the shift towards team-based knowledge work, a shift towards horizontal, distributed or shared leadership occurred (Carson, Tesluk, \& Marrone, 2007). With this type of leadership, all participants are engaged in leading the team and guiding their fellow participants (Pearce \& Sims, 2002). This type of leadership structure is the aim in TDTs; they are expected to constitute self-regulating teams in which shared leadership is central.

However, this does not mean that vertical leadership must be entirely abandoned in favor of shared leadership (Carson et al., 2007). The vertical, designated leader of a team plays an important role in developing shared leadership (Pearce, 2004). The vertical leader should maintain a climate that is open for shared leadership by actively encouraging participants to make decisions. Furthermore, the vertical leader can provide vision and clarity. However, vertical leaders should beware of being too persuasive during the process, as this could undermine the participants' sense of responsibility.

Shared and vertical leadership are not rigid either-or categories; these two concepts can be considered as endpoints in a continuum (Gronn, 2009). It might be a challenge for the leader to find the right balance between vertical and shared leadership. 


\subsubsection{Vertical and shared leadership behaviors}

Besides the question of who is in charge of leading the team, it is important to question what type of leadership behaviors should be exhibited. Various types of leadership behaviors have been identified over many years of research on leadership. While these are obviously relevant to the vertical leader, it is also important to address how team members themselves enact leadership behavior (Carson et al., 2007). Regardless of how leadership is structured (vertical or shared), four important types of leadership behaviors are (Pearce et al., 2003; Pearce, 2004):

Directive leadership, which is task-oriented leadership behavior, in which directions and recommendations are provided. Directive leadership behavior can give structure to complex tasks. Typically, the vertical leader exhibits directive leadership behavior. However, shared directive leadership behavior might also be exhibited, for example, when participants instruct one another about how to perform specific tasks.

Transactional leadership, which involves providing rewards, such as praise or compensation, to stimulate the team's effectiveness. Similar to directive leadership, transactional leadership is typically exhibited by the vertical leader, as he or she is the source of the rewards. However, shared transactional leadership might also be exhibited by praising one another for contributions to the team.

Transformational leadership, which is leadership behavior that makes a positive change in the environment. An example could be identifying the need for change and providing a vision and inspiration to enhance emotional engagement and commitment to the team. The vertical leader could exhibit transformational leadership by clarifying the team's vision. Shared transformational leadership might be exhibited by the whole team's working to create a shared vision.

Empowering leadership, which emphasizes participants' self-regulation rather than top-down regulation. Vertical leaders could exhibit empowering leadership behavior by encouraging participants to lead the team themselves. Participants can also encourage one another to take the lead and support others in doing so.

Another perspective on categorizing types of leadership is to look at what the leadership is oriented towards. Within this perspective, four types of leadership behavior can also be distinguished (Yukl, 2012):

Task-oriented leadership is aimed at accomplishing work efficiently. It includes features such as planning, clarifying and problem solving. 
Relations-oriented leadership is aimed at increasing the quality of human resources and relations. This type of leadership includes supporting, recognizing and developing.

- Change-oriented leadership is aimed at increasing innovation and collective learning. This includes advocating and envisioning change and facilitating collective learning.

- External leadership is aimed at acquiring necessary information and resources and defending the team's interests. This includes representing and networking.

As team settings are often very complex, coordination requires a wide variety of leadership behaviors in order to shape the team's work process and promote higher performance (Bergman et al., 2012). The likelihood that a team will experience the full range of these leadership behaviors increases when multiple team members share leadership.

\subsection{Guidelines for leadership behavior in TDTs}

In this section, we integrate the various leadership behaviors that were found in the literature with the ten process features for productive TDTs. For each process feature, we indicate a specific leadership activity that could be supportive. Furthermore, we identify the types of leadership behaviors that could be involved. This resulted in a set of ten guidelines for leadership behavior that could support the TDT process. A summary of these guidelines can be found in table 4.1 (third and fourth columns).

\subsubsection{Leadership guidelines regarding goal alignment}

\section{Participants define the team goal together}

It is crucial for a team to have goals that are engaging for all participants, as these goals give participants a sense of why the team exists (Wageman, 1997). A shared process in which both participants and leaders articulate the goal together helps to ensure that the goals are aligned with the teachers' own practice (Wageman, 2001). Therefore, shared transformational leadership behaviors - such as exchanging individual views and creating a shared vision - are powerful (Pearce, 2004). 


\begin{tabular}{|c|c|c|c|c|c|c|c|c|c|c|}
\hline 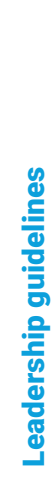 & 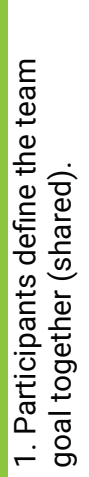 & 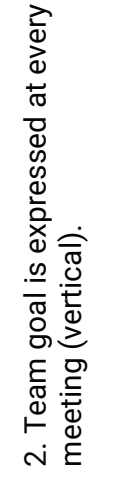 & 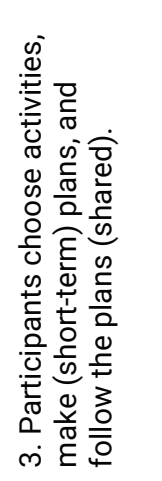 & 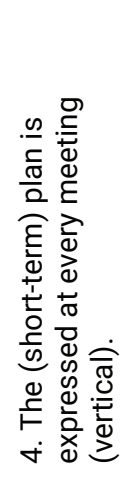 & 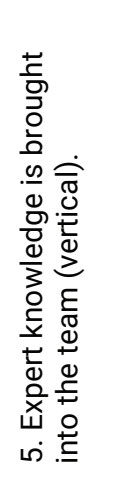 & 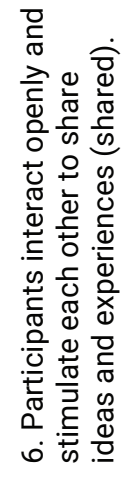 & 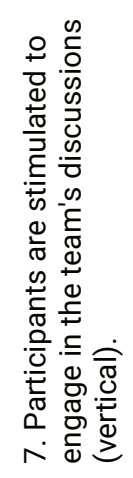 & 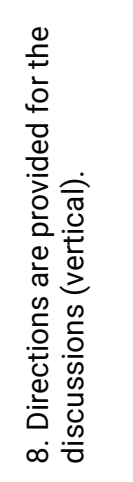 & 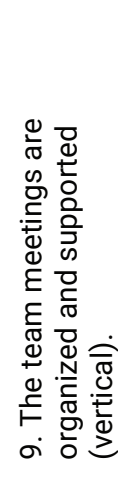 & 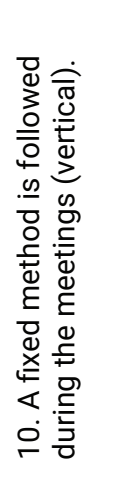 \\
\hline 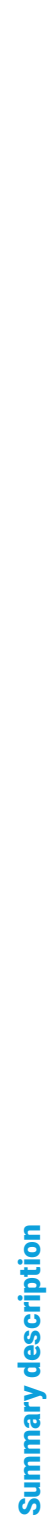 & 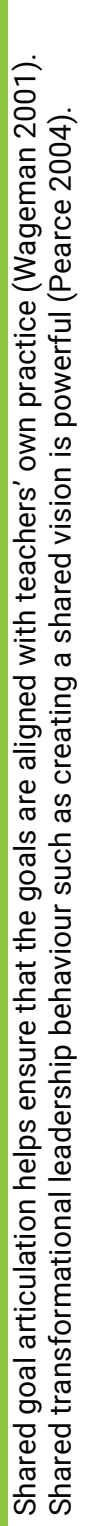 & 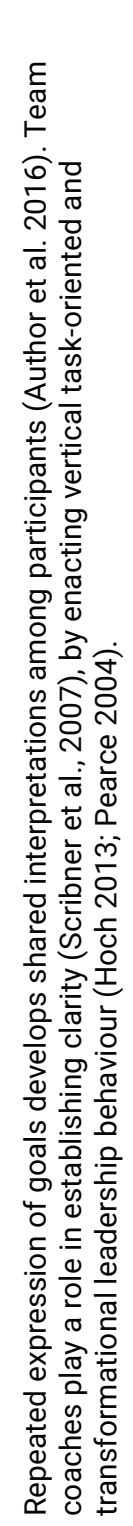 & 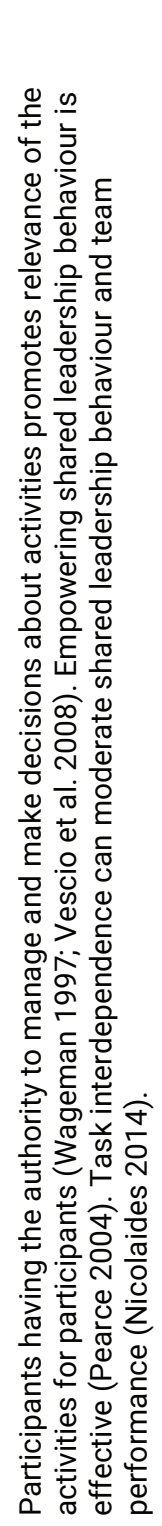 & 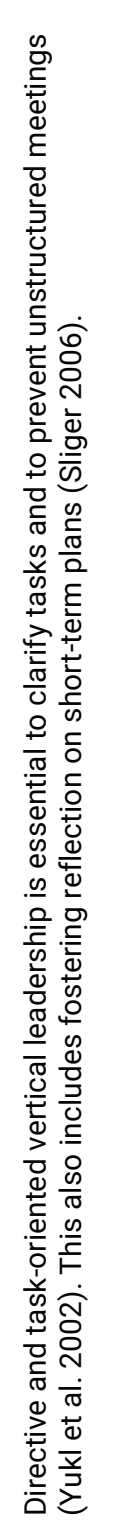 & 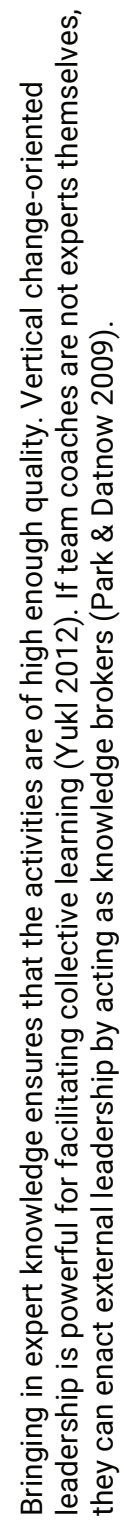 & 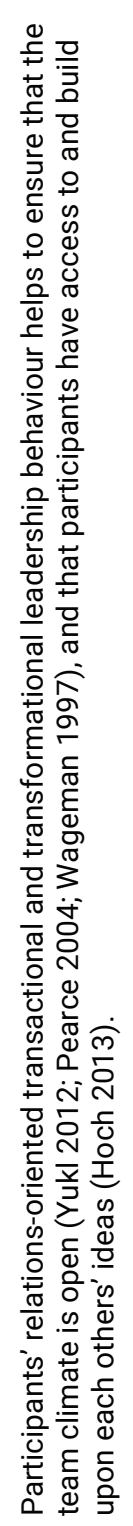 & 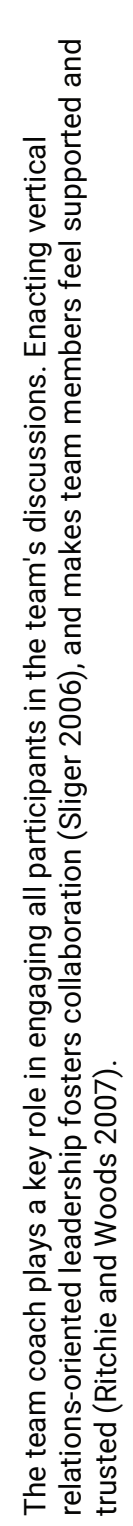 & 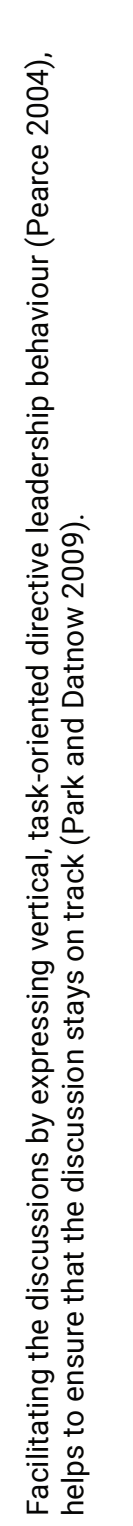 & 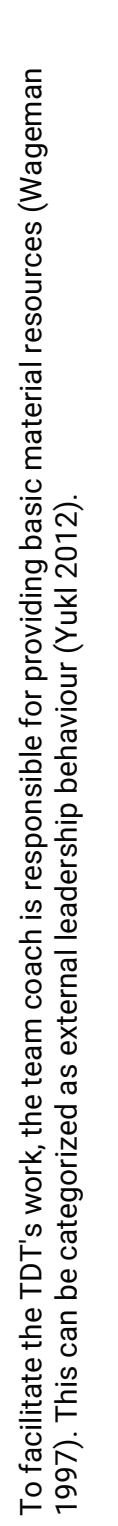 & 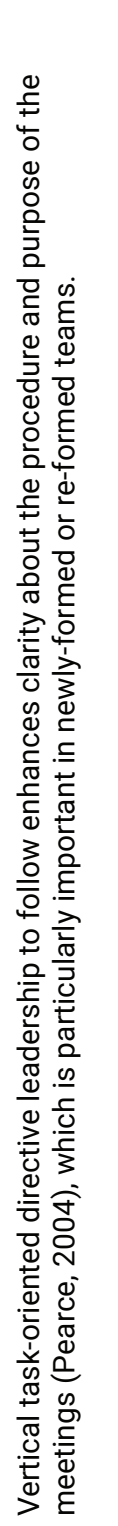 \\
\hline 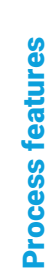 & 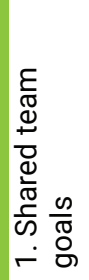 & 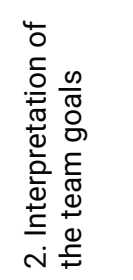 & 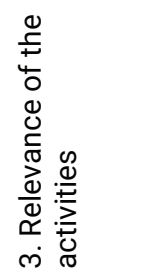 & 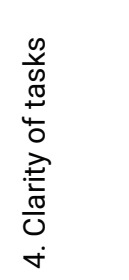 & 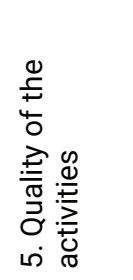 & 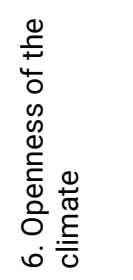 & 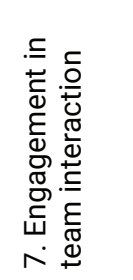 & 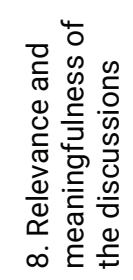 & 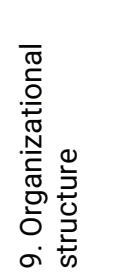 & 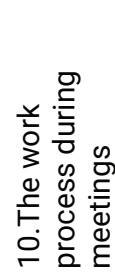 \\
\hline 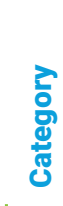 & 䒿 & & 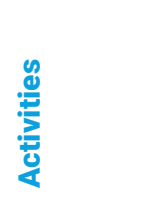 & & & 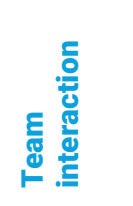 & & & 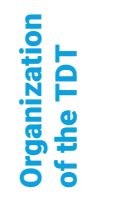 & \\
\hline
\end{tabular}


Of course, team coaches are also involved in the process of formulating a team goal. They can also enact vertical transformational leadership behaviors to explain their views and vision during the discussions about the team goal. But it is important that the participants are central; the team goal needs to be appealing to them. In other words, the focus needs to be on shared leadership. For team coaches, this means that they must beware of stepping too strongly into the discussions.

\section{The team goal is expressed at every meeting}

Chapters 2 and 3 of this dissertation indicated that in many TDTs, the team coach only expresses the team goal during the first meetings, which leads to reduced focus and lack of a shared vision during the TDT process. Repeated explanation of the team goal could promote a shared interpretation. Although team coaches are not always aware of the important role they play in helping to establish clarity regarding the team goals (Scribner et al., 2007), they can clarify the shared vision of the group, using task-oriented and transformational leadership behaviors (Hoch, 2013; Pearce, 2004).

\subsubsection{Leadership guidelines regarding activities}

\section{Participants choose activities, make (short-term) plans and follow the plans}

If participants have the authority to manage and to make decisions about the activities that take place, they can ensure that the activities are relevant for their own practice (Vescio et al., 2008; Wageman, 1997). Therefore, empowering shared leadership behavior, such as encouraging one another to choose and to enact tasks, is needed (Pearce, 2004). In particular, when task interdependence is high, shared leadership behaviors lead to better performance (Nicolaides et al., 2014), because when participants depend on each other to succeed, they need to use each other's expertise. This calls for increased mutual coordination and interaction.

As with the first leadership guideline, the team coach is also involved in the discussions in which activities are initiated, planned and enacted. However, again, the participants should be central in these discussions, in such a way that they feel they have the authority to make decisions. For team coaches, this means that they must beware of proposing too many ideas for activities or being too persuasive. 


\section{The (short-term) plan is expressed at every meeting}

Although the participants should have the authority to make decisions regarding the team's tasks, vertical task-oriented directive leadership behavior to clarify the team's plans is essential to prevent unstructured meetings (Yukl, Gordon, \& Taber, 2002). With this type of leadership behavior, team coaches can make sure that all participants have the same understanding about the tasks. Clarifying plans does not just include looking forward. Looking back at the (short-term) plan, and fostering reflection on whether this plan was realistic is also important, as the team can learn from it, and improve the plan the next time (Sliger, 2006).

\section{Expert knowledge is brought into the team}

If team coaches bring in their expert knowledge, they can ensure that the activities are of high enough quality. This can be categorized as change-oriented vertical leadership, as the team coach facilitates collective learning (Yukl, 2012). If the team coaches are not experts in the field themselves, they can act as knowledge brokers (Park \& Datnow, 2009), by connecting participants to one another or by introducing external experts to the team in order to exchange knowledge and expertise. Bringing in expert knowledge can broaden the participants' repertoire of problem-solving skills (Wageman, 1997). This can be characterized as external leadership behavior (Yukl, 2012).

\subsubsection{Leadership guidelines regarding team interaction}

\section{Participants interact openly and stimulate each other to share ideas}

An open climate for team interactions in which participants share experiences and ideas is essential for TDTs. In part, this can be seen as a precondition; participants should be autonomously motivated to participate in the TDT and they should be willing to modify their teaching practice (Gorozidis \& Papaioannou, 2014). In other words, enthusiastic and pro-active attitudes are expected from all participants. They need to find ways to work together, negotiate tensions and celebrate successes (Borg, 2012).

But in the ideal situation, they take it one step further and motivate, praise and inspire one another, by enacting relations-oriented transactional and transformational shared leadership behaviors (Pearce, 2004; Wageman, 1997; Yukl, 2012). With this type of shared leadership behavior, participants can have access to and build upon each others' ideas (Hoch, 2013). 
Of course, team coaches are also involved in these interactions, and they can also enact (vertical) transactional and transformational leadership behaviors to motivate participants, but the emphasis is on shared leadership. For the team coaches, this means that sometimes they need to take a step back.

\section{Participants are stimulated to engage in the discussions}

If a situation occurs in which some participants do not actively participate in the discussion, the team plays a key role in ensuring that they are involved in the discussions. Enacting vertical relations-oriented leadership, such as suggesting stimulating working methods that involve all participants in the discussions, fosters collaboration and allows the team to do the best work they possibly can (Sliger, 2006). Furthermore, team coaches can explicitly ask for the views and opinions of the participants who do not actively participate in the discussions. With this type of empowering leadership behavior, team coaches can make the participants feel trusted and supported, which is important in team interaction (Ritchie \& Woods, 2007).

\section{Directions in the discussions are provided}

Team coaches can facilitate the team discussions, to keep discussions on track and to ensure the discussions are relevant and meaningful (Park \& Datnow, 2009). If a situation occurs in which the discussions tend to lose focus, team coaches are advised to exhibit directive leadership behavior, by providing task-oriented directions in the discussions (Pearce, 2004).

\subsubsection{Leadership guidelines regarding organization of the TDT}

\section{The team meetings are organized and supported}

Team coaches play an important role in organizing and facilitating the work of TDTs. Team coaches are responsible for providing basic material resources (Wageman, 1997), such as basic tools, catering and an appropriate meeting space. This can be categorized as external leadership (Yukl, 2012). Furthermore, team coaches should ensure that the meetings take place on a regular basis and that meetings are not (often) cancelled (Handelzalts, 2009). 
Chapter 3 indicated that a fixed method for team meetings might promote the clarity and structure of the team's work process. This type of vertical task-oriented, directive leadership is particularly important in newly-formed or re-formed teams (Pearce, 2004).

\subsection{A method to support TDTs}

The ten guidelines for leadership behavior that we described in the previous section can support the ten features for a productive TDT process and hence improved effectiveness. However, without specifying a method, it will not be clear how team coaches can ensure that these behaviors are exhibited in an integrated fashion. In this section we propose a step-by-step method that supports team coaches with enacting the leadership behaviors laid out in table 4.1.

\subsubsection{Inspired by agile development}

The method we propose is inspired by agile product development, which is very common in self-regulated teamwork, especially in the field of software development (Highsmith, 2010). Agile development methodology, such as SCRUM (Schwaber, 1997), is an iterative, incremental approach that can be used for the development of complex products by a team. The basic idea of this approach is that the team works towards a (shared) team goal in small iterations. Participants create a backlog of tasks that are needed to accomplish the team goal. For each iteration, participants define a clear sub-goal and make a clear plan by choosing (small) tasks from the backlog to complete this sub-goal. At the end of each iteration, the team reflects on the process and makes plans for the next iteration. The team's goals, plans and tasks are all displayed on a planning board, which is visible for all team members.

The iterative nature of agile development methods promotes participants' learning about the domain and about the materials they design (Karhatsu, Ikonen, Kettunen, Fagerholm, \& Abrahamsson, 2010), in particular, when attention is paid to the shared understanding of tasks in the cyclical design process (Voogt et al., 2015). As teacher professional development is one of the main objectives for TDTs, an agile approach might be promising for TDTs. Moreover, agile development methods were shown to be very suitable for teamwork aimed at developing complex products (Highsmith, 2010). The educational materials developed within TDTs can typically be considered complex, as they often 
require emphasis on new pedagogies, new subject matter, various stages of learning, and how to provide adequate structuring for learners and teachers. As a consequence, it could be helpful to use agile development methods for this type of product.

Another reason why agile development is promising for TDTs is that in agile development, the plan is flexible rather than fixed, while - at the same time - the process is clearly structured (Moe, Dingsoyr, \& Kvangardsnes, 2009). Although shared leadership is central, vertical leadership also plays an essential role in agile methods. For example, Moe et al. (2009) describe a case study of an agile project that was less successful than they hoped, due to a lack of transformational and empowering leadership behavior from the team leader. Agile teams with a good balance between leadership from team leaders and participants perform better, especially when the team leader's style is one of leadershipcollaboration rather than command-control (Highsmith, 2010).

Although these aspects of agile development sound promising, we must bear in mind that TDTs are not the same as software development teams. In contrast to members of a software development team, the core activity of TDT participants is being a teacher, not being a TDT member. TDT participants only see one another once a month, rather than daily. Therefore, the method is only inspired by agile development, and not the same.

\subsubsection{The TDT method step by step}

In this section we explain how the method inspired by agile development works and how it provides opportunities to integrate and enact the leadership behaviors identified in the guidelines. Throughout this section we give practical examples in the context of TDTs

\section{Enacting leadership behaviors regarding goal alignment}

The method starts with brainstorming about the team goal (figure 4.1, A). While brainstorming, participants can bring in their own ideas and vision for the TDT. Participants could propose ideas such as: 'We could design a lesson series about renewable energy', or 'I think it is interesting to do something with digital tools for education'. Explicitly incorporating time to discuss the team goal with the whole team provides opportunities for participants to enact shared leadership behavior related to goal definition, which is the first guideline for leadership behavior that we specified. 


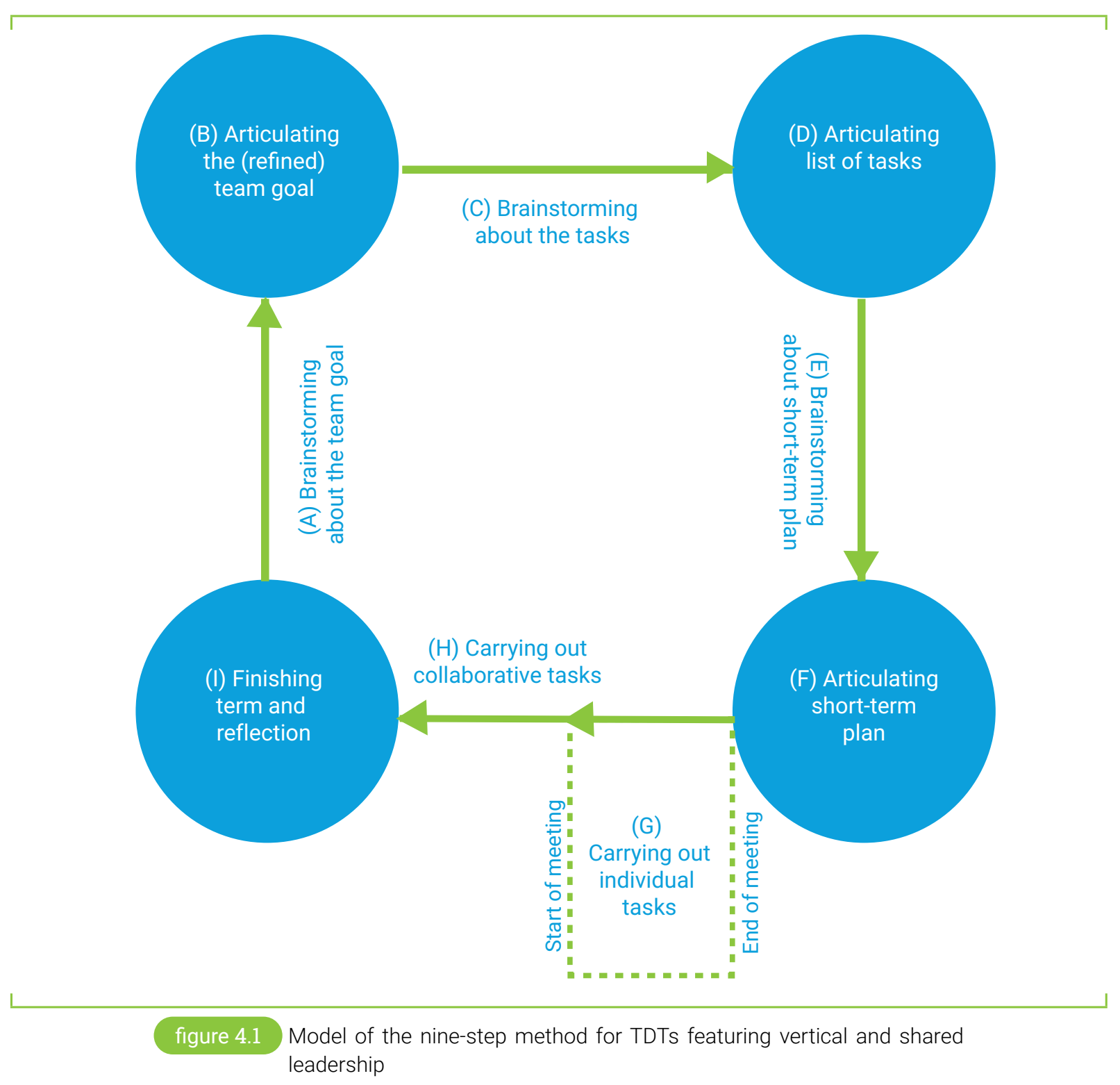

When the team agrees on the team goal, it needs to be articulated clearly, including the requirements for meeting it (figure 4.1, B). An example of a team goal could be: 'The goal for the TDT is to design a 4-week digital lesson series about renewable energy, which will be tested in the classroom by all participants'. Writing down the team goal on a planning board that is visible for all team members ensures that the goal is expressed, which is our second guideline for leadership behavior. Moreover, because it is an iterative process, the (refined) team goal is expressed on a regular basis, every meeting. 
The next steps in the method all concern the team's activities. Shared leadership to make the (short-term) plan and vertical leadership to articulate this plan - the third and fourth guidelines for leadership behavior - alternate with each other in these steps. Participants first discuss which activities or tasks are needed to accomplish the team goal (figure 4.1, C, shared). Then these tasks are articulated as a backlog by writing the tasks on sticky notes and affixing them to the planning board (figure 4.1, D, vertical). Examples of tasks could be: 'Make a list of relevant concepts in the theme renewable energy', or 'Write an introduction section for the lesson series'. Subsequently, participants collaboratively brainstorm about what should be done by the next meeting (figure 4.1, E, shared), by choosing a sub-goal, selecting corresponding tasks and allocating these tasks among the participants. An example of a short-term sub-goal could be: 'Gaining insight into the main concepts and contexts in the theme renewable energy.' Again, the planning is articulated by moving the relevant sticky notes from the backlog to the part where short-term planning is shown (figure 4.1, F, vertical). When all participants agree upon the plan, the meeting ends. Between the two meetings, participants have time to carry out the individual tasks in their classrooms or on their own time (figure 4.1, G, shared). When the next meeting starts, participants can carry out the collaborative tasks, such as discussing their various experiences with the individual tasks or bundling the individual products into a joint product (figure 4.1, H, shared). To complete the short-term plan, the team reflects on their process, by looking back at the plan and asking themselves whether they achieved the short-term sub-goal. In this way, reflection on the plan is expressed (figure 4.1, l, vertical).

After finishing with the short-term plan, the work process starts over, with the first step of the method. First, the team discusses whether the formulated team goal is still relevant. If needed, the team goal can be refined. Then the team discusses the backlog of tasks and provides adjustments if needed. After that, the team starts planning and carrying out the next short-term plan.

During the three steps that concern the activities, the team coach actively participates in the discussions. Although team coaches should be wary of being too dominant in the discussions, it provides opportunities for them to bring in their expert knowledge to ensure that the quality of the activities is high enough, which is the fifth guideline for leadership behavior. For example, the team coach can suggest relevant literature, or provide the team with examples of educational materials. 
Team interaction takes place during the entire cycle in this method. As the method incorporates much time for discussions and brainstorming about the possible goals, possible tasks and dividing the tasks (figure 4.1, A, C, E and H), the participants have plenty of opportunities to bring in their own ideas and share their experiences. Moreover, as these whole-group discussions are central in the team meetings, participants are encouraged to stimulate each other to share their experiences and praise each other's ideas, which is the sixth guideline for leadership behavior. This method encourages participants to exhibit the transformational and transactional leadership behaviors that support the sixth guideline.

The seventh and eighth guideline for leadership behavior, concern behaviors that team coaches enact when the discussions tend to go the wrong way. During the whole-group discussions, the team coaches can intervene if they notice that not all participants are engaged in the discussions. The fact that all individual tasks are explicitly formulated and displayed on a planning board gives the team coach opportunities to ask about the experiences or opinions of all participants. Or when team coaches observe that the discussions are going nowhere, they can easily go back to the team's plan that is displayed on the planning board, to steer the discussion in the right direction again.

\section{Enacting leadership behaviors regarding organization of the TDT}

The ninth guideline for leadership behavior - vertical leadership to organize and support the meetings - is not directly related to the method that we proposed. However, in order to make this method successful, the basic resources for facilitation of the team's work should be provided.

To conclude, this method provides clear instructions for the process within the meetings. If the team coach ensures that this method is followed, which is the tenth guideline for leadership behavior, the team meetings will be clear and structured. At the same time, this method provides plenty of opportunities to be flexible - for example by making adjustments due to new insights - in the long-term plan. 


\subsection{Final remarks}

In this chapter, we integrated ten features that are associated with the work process of productive TDTs with effective leadership behaviors that are known from the literature. This resulted in a set of ten research-based guidelines for effective leadership behavior in TDTs. These guidelines contribute to theory about balancing vertical and shared leadership in teacher teams.

As a practical contribution, we proposed a nine-step method that supports team coaches with enacting these behaviors in an integrated manner. As the method is inspired by agile product development, the planning is flexible rather than fixed and participants have plenty of opportunities to be creative, bring in ideas and initiate activities themselves. At the same time, the method provides for a clearly defined process, which prevents unstructured meetings and unclear team goals.

Although this nine-step method provides many opportunities to improve the TDT process and hence the effectiveness of TDTs, we also need to address some difficulties. First, with this method, the team coaches still have many tasks; they must provide expert knowledge, they need to keep an eye on the team interactions, and they need to manage the process. Therefore, it might be useful to split up roles, for instance by having a domain expert who provides expert knowledge on the subject and a second person who manages the team following the nine-step method. In particular, this could be helpful for teams who are using the TDT process for the first time. Second, when this method is introduced to participants, they need to agree to work this way. Therefore, the potential benefits of this approach should be explained clearly at the start of the TDT.

Although the main focus of this study was on developing a method to support team coaches in leading TDTs, we must also bear in mind the preconditions for participation. First, it matters who the participants in the TDT are. As we stated before, participants should be autonomously motivated to participate in the TDT and they should be willing to adapt their teaching practice, to ensure enthusiastic and pro-active attitudes (Gorozidis \& Papaioannou, 2014). Second, it matters how the participants' schools support their teachers' participation. For example, it is important that schools provide practical conditions, such as adequate time and space for the TDT's work (Admiraal et al., 2015; Stoll et al., 2006) and that the aims of the TDT are coherent with the (reform) aims of the school (van Veen et al., 2010). Furthermore, schools should give their teachers the opportunity to adapt their own teaching practice (Scribner et al., 2007). Self-regulating teams tend to be more effective when participants can make decisions at the micro-level, such as decisions in teachers' own classrooms (Tata \& Prasad, 2004). 



\section{Revealing a balancing}

act of shared and vertical leadership in Teacher Design Teams

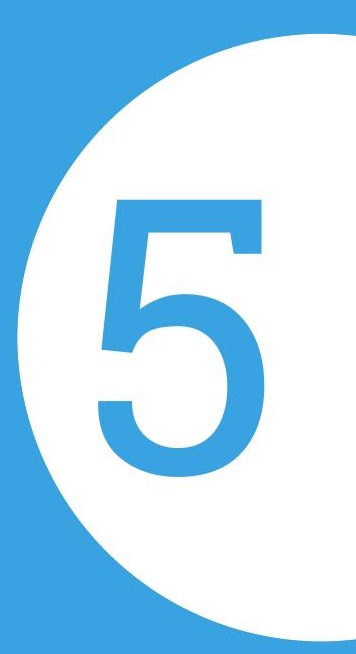

Based on: Binkhorst, F. Poortman, C.L., McKenney, S., and van Joolingen, W.R. (under review). Revealing the balancing act of vertical and shared leadership in

Teacher Design Teams. 
ABSTRACT Teacher Design Teams (TDTs) are professional learning communities in which teachers collaborate to (re)design educational materials. Although studies have indicated that leadership is vital for TDTs' functioning, providing adequate leadership is challenging. Both shared and vertical leadership are needed, and how to combine them is not obvious. TDT participants and coaches might benefit from insight into what shared and vertical leadership look like in practice. In this study, we monitored two TDTs that used a stepwise method that integrates shared and vertical leadership. Findings reveal that combining shared and vertical leadership in TDTs is possible, and can support effective processes. However, providing adequate leadership remains a challenging balancing act.

\subsection{Introduction}

Designing educational materials is increasingly considered to be a core aspect of teachers' work (Carlgren, 1999; Cober et al., 2015; Koehler \& Mishra, 2005; McKenney et al., 2015). Being engaged in the process of designing new educational materials contributes to a sense of ownership (Cviko et al., 2013; Visser et al., 2012), increasing the probability that teachers will actually implement these new materials in practice (Wikeley et al., 2005). Therefore, engaging teachers as designers can support sustained implementation of educational innovations in practice (Bakah et al., 2012b; McKenney et al., 2016). The aim of engaging teachers as designers is reflected in national educational policies. The Dutch government, for example, recently articulated the intention to give teachers a substantial role in the design of educational materials (Platform Onderwijs2032, 2016).

One way of having teachers take on the role of designers is to encourage their participation in Teacher Design Teams (TDT). TDTs are a specific type of professional learning community in which teachers collaborate in (re)designing educational materials While designing materials in TDTs, teachers can share expertise and experiences, allowing them to gain new knowledge and skills and use these to improve their overall teaching practice (Bakah et al., 2012a; Kafyulilo et al., 2014). In this way, TDTs can contribute to teachers' professional growth, potentially leading to increased student achievement (Voogt et al., 2011). Furthermore, professional growth can lead to greater professional satisfaction for teachers, which makes the teaching job more attractive (Guskey, 2002b).

TDTs can have either participants from the same school (school-based TDTs) or participants from various schools (networked TDTs). This study is focused on networked TDTs, as several studies have indicated that teacher networks have the potential to move beyond 
the knowledge that is available within the school to create even higher quality learning than when teachers from a single school work together (Bryk et al., 2011; Chapman, 2014; Hofman \& Dijkstra, 2010; Stoll, 2010).

\subsubsection{The role of leadership}

Although the potential outcomes of TDTs are promising for teachers, as they can contribute to both the design of renewed educational materials and to teachers' professional development, various studies have indicated that the effectiveness of the process and the quality of the outcomes produced by TDTs are mixed (Becuwe et al., 2016; Huizinga et al., 2014). Previous research, including the studies discussed in chapters 2 and 3 of this dissertation, has shown that leadership behavior plays a vital role in shaping the process, and hence the outcomes, of TDTs (van Driel et al., 2012). However, providing adequate leadership is challenging (Becuwe et al., 2016; Huizinga et al., 2013; Vangrieken et al., 2017). On the one hand, TDTs are self-regulating teams in which participants have the authority to make decisions themselves (Handelzalts, 2009). Therefore, team coaches are expected to create an environment in which teachers take the lead by participating in making decisions, sharing ideas, initiating activities and carrying them out (Bouwmans, Runhaar, Wesselink, \& Mulder, 2017). On the other hand, team coaches need to enact top-down or vertical leadership to provide structure, clarity and quality during the team's design process. For example, they are expected to organize the TDT meetings, to provide basic process support and to bring in expert knowledge about designing and pedagogy (Becuwe et al., 2016; Huizinga et al., 2013; McKenney et al., 2016).

\subsubsection{Problem statement}

How to combine these shared and vertical leadership behaviors in practice is not obvious, and is sometimes even described as paradoxical (Binci et al., 2016; Elloy, 2006; Meirink et al., 2010). For example, in chapter 3 participants and team coaches explained that it was important that participants could take the lead in defining the team goals, as this promoted their sense of ownership. At the same time, however, participants expected the team coach to take the lead more in defining the team goals, as this could have supported greater clarity and focus in the team's work process. In this example, the participants and team coaches indicated that both shared and vertical leadership were needed, but they struggled with combining these leadership behaviors. Various other TDTs or teacher teams have reported similar leadership difficulties (Becuwe et al., 2016; Huizinga et al., 2013; van Driel et al., 2012). 
Therefore, TDTs could benefit from practical insight into what vertical and shared leadership behaviors look like in practice and how they can be balanced. Such insight could help TDTs in three ways: (1) by helping them to recognize their own leadership behaviors, (2) by helping them to become more aware of how leadership can support the design process and (3) by helping them to avoid potential pitfalls related to leadership.

Therefore, the present study investigated how shared and vertical leadership behavior are manifested in TDTs and how these behaviors might support the TDT process, and identified leadership challenges for TDTs.

\subsubsection{Nine-step method for TDTs}

To promote blending of shared and vertical leadership behaviors, we developed a nine-step method that integrates both types of leadership in the previous chapter. The method was inspired by agile product development, which is very common in self-regulating teams of software developers (Highsmith, 2010). Similar to teams of software developers, TDTs aim to develop complex products such as curricular units and lesson series. TDTs that follow this method work in small, achievable iterations, which stimulates participants to be creative, bring in ideas and formulate their own plans on a planning board. In order to make clear the procedure, we will describe each of the nine steps using the model displayed in figure 4.1.

The nine-step method starts with brainstorming about the team goal (figure 4.1, A). While brainstorming, participants can bring in their own ideas and vision for the TDT. When the team agrees on the team goal, it is articulated in a clear way by writing it down on a planning board that is visible for all participants (figure 4.1, B).

Then participants will brainstorm which activities or tasks are needed to achieve this team goal (figure 4.1, C). These tasks are also spelled out on the planning board (figure 4.1, D). This results in a list of tasks.

Subsequently, participants collaboratively brainstorm about a sub-goal for the time period from step G to step I, which is referred to as a 'term', and participants select which tasks they want to perform during this term (figure 4.1, E). After writing up the short-term plans on the planning board (figure 4.1, F), the meeting ends. 
Between the two meetings, participants have time to carry out the individual tasks that they chose to take on (figure 4.1, G). When the next meeting starts, participants briefly report on the individual tasks and perform the collaborative tasks; for example, this could involve discussing their various experiences with the individual tasks or working to merge their individual products to a joint product (figure 4.1, H).

To finish the term, the team reflects on the process by looking back at the short-term plan and asking themselves whether they achieved the sub-goal for the term (figure 4.1, I).

After finishing the term, the nine-step method starts over. First, the team discusses whether the formulated team goal is still relevant. If necessary, the team goal can be changed or refined. Then the team discusses the backlog of tasks and makes adjustments if needed. After that, the team starts planning and spelling out the goals and tasks for the next term.

\subsection{Theoretical framework}

In this section, we will discuss the two main types of leadership that are needed in TDTs: shared leadership and vertical leadership. With shared leadership, all team members are engaged in leading the team and guiding their fellow participants (Pearce \& Sims, 2002). In the nine-step method, this type of leadership can occur in the steps where the team is brainstorming or carrying out tasks (figure 4.1, A, C, E, G and H).

However, with vertical leadership, one appointed leader guides the team (Pearce, 2004), which is needed to provide focus, to ensure high quality and to prevent unstructured meetings (Yukl et al., 2002). In the nine-step method, this type of leadership can occur in the steps where goals and plans are articulated or evaluated (figure 4.1, B, D, F and I).

In the previous chapter, ten possible leadership behaviors - both vertical and shared that might support the process and hence the outcomes of TDTs were identified. These ten leadership behaviors were identified after analyzing literature from the field of educational sciences about teacher teams and literature from the field of management and organization about leadership behavior. Below we describe these ten leadership behaviors, and we explain how they might support different aspects of the TDT process. These leadership behaviors are summarized in table 5.1. 


\section{Shared process of defining the team goals}

In all types of teamwork, having goals that are engaging for all participants gives participants a sense of why the team exists (Wageman, 1997). These goals are best aligned with the teachers' own practice if participants and leaders articulate the goals together (Wageman, 2001). Therefore, shared leadership behaviors aimed at defining the goals such as exchanging individual views and creating a shared vision - are powerful (Pearce, 2004).

\section{Explicitly expressing the team goals}

Team coaches are not always aware of the important role they play in helping to establish clarity regarding the team goals (Scribner et al., 2007). However, chapter 3 showed that repeated explanation of the team goal could promote a shared interpretation. Therefore, vertical leadership behaviors by team coaches play a key role in clarifying the group's shared vision (Hoch, 2013; Pearce, 2004).

\section{Shared process of defining and carrying out (short-term) plans}

Having the authority to manage and to make decisions about the activities that take place helps to ensure that the activities are relevant for participants' own practice (Vescio et al. 2008; Wageman, 1997). Therefore, shared leadership behavior - such as encouraging one another to choose and to carry out tasks - is needed (Pearce, 2004).

\section{Explicitly expressing (short-term) plans}

Despite the importance of shared leadership behavior to make decisions for the team, vertical leadership behavior to clarify the team's plans is also essential to prevent unstructured meetings and to make sure that all participants have the same understanding regarding the tasks (Yukl et al., 2002). This also includes looking back at the (short-term) plan, and prompting reflection on whether this plan was realistic, as the team can learn from this, and improve the plan the next time (Sliger, 2006). 


\section{Bringing expert knowledge into the team}

To ensure that the activities are of high enough quality and to facilitate the team's collective learning, team coaches can enact vertical leadership behavior by bringing in their expert knowledge (Yukl, 2012). If the team coaches are not experts in the field themselves, they can act as knowledge brokers (Park \& Datnow, 2009), by connecting participants to one another or by bringing external experts into the team in order to share knowledge and expertise.

\section{Interacting openly and encouraging each other to share ideas and experiences}

An open climate for team interactions in which participants share experiences and ideas is essential for teacher teams (Stoll et al., 2006). In part, this can be seen as a precondition; participants should be autonomously motivated to participate in the TDT and they should be willing to modify their teaching practice (Gorozidis \& Papaioannou, 2014). But participants can take it one step further and motivate, praise and inspire one another, by enacting shared leadership behaviors (Pearce, 2004; Wageman, 1997; Yukl, 2012). This provides participants with opportunities to gain access to and build upon each others' ideas (Hoch, 2013).

\section{Engaging all participants in the discussions}

Equal participation in the team discussions can strengthen commitment to the team (Stoll et al., 2006). Team coaches can ensure that all participants remain engaged in the discussions. Enacting vertical leadership behavior, such as suggesting active working methods that involve all participants in the discussions, or explicitly asking for the views and opinions of the participants who do not actively participate in the discussions, fosters collaboration and allows the team to do the best work they possibly can (Sliger, 2006). With this type of vertical leadership behavior, team coaches can make the participants feel trusted and supported (Ritchie \& Woods, 2007).

\section{Providing direction in the discussions}

Team coaches can play a facilitating role to keep the discussions on track and to ensure that the discussions remain relevant and meaningful (Park \& Datnow, 2009). If a situation occurs in which the discussion tends to lose focus, team coaches can exert vertical leadership behavior, by providing explicit direction during the discussion (Pearce, 2004). 
table 5.1 Ten vertical and shared leadership behaviors to support the TDT process

\begin{tabular}{|lll|}
\hline $\begin{array}{lll}\text { Process } \\
\text { features }\end{array}$ & Shared leadership behaviour & Vertical leadership behaviour \\
\hline Goals & $\begin{array}{l}\text { 1. Shared process of defining the team } \\
\text { goals }\end{array}$ & 2. Explicitly expressing the team goals \\
\hline Activities & $\begin{array}{l}\text { 3. Shared process of defining and carrying } \\
\text { out (short-term) plans }\end{array}$ & 4. Explicitly expressing (short-term) plans \\
& $\begin{array}{ll}\text { 5. Interacting openly and encouraging } \\
\text { each other to share ideas and experiences }\end{array}$ & 7. Engaging all participants in the discussions \\
\hline $\begin{array}{l}\text { Team } \\
\text { interaction }\end{array}$ & 8. Providing direction in the discussions \\
\hline $\begin{array}{l}\text { Organization } \\
\text { of the TDT }\end{array}$ & 9. Organizing and facilitating the team meetings \\
\hline
\end{tabular}

\section{Organizing and facilitating the team meetings}

Team coaches are responsible for providing organization and facilitating the work of TDTs, by providing basic material resources (Wageman, 1997), such as basic tools, catering and an appropriate meeting space. This facilitating role can be categorized as vertical leadership behavior (Yukl, 2012). Furthermore, team coaches are expected to ensure that the meetings take place on a regular basis (Handelzalts, 2009).

\section{Following a fixed method during the meetings}

In chapter 3 , we indicated that following a structured method for team meetings promotes the clarity of the team's work process. This type of vertical leadership behavior is particularly important in newly-formed or re-formed teams (Pearce, 2004).

\subsubsection{Research questions}

The nine-step method was developed to integrate vertical and shared leadership behaviors, which are both needed in TDTs. However, as explained in the problem statement, TDTs could benefit from insight concerning what these leadership behaviors look like in practice. 
To develop this practical insight, in-depth understanding from practice is needed. Therefore, in this study we addressed the following research questions:

1 How were vertical leadership and shared leadership manifested when applying the nine-step method?

2 How did these leadership behaviors appear to support the team's work process?

3 What leadership challenges did the TDTs encounter?

\subsection{Methods}

We studied two networked TDTs that applied the nine-step method for one academic year. We collected qualitative data from multiple perspectives to gain in-depth insight into the leadership behavior and the teams' work process. We observed the team meetings, collected logbooks and interviewed participants and team coaches by the end of the year. The ethical committee of our university approved the design of this study beforehand.

\subsubsection{Case descriptions and participants}

Our university has been organizing TDTs since 2010. The duration of a TDT is always one academic year (from September to June), but teachers can decide to participate for several years. The TDTs in this study had monthly 3-hour meetings.

TDT 1 was a group of five chemistry teachers from various secondary schools in the east part of the Netherlands. The team coach was a full-time chemistry teacher educator at the university, who has been leading TDTs since their start in 2010. The team held ten meetings in total. In this TDT, the participants collaboratively determined the team goals during the TDT meetings. The materials they designed were for their own use.

In TDT 2 , the team goal was determined beforehand: redesigning a ten-week module on Dynamic Modeling for the multidisciplinary secondary school subject Nature, Life and Technology (NLT). They planned to complete this redesigned module in two years, but we monitored only the first year. The TDT collaboratively chose a sub-goal for this year: defining a new structure for the module. The final module was meant for all NLT teachers across the country. TDT 2 was newly-formed, with three core participants who all teach NLT and another science subject (physics, chemistry, mathematics) at different schools in the Netherlands. Furthermore, this TDT had a 'following group' consisting of teachers, scientists and software developers who kept an eye on the team's progress and joined 
the meetings now and then. The team coach was a part-time teacher educator at the university and also a part-time biology and NLT teacher at a secondary school. This team coach had experience with leading TDTs since their start in 2010. Over the year, the team held a total of seven meetings.

In both TDTs, the first author was present as technical chair to ensure the nine-step method was followed as intended. Furthermore, she made observations as a researcher. The team coaches were not involved as researchers or authors of this chapter.

\subsubsection{Instruments}

During the year, all TDT meetings were audiotaped. After each meeting, both the team coach and the technical chair completed a logbook entry about the meeting. This logbook addressed explicit open-ended questions about the leadership behaviors shown during the nine steps of the method.

After the last meeting, we held semi-structured interviews with the team coaches and the eight participants of the two TDTs. These interviews involved reflection on leadership behaviors, the TDT process, and the links between them.

\subsubsection{Data analysis}

All interviews were audiotaped and then transcribed verbatim. We developed a coding scheme based on the theoretical framework. The ten leadership behaviors were defined as separate codes, and every category related to the TDT process (Goals, Activities, Team interaction and Organization of the TDT) was defined as a separate code. As the interviews also emphasized the links between leadership behavior and the team's work process, sometimes both leadership behavior and process categories were mentioned in the same sentence. For example: "Because we all mentioned ideas for the goals, the goals were supported and shared by all of us". In these situations, the text sections were labelled with a new code, identifying the link. The transcripts were coded by labeling text sections based on this coding scheme. To ensure that the coding scheme was reliable, a researcher from our department who was not involved in this study double-coded $10 \%$ of the codes. The calculated reliability based on Cohen's kappa was .80. The next step was that the codes for each case were sorted in a matrix. We summarized the perceptions of each individual respondent per code and we searched for similarities and differences between the individual respondents. These summaries revealed how leadership behaviors were shown, how participants perceived the team's work process and how the leadership behavior was linked with the process. 
The logbook entries were coded by labelling text sections according to the leadership behaviors. As the logbooks were already structured according to the nine steps, this analysis revealed the steps during which the ten leadership behaviors were evident.

Furthermore, the logbooks were used to identify situations during the meetings that could serve as examples of the combination of vertical and shared leadership. We selected three situations in which the logbooks for both the team coach and the technical chair explicitly described collaboration between participants and input from the team coach. After selecting these three situations, the audio recordings of these situations during the meetings were transcribed verbatim.

\subsection{Results}

For each of the nine steps, we describe when and how the ten vertical and shared leadership behaviors were demonstrated, and how participants and team coaches perceived that the leadership behavior supported the teams' work process. Furthermore, we explain what difficulties the TDTs encountered. These findings are summarized in table 5.2.

Additionally, to illustrate these results, we provide three examples from the team meetings. In these examples, we used the overview in table 5.2 to identify which shared and vertical leadership behaviors were evident and which leadership behaviors were missing. Furthermore, we explain how the leadership behaviors supported the TDT's work process in these examples.

\section{A. Brainstorming about the team goal}

The aim of step A was to collaboratively brainstorm about the team goals (figure 4.1, A). For both teams, this step took up most of the time in the first meeting held in September. In most of the following meetings, the teams concluded that these goals were still relevant. However, in the fifth meeting of TDT 1 , the group decided to add an extra goal.

As all participants in both TDTs provided input for the team goals, by addressing issues, mentioning ideas or by pointing out the relevance of these ideas, the participants demonstrated the first leadership behavior: 1. Shared process of defining the team goals. For example, a participant from TDT 1 explained in the final interview: "Yes, we all provided input in defining the goals. We could put forward all kinds of topics." Participants from both TDTs indicated that collaboratively defining goals was important for the team's work process, as it provided opportunities to find a shared meaning for the TDT. One participant from 
TDT 2 explained: "It gave me this feeling like, hey, this is what we all want. This is what we want to achieve together." The team coach from TDT 1 also explained why shared leadership behavior in defining the goals was important: "These are not my decisions to make. I'm not going to teach this, they are. So they must decide what is most relevant for their teaching".

\section{B. Articulating the (refined) team goals}

In this step, the technical chair wrote down the team goals on sticky notes, which were placed on the planning board (figure 4.1, B). In the first meeting of TDT 1 their goals were defined as: "Designing practical exercises on the theme of green chemistry" and "Getting familiarized with the new chemistry examination program". In the fifth meeting, their extra goal was added: "Gaining insight into the role of language skills in chemistry education". In TDT 2, the initial goal was: "Designing a new structure for the existing module on Dynamic Modeling". In the fifth meeting, this formulation was tightened: "Providing outlines for each part of the module, which can be used as building blocks to finish the module next year."

By writing down the goal and by repeating it every meeting, the technical chair demonstrated the second leadership behavior in both TDTs: 2. Explicitly expressing the team goals. One participant from TDT 1 explained: "Every time, the technical chair pointed out the goals and we discussed: these are the goals, are we still on track? Then you can move forward." The team coach from TDT 2 explained why this was very useful for the process: "Because we discussed the goal every meeting, it was possible to keep the process realistic along the way." Consequently, the goals were clear for everyone and everyone had the same interpretation of them. However, participants from TDT 2 also indicated that just clarifying the goals was not enough. They felt that although the goals were clear, the goals were still too broad. Despite the fact that their goal was tightened in the fifth meeting, it remained too broad, according to this participant: "It was clear that we worked on a new structure, a revision. [...] But this was still rather broad. I would have preferred to work towards concrete products."

\subsubsection{Example from the meeting: goal setting}

As steps A and B both addressed the team goals, these steps were closely related. Moreover, in the team meetings, the conversations often covered both steps simultaneously. An example of such a conversation is shown below. This conversation occurred in the fifth meeting of TDT 1.

When P1 brought up one of the goals, P2 and P3 both indicated that they were interested in a new perspective: the role of language. In this way, participants put forward their own ideas for the team goal, which can be recognized as the first shared leadership behavior 
P1: I think this goal, 'getting familiar with the new examination program', is more or less finished, right?

P2: Well, maybe if we link it to...

P3: Language!

P2: Indeed, I think it might be interesting to know more about the role of language in the examinations.

Technical chair: Ok, you mean that the role of language should be added as a goal?

P1: Yes!

P3: Indeed.

Team coach: Yes, we now have some insight into the direction of the new examination program, but we could pay some more attention to the linguistic aspects.

P4: Yes, until now we just focused on the role of chemistry. We could pay more attention to language. How do you formulate good questions? We could formulate test questions ourselves.

Technical chair: So you want to add this as a goal?

P4: Yes, I think that is relevant for all of us.

(1. Shared process of defining the team goals). Subsequently, the technical chair emphasized that this goal could be added to the planning board and the team coach clarified the situation by summarizing what had been done so far and what could be the next step. In this way, both the technical chair and the team coach demonstrated the second vertical leadership behavior (2. Explicitly expressing the team goal). Then P4 brought in an idea to make this new goal more concrete, and pointed out its relevance for all of them. By including a mix of shared and vertical leadership behaviors regarding the team goal, the TDT's work process was supported in two ways: (1) Enacting shared leadership behavior created opportunities to focus on a topic that was relevant for all participants: the role of language in chemistry education; (2) Enacting vertical leadership behavior ensured that concrete plans were formulated, which brought focus and clarity.

\section{Brainstorming about tasks}

Except for the first meetings, the TDTs did not always discuss the complete backlog of tasks (figure 4.1, C). Instead, in most of the meetings ideas for tasks were mentioned during step $\mathrm{H}$, while carrying out collaborative activities. In TDT 1 , the participants proposed most tasks, while in TDT 2 the coach also initiated several tasks.

While mentioning ideas for tasks, the participants exerted part of the third leadership behavior: 3. Shared process of defining and carrying out (short-term) plans. One participant from TDT 1 explained: "As a group, we decided everything. We discussed what we had to do, and what tasks were needed for that." However, this particular leadership behavior was more 
present in TDT 1 than in TDT 2. One participant from TDT 2 indicated that she always felt the need to ask for approval from the team coach: "I could take the initiative by mentioning tasks, but I was never sure it was in line with the expectations of the team coach."

\section{Articulating list of tasks}

The technical chair wrote down the tasks when they were mentioned (figure 4.1, D). Examples of such tasks were: "Searching for relevant contexts for the practical exercise about green chemistry" (TDT 1), or: "Making a list of topics that should be addressed in the introduction of the module" (TDT 2). The technical chair repeated the tasks she wrote down, in order to receive confirmation from the participants.

While writing down and repeating the tasks, the technical chair demonstrated part of the fourth leadership behavior: 4. Explicitly expressing (short-term) plans. One participant from TDT 1 explained why writing down the concrete tasks fostered clarity in the process: "I really liked having a technical chair, because she noticed everything during the conversations and directly wrote it down. By the end she said: you mentioned all these tasks, are we going to do this? This made everything very clear." Although the ideas for tasks were mentioned by the participants themselves, in both TDTs the technical chair or the team coach sometimes helped them to provide more concrete formulations of the tasks. Despite this help, the logbooks from the team coach and technical chair in TDT 2 both indicated that the team kept having difficulties with defining concrete and small tasks. In the interviews, the participants explained that this was related to the fact that the defined team goal was too broad.

\section{E. Brainstorming about short-term plan}

In TDT 1, all participants provided input during the brainstorming about the short-term plan (figure 4.1, E). Every meeting, they each volunteered to perform some tasks for the next term. In TDT 2, this was sometimes a difficult process, primarily when some of the participants were absent. In these cases the team coach asked specific members to take a task, or the coach proposed to do it himself.

While participants were brainstorming about the short-term plans and choosing tasks, they enacted part of the third leadership behavior: 3. Shared process of defining and carrying out (short-term) plans. The team coach from TDT 1 explained how this worked: "At the end of the meeting you make plans for the next time with this method. This gives the participants many opportunities to express their preferences." The participants explained that this enabled them to set boundaries, to ensure that the plans remained doable for them. Furthermore, one 
of the participants explained how this shared leadership behavior promoted her sense of responsibility: "We collaboratively decided, you are going to do this, you are going to do that. This made me feel responsible to actually do the things I had agreed to." In TDT 2, participants were somewhat more cautious about volunteering for tasks, as this participant explained: "In a way, everyone was somewhat cautious. I didn't hear anyone explicitly say: we are going to do this all." He argued that this was related to the fact that sometimes participants were absent, because if only some of the participants are present to volunteer for tasks, the team cannot really make progress.

Furthermore, during this step both team coaches sometimes demonstrated the seventh leadership behavior: 7. Engaging all participants in the discussions. This mainly happened in TDT 2, where the team coach felt the need to engage all participants by asking them to take on specific tasks. He explained: "If I saw someone who was quiet, but maybe wanted to do something, then I needed to find ways to actively engage him, for example by proposing tasks."

\section{F. Articulating short-term plan}

In all meetings of both TDTs, the technical chair wrote down the sub-goal for the next term that the participants had defined (figure 4.1, F). This was put up on the planning board, along with the selected tasks. The technical chair summarized the plan at the end of each meeting.

In this step, the technical chair enacted the fourth leadership behavior in both teams: 4. Explicitly expressing (short-term) plans. One participant from TDT 1 indicated: "At the end of the meeting we discussed what we were going to do next time. Everyone knew what to do." The team coach from TDT 1 explained that this ensured that the plans remained clear and manageable: "It is very pleasant to end each meeting with concrete plans. This makes it more explicit, tangible and clear."

\subsubsection{Example from the meeting: making short-term plans}

Similar to steps A and B, steps C to F were closely related, as they all addressed development and articulation of tasks and plans. Again we will provide an example of a conversation that covered both shared and vertical leadership regarding planning the activities. The conversation below comes from the first meeting of TDT 2 : 
P1: Can I make a suggestion for the next meeting?

Technical chair: Yes.

P1: Maybe we can all just think about our ideas for the three different levels. What do we consider the basic level, what is intermediate and what is expert? Because now I have heard so much new information, and I have so many new ideas... Now I just want to read the module again and see for myself what I think belongs to the basic level and what belongs to expert. I think for now it is too difficult to do one of the other tasks.

Team coach: Ok, so basically you mean, let's all do the same. You all have an idea about the different levels, with your own experiences in the classroom. And you can all work that out in your own language.

P1: Yes.

Team coach: Then I can imagine we will all give a short presentation next meeting, in which you all say: this is how I see it. Then we all will get more feeling about where we want to go with this module.

Technical chair: Ok, then we can take this task you just mentioned, 'mapping the characteristics of the different levels', and put it on the planning board.

Team coach: Yes, but then it is not a task that we divide, but a task we are all doing.

In this situation, $\mathrm{P} 1$ demonstrated the third leadership behavior (3. Shared process of defining and carrying out (short-term) plans) by making a suggestion for the plan for the next term. She set her boundaries by indicating that she had so many new ideas, and that she just wanted to go back to the module again, to determine for herself what she thinks belongs to the three different levels. By indicating that doing more than that would be too difficult, she created opportunities to digest the new information and actually learn new things. Subsequently, the team coach followed up on this idea; he clarified it and formulated a concrete plan for the next term. Then the technical chair moved the relevant sticky notes onto the planning board. In this way, both the team coach and the technical chair demonstrated the fourth leadership behavior (4. Explicitly expressing (shortterm) plans). As both shared and vertical leadership behaviors were enacted, the team made concrete plans to move forward in a direction that was relevant for the participants. However, only one of the participants was engaged in this conversation. To ensure that all participants were engaged and committed to the plans, the team coach could have enacted the seventh leadership behavior, by asking the other participants to join the conversation and express their preferences. 


\section{G. Carrying out individual tasks}

Between the meetings, the participants of both TDTs carried out almost all of the tasks they had agreed to (figure 4.1, G). However, the depth of fulfillment of the tasks varied from person to person. Furthermore, in TDT 2, not all tasks were equally concrete. The concrete tasks - such as "Developing a modeling assignment in a biology context" - were completed most of the time, whereas the less concrete tasks - such as "Considering which topics should be addressed in the introduction to the module" - were not always understood correctly, and hence not always completed properly.

While carrying out the individual tasks, the participants again demonstrated part of the third leadership behavior: 3. Shared process of defining and carrying out (short-term) plans. One participant from TDT 1 explained that carrying out individual tasks provided learning opportunities, as long as the experiences were shared during the following meeting: "He [another participant] came back with many results. It was interesting to see how he had to make adjustments. You learn a lot from these experiences".

Furthermore, in the time between the meetings, both team coaches demonstrated the ninth leadership behavior: 9. Organizing and facilitating the team meetings. Both team coaches provided the teams with the resources they needed, such as facilitating the meeting rooms and catering. Furthermore, they always sent an invitation by e-mail prior to the next meeting. All participants indicated that they were happy with how the TDT meetings were organized.

\section{H. Carrying out collaborative tasks}

In both TDTs, this step took the most time during every meeting: between 1.5 and 2.5 hours. Examples of collaborative activities were: discussing outlines of educational materials, collaboratively constructing materials and sharing experiences from practice.

As this step took the most time every meeting, it provided opportunities for enacting various leadership behaviors. Again, the participants enacted the third leadership behavior: 3. Shared process of defining and carrying out (short-term) plans, as participants completed the collaborative tasks they had agreed to in the previous meeting. Working on concrete collaborative tasks was highly valued, as this participant from TDT 2 explained: "The moments we were actually constructing something, resulted in the most discussions and coherence in the group. I think this contributed most." 
Furthermore, both team coaches demonstrated the fifth leadership behavior during step $\mathrm{H}$ : 5. Bringing expert knowledge into the team. The team coaches provided expert knowledge about science education and pedagogy, for example by explaining concepts, by providing relevant examples or by raising issues related to the quality of the designed material. One participant from TDT 1 explained that this expert knowledge improved the quality of the activities and provided opportunities to make progress and to learn: "There is certain expertise within the TDT, which improves the quality. For example, the team coach brings in his knowledge. Therefore we could move forward and learn new things."

Additionally, the team coach of TDT 1 invited other experts from his network on two occasions: one to provide content knowledge about green chemistry, and two experts on the role of language skills in chemistry education. In TDT 2, the team coach also made connections with external experts outside of the TDT meetings. Although two participants explained that these connections were very valuable, one participant explained that the added value of this external knowledge was not always clear, as its relation with the goals and plans were unclear: "Sometimes the team coach kept talking about some congress he had attended. I didn't really understand the added value of all this information in relation to what we were doing."

The participants also demonstrated the sixth leadership behavior during step H: 6. Interacting openly and encouraging each other to share ideas and experiences. In TDT 1 in particular, the participants openly asked each other for feedback, provided feedback and asked each other to share experiences. One participant from TDT 1 stated: "We dared to make ourselves vulnerable. Nobody was afraid to give his opinion or to ask for feedback." Although this leadership behavior was also present in TDT 2, the participants provided fewer examples of how they prompted or motivated each other. One participant suggested that the process could have been accelerated if the participants had been more inclined to share expertise: "People didn't react to each other's ideas immediately. [...] The process could have been accelerated if people had shared their expertise more openly."

Both team coaches also demonstrated the seventh leadership behavior in step H: 7. Engaging all participants in the discussions. This mainly happened in TDT 2, where the team coach sometimes proposed active working methods to engage all participants in the collaborative tasks they had defined in the previous meeting. In this way, all participants contributed to the collaborative activity.

The eighth leadership behavior was also enacted in step $\mathrm{H}$ : 8. Providing direction in the discussions. However, in TDT 1, the participants explained that it was not always the coach or technical chair that kept the discussions on track, but that the planning board provided direction for the discussions: "When that happened [loss of focus in the discussions], as 
participants we said, well, maybe we need to go back to... And because we used the planning board, it was clear where the discussion needed to go". Participants indicated that in this way, the discussions all remained relevant.

\subsubsection{Example from the meeting: enacting collaborative activities}

Again we will provide an example of a conversation that covered various leadership behaviors. This third example comes from step H during the eighth meeting of TDT 1 , while participants were collaboratively constructing a roadmap for strategies for reading and answering test questions in the science subjects. The aim of this roadmap was to help students to read test questions correctly and to formulate their answers clearly. In this example, the discussion just has gotten off-track, and one of the participants looks at the planning board to go back:

P1: Shouldn't we go back to what we were doing? [Points at the planning board]

P2: Yes, maybe we should get back to finalize this

Team coach: Yes, let's go back

P2: Okay, this roadmap we created, is it ehm... Do we have to adjust it further, or do you think it can be used like this? Are you planning to use it?

P1: Well, like I just said...

P3: I'm going to use it

P1: I signed up for a committee within my school that deals with language issues, so I'm definitely going to use it. But I think that starts next year.

P2: Okay, I e-mailed you what I just wrote down, so you can use it. So this version is specifically aimed at the science subjects.

P4: Oh great, because I forgot to write it down myself.

Team coach: Okay, but actually, I think it is a good idea to test it first with a few students. To see what they do and how they do it. Because, we can just guess this might work, but students always use it in their own ways. I think testing might help to refine it. But for now it looks good. Good enough to test it.

In this example, $\mathrm{P} 1$ used the planning board to provide a direction in the discussion, which is the eighth leadership behavior (8. Providing direction in the discussion). Subsequently, P2 asked the other participants whether they were planning to use the roadmap they just created. Two participants explicitly confirmed that they were planning to use it. In this way, the participants prompted one another to use the materials in practice, which is the sixth leadership behavior (6. Interacting openly and encouraging each other to share ideas and experiences). Then the team coach demonstrated the fifth leadership behavior, as he raised a quality issue by adding that the roadmap should be tested first (5. Bringing expert knowledge into the team). In this way, the team coach supported the quality of the design process. 


\section{l. Finishing term and reflection}

As step $\mathrm{H}$ took most of the time in the meetings of both TDTs, often there was not much time left for reflection (figure 4.1, I). When the TDT did take time for reflection, they concluded that the process was going well and everyone was satisfied. Concrete issues were raised on only a few occasions, such as that they wanted to spend more time on collaboratively constructing educational materials. At the end of their last meeting, the participants of both TDTs concluded that their goals had been met. They had designed the educational materials that they planned to design and furthermore, they indicated that they had gained new knowledge and skills along the way.

While emphasizing reflection on the plans, the technical chair enacted the fourth leadership behavior again: 4. Explicitly expressing (short-term) plans, as this also included looking back at the short-term plan. Participants indicated that it gave them a good feeling to reflect on their planning and to move the tasks to 'done' on the planning board, as this made their progress more visible.

To conclude, by initiating the nine steps of this method in all of the meetings, the technical chair and sometimes the team coach enacted the tenth leadership behavior: 10. Following a fixed method during the meetings. In the final interviews, the participants and team coaches from both TDTs indicated that they were happy with this nine-step method. One of the participants from TDT 1 explained that the method forced them to formulate clear goals and concrete tasks, which promoted achievement of the intended outcomes: "Maybe it's an open door, but if the goals are clear, the outcomes are better. And because the goals were clear, we could define clear tasks that are directed towards that goal". Furthermore, they indicated that the nine-step method stimulated them to participate in making decisions for the team. 
table 5.2 Shared and vertical leadership behaviors in practice

\begin{tabular}{|c|c|c|}
\hline $\begin{array}{l}\text { Process } \\
\text { features }\end{array}$ & Shared leadership behaviour & Vertical leadership behaviour \\
\hline Goals & $\begin{array}{l}\text { 1. Shared process of defining the team } \\
\text { goals } \\
\text { When: Step A. } \\
\text { How: Participants address issues, } \\
\text { mention ideas or point out the relevance } \\
\text { of these ideas for goals, based on their } \\
\text { own needs in the classroom. } \\
\text { This supported: Shared meaning and } \\
\text { relevance. }\end{array}$ & $\begin{array}{l}\text { 2. Explicitly expressing the team goals } \\
\text { When: Step B } \\
\text { How: Writing down concrete formulation of } \\
\text { goals and repeating them every meeting. } \\
\text { This supported: Clarity regarding goals, realistic } \\
\text { goals and shared interpretation. }\end{array}$ \\
\hline Activities & $\begin{array}{l}\text { 3. Shared process of defining and carrying } \\
\text { out (short-term) plans } \\
\text { When: Steps C, E, G and H } \\
\text { How: Participants discuss which tasks are } \\
\text { needed, divide tasks, set boundaries, } \\
\text { make plans, and complete the tasks. } \\
\text { This supported: Initiating and dividing } \\
\text { tasks ensured that plans remained doable } \\
\text { and supported sense of responsibility. } \\
\text { Completing tasks provided opportunities } \\
\text { to actually learn and produce educational } \\
\text { materials. }\end{array}$ & $\begin{array}{l}\text { 4. Explicitly expressing (short-term) plans } \\
\text { When: Steps D, F and I } \\
\text { How: Writing down tasks, repeating plans and } \\
\text { initiating reflection. } \\
\text { This supported: Clarity regarding tasks and } \\
\text { plans, realistic plans, visualizing progress. } \\
\text { 5. Bringing expert knowledge into the team } \\
\text { When: Step H } \\
\text { How: Explaining concepts, providing examples, } \\
\text { raising quality issues and inviting external } \\
\text { experts. } \\
\text { This supported: Quality of the activities, } \\
\text { progress in developing products and learning } \\
\text { opportunities. }\end{array}$ \\
\hline $\begin{array}{l}\text { Team } \\
\text { interaction }\end{array}$ & $\begin{array}{l}\text { 6. Interacting openly and encouraging } \\
\text { each other to share ideas and experiences } \\
\text { When: Step H } \\
\text { How: Participants provide feedback, ask } \\
\text { each other for feedback and encourage } \\
\text { each other to share experiences. } \\
\text { This supported: Acceleration of the } \\
\text { team's work process. }\end{array}$ & $\begin{array}{l}\text { 7. Engaging all participants in the discussions } \\
\text { When: Step F and H } \\
\text { How: Asking participants to complete specific } \\
\text { tasks and proposing active working methods. } \\
\text { This supported: Whole team engagement and } \\
\text { commitment. } \\
\text { 8. Providing direction in the discussions } \\
\text { When: Step H } \\
\text { How: Using the planning board to stay on track. } \\
\text { This supported: Relevance of discussions }\end{array}$ \\
\hline $\begin{array}{l}\text { Organization } \\
\text { of the TDT }\end{array}$ & & $\begin{array}{l}\text { 9. Organizing and facilitating the team } \\
\text { meetings } \\
\text { When: Step G } \\
\text { How: Providing resources (e.g. meeting room, } \\
\text { catering) and sending invitations for meetings. } \\
\text { This supported: Basic needs for TDT. } \\
\text { 10. Following a fixed method during the } \\
\text { meetings } \\
\text { When: Start of all steps } \\
\text { How: Initiating the steps of the fixed method. } \\
\text { This supported: Active participation in making } \\
\text { decisions and clarity regarding goals, plans and } \\
\text { focus of the TDT. }\end{array}$ \\
\hline Difficulties & $\begin{array}{l}\text { - Participants were not always willing to } \\
\text { volunteer for tasks. } \\
\text { - Participants sometimes felt the need to } \\
\text { ask the coach for approval. } \\
\text { - Participants did not always openly share } \\
\text { ideas and experiences. }\end{array}$ & $\begin{array}{l}\text { - Some goals were too broad. } \\
\text { - There were some difficulties with formulating } \\
\text { concrete tasks. } \\
\text { - Less concrete tasks were not always enacted } \\
\text { as intended. } \\
\text { - Expert knowledge was not always connected } \\
\text { to goals and plans. }\end{array}$ \\
\hline
\end{tabular}




\subsection{Discussion}

This study reveals the balancing act involved in combining shared and vertical leadership behaviors in TDTs. We aimed to understand how shared and vertical leadership were demonstrated in TDTs, how these leadership behaviors appeared to support the teams' work process, and what leadership challenges the TDTs encountered.

\subsubsection{Enacting shared and vertical leadership behavior}

All ten leadership behaviors that we defined in the previous chapter were observed to be enacted at some point during the nine-step method the TDTs used. In table 5.2, we summarized how these leadership behaviors were demonstrated and during which steps. By means of three examples from the meetings, we illustrated how this table can be used to recognize the various leadership behaviors and to indicate which leadership behaviors could be expected. In this way, this overview can be used as a tool for researchers to monitor leadership behavior in teacher teams. Furthermore, it can raise awareness among team coaches and participants, which might help them to successfully facilitate teacher teams (Borko, Jacobs, Seago, \& Mangram, 2014).

Furthermore, findings from this study strengthened our theoretical understanding about combining vertical and shared leadership in teacher teams. As expected from the literature (Pearce, 2004; Yukl, 2012), we found that shared leadership behavior mostly occurred in the brainstorming steps and task completion steps, when participants proposed ideas for goals or tasks and carried them out (figure 4.1, A, C, E, G and H), whereas vertical leadership behaviors mostly occurred in the articulating steps (figure 4.1, B, D, F and I). As these steps alternated in the nine-step method, the successive steps were sometimes carried out almost simultaneously, which meant that the conversations often included both shared and vertical leadership. In contrast to previous research that indicated that combining shared and vertical leadership could be experienced as paradoxical (Binci et al., 2016; Elloy, 2006; Meirink et al., 2010), none of the participants experienced these leadership behaviors as conflicting. It could therefore be suggested that explicitly mentioning 'brainstorming' and 'articulating' as separate steps emphasizes the importance of both shared and vertical leadership behaviors, even if they are exhibited in the same conversation. 
This study also deepened our understanding of how shared and vertical leadership supported the work process of the TDTs. These findings were also summarized in the overview in table 5.2. In practice, this overview might help participants and team coaches to become more aware of how their leadership behavior might affect the team's design process.

First, we showed how shared leadership behaviors supported the design process in various ways. Participants indicated that being able to propose ideas for the team goals contributed to shared meaning and relevance for the team. Furthermore, they explained that the fact that they chose their own tasks made them feel responsible to complete the tasks, which is needed to actually learn new things and design materials. Participants also explained that sharing their own experiences and ideas could accelerate the process. These findings about how shared leadership supported the process are in line with other studies that have indicated that shared leadership is positively related with shared purpose (Carson et al., 2007; Wageman, 2001), that it can create a sense of ownership (Ritchie \& Woods, 2007) and that it can accelerate the process if the team interdependence is high (Nicolaides et al., 2014).

Second, we showed how vertical leadership behavior could be supportive for the team's work process. Participants and team coaches indicated that vertical leadership behavior contributed to clarity regarding the goals and the plans, and that the overview on the planning board made the team progress visible. Furthermore, participants indicated that vertical leadership contributed to the quality of the team's design process, as the team coaches brought in expert knowledge and they provided basic resources for the TDT. Vertical leadership behavior also ensured that all participants were actively engaged in the discussions. These findings further support the idea that both shared and vertical leadership behaviors are needed to support the team's work process (Binci et al., 2016; Gronn, 2009; Pearce, 2004).

Additionally, the three examples from the meetings showed how the combination of vertical and shared leadership behaviors contributed to the process. In all these examples, the participants took the lead by exhibiting shared leadership behavior. In this way, the participants had opportunities to make the goals or the activities relevant or doable for their own practice. In all examples the team coach or the technical chair subsequently exhibited vertical leadership behavior to provide focus, clarity or quality. Therefore, 
these examples showed how a blend of shared and vertical leadership behaviors created opportunities to promote clarity and structure in the team's work process, without impeding participants' initiative and creativity.

\subsubsection{Remaining leadership challenges}

Although this study showed how shared and vertical leadership behaviors could be combined in TDTs when using the nine-step method, we also identified several difficulties, which are listed in table 5.2. This overview can help researchers, participants or coaches to avoid these potential pitfalls in their TDTs. Furthermore, the overview of leadership difficulties contributes to our theoretical understanding about leadership in TDTs. These difficulties could be summarized as two general leadership challenges.

The first challenge is related to shared leadership behavior. In this study, all participants volunteered to join the TDT. Before the TDT started, they committed to investing a considerable amount of time in the TDT and their schools supported their participation. Previous research has indicated that these preconditions could instigate enthusiastic, pro-active attitudes, and hence stimulate shared leadership behavior (Admiraal et al., 2015; Gorozidis \& Papaioannou, 2014; Stoll et al., 2006). Furthermore, the nine-step method was designed to stimulate shared leadership behavior, as it explicitly incorporated time to put forward ideas and plans. However, the participants from TDT 2 did not always feel they had the autonomy to make decisions for the team, as they tended to ask for approval from the team coach when initiating tasks. Furthermore, they were not always willing to volunteer for tasks during the planning phase. They explained that this was related to the fact that the team struggled with participants being absent from the meetings and they found it difficult to volunteer for tasks, knowing that the team would not really make progress if only part of the team was present. Additionally, the participants from TDT 2 did not always openly share their ideas and experiences, which could have accelerated the process. All these issues point to limited engagement or commitment to the TDT. This is in line with other studies, which have suggested that teachers are often individually occupied with everyday issues, and they may find it difficult to completely commit themselves to the team (Bouwmans et al., 2017; Vangrieken, Dochy, Raes, \& Kyndt, 2015). In the present study, the team coach took care of this to some degree, as he enacted vertical leadership behavior to stimulate engagement by all participants, for example, by asking participants to take on tasks or by suggesting active working methods. However, he could not enforce intrinsic engagement in the TDT's work. Therefore, we argue that TDTs need more than effective preconditions and a method that stimulates shared leadership behavior. An ongoing sense of relevance and urgency is needed to ensure intrinsic 
engagement. Team coaches need to be aware of this and they need to actively address participants' intrinsic engagement in the meetings. In particular in TDTs such as TDT 2 , with a very large task, assigned from the outside, and extending beyond the personal teaching practices of the participants.

The second major challenge is related to vertical leadership behavior. While applying the nine-step method, the vertical leaders explicitly took time to formulate the goals and tasks, which could create focus and clarity (Scribner et al., 2007; Yukl et al., 2002). However, we observed that the TDTs sometimes struggled with formulating tangible goals and defining concrete tasks. This has also been found in other studies, where the conclusion was drawn that successful goal setting in teacher teams is not a given (Kippers, Poortman, Schildkamp, \& Visscher, 2017; Van Gasse, Vanlommel, Vanhoof, \& Van Petegem, 2016). It is very challenging for teachers to think about goals and tasks and therefore, they need help from the vertical leader to create clarity. Our findings suggest that this help should move beyond expressing, repeating and clarifying goals and tasks; vertical leaders need to actively help the team with formulating a clear, concrete operationalization of the goals and tasks. However, in this study, we illustrated that thinking in goals and tasks was difficult for team coaches as well. For example, the team coach from TDT 2 sometimes brought in expert knowledge that was not directly related to the team's goals, which caused confusion among participants. Therefore, we argue that TDTs could benefit from having team coaches be more aware of how they could promote effective thinking about goals and tasks.

\subsubsection{The balancing act}

TDTs have the potential to contribute to the design of improved educational materials and to teachers' professional development (Bakah et al., 2012a; Huizinga et al., 2014; Voogt et al., 2011). In the section 5.1.2 we provided an example from chapter 3: participants and team coaches indicated that both shared and vertical leadership were needed in defining their goals, but they struggled with combining these leadership behaviors. This was not a rare example; many other TDTs or teacher teams have reported similar leadership difficulties (Becuwe et al., 2016; Huizinga et al., 2013; van Driel et al., 2012). This study shows how these TDTs could benefit from using the stepwise method, as this method was developed in order to combine shared and vertical leadership.

More specifically, the overview in table 5.2 can help to support these TDTs in three ways. First, the overview could help TDTs to recognize their own leadership behaviors related to the team's goals. By comparing their own leadership to the examples in table 5.2, they can see how shared and vertical leadership behaviors can be combined. For example, 
they can notice that participants can take the lead in mentioning ideas for the goals and that team coaches can take the lead in formulating and repeating these goals. Second, for each of these leadership behaviors, the overview can help TDTs by providing insight into how this type of behavior might support the team's work process. This helps to raise awareness of the importance of both shared and vertical leadership. Third, teams can recognize potential pitfalls by looking at the list of leadership difficulties in table 5.2. For example, they could be warned that the defined goals should not be too broad.

In sum, the findings offer both insight into what vertical and shared leadership behaviors look like and challenges that can be anticipated when blending these types of leadership in TDTs. This information has value for those who would organize, participate in or study TDTs.

\subsubsection{Limitations and future research}

A limiting factor in this study is that the research is mainly based on perceptions. However, we used various sources of evidence in terms of data and methods (i.e., interviews, observations, logbooks), to reduce bias (Poortman \& Schildkamp, 2011). Furthermore, we chose an in-depth qualitative research design, which could be relevant for teacher teams in various contexts, as the findings could serve to some extent as an example. However, the generalizability of our findings is limited, given the very specific contexts in which these data were obtained. Therefore, as a next step, more research in different settings is needed to obtain a broader understanding of vertical and shared leadership behaviors in teacher teams. Additionally, future research could be

aimed at solving the remaining leadership challenges that were identified in this study. For example, studies could investigate how team coaches could be trained or prepared beforehand, to promote effective thinking about goals and tasks. 

Conclusion and
discussion

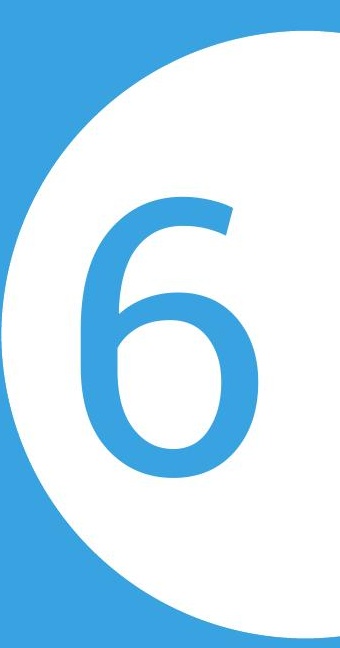


QUOTE "We chose a theme that is in line with the examination program. The topic of biofuels seemed to be perfectly suitable because it is an interesting context and it includes many Chemistry concepts. And in a way, students can actually do scientific research with this theme. So groups of students were instructed to make their own biofuel, each group with a different strategy. And by the end, they had to decide which strategy was the most 'green'. And well, I learned so many new things! [...] So yes, I really invested a lot in creating and testing this material. And I would never have done this without this [nine-step] method. Without the planning board and the concrete tasks, it would have been easy to just be here every meeting and achieve nothing."

- TDT participant, June 2016.

This quote from a participant in a Teacher Design Team illustrates several key ideas central to this research. First, the participant described how he benefited from his participation in a TDT that created innovative materials and that he learned from that experience. Subsequently, the participant points out that participating in a TDT does not automatically lead to these outcomes. Finally, by stating: "I would never have done this without this [nine-step] method," he confirms that that the nine-step method developed in this project supported the functioning of his TDT.

This brings us back to the overarching question that guided this dissertation: How can the implementation of TDTs be supported? This final chapter addresses this question, starting with a reflection on the findings and a reflection on the methods. Then, recommendations for educational practice and policy are made. To conclude, final considerations address how the findings from this research can be used in the context of educational change.

\subsection{Reflecting on the findings}

\subsubsection{Descriptive framework}

The first research question that was addressed in this dissertation was: How can the characteristics of TDTs be captured in a descriptive framework? This research question was addressed in chapter 2.

Previous research has indicated many distinct factors that can promote or interfere with the effectiveness of TDTs. For example, researchers have studied the role of design activities (Huizinga et al., 2014), the role of teachers' conversations (McKenney et al., 2016) or the role of the facilitator (Becuwe et al., 2016). In this study, we aimed to develop an integrated descriptive framework that connects these different factors. The starting 
point of this chapter was a broad theoretical exploration of the different factors that could promote or interfere with the effectiveness of TDTs. This resulted in a conceptual framework for TDTs including three elements: input, process and outcome.

Both qualitative and quantitative data from practice were used to evaluate the conceptual framework and to refine it into an integrated descriptive framework. This included nine categories of factors that were considered relevant. In the input stage, we distinguished two categories: (1) individual (teacher) characteristics and (2) contextual (school) characteristics. The process stage included five categories: (3) team interaction, (4) goal alignment, (5) activities (6) organization of the TDT and (7) leadership by the team coach. As the results indicated that specific actions the coach took or could have taken were always aimed at other process factors, the team coach's leadership was placed as a central factor in the descriptive framework. Finally, two categories of outcomes were distinguished in the descriptive framework: (8) professional development and (9) designed materials.

The descriptive framework is a useful tool for researchers to describe and analyze the functioning of TDTs. Furthermore, as the framework is based on both literature and practice, it can be considered a fundamental first step in the development of a theoretical and practical foundation for successful implementation of TDTs.

\subsubsection{Key elements}

The second research question was: Which key elements of this descriptive framework can be influenced to support TDTs? The study described in chapter 3 set out to address this research question. In this study, the descriptive framework was used to monitor the functioning of three TDTs for one year, focusing on their processes and outcomes. Whereas the study reported in chapter 2 analyzed TDTs retrospectively, the data reported in chapter 3 were obtained by observing the meetings, collecting logbooks after every meeting and interviewing participants and coaches at the start and the end of the year.

The results indicated that the perceived outcomes of the TDTs were mixed. Several links between the processes and outcomes were found. For example, a link between shared leadership and ownership was identified, in the sense that participants who felt they could provide direction and make decisions for the team reported a stronger sense of ownership. This finding supports the idea that shared leadership can strengthen the sense of ownership, which is in line with other literature (Ensley et al., 2006; Nappi, 2014). However, not all participants felt that they could provide direction and make decisions for the team, and thus, not all participants felt ownership of the TDT. Similarly, a sense of 
ownership appeared to be linked with the outcomes of the TDT. Although we found that teachers' participation in TDTs always resulted in the design of educational materials, which is consistent with other studies about TDTs in various settings (Coenders et al., 2010; Handelzalts, 2009; McDermott, 2016), these materials were not always implemented in practice, which was expected from the literature (Mooney Simmie, 2007; Penuel et al., 2007). This study revealed that only participants with a strong sense of ownership tended to actually use the designed material in practice to change their teaching. Following this line of reasoning, it seems plausible that shared leadership could indirectly promote the outcome of bringing educational change into teachers' practice.

Furthermore, participants explained that shared leadership was needed to ensure that the learning goals were adapted to their own needs. Similar to other research on teacher professional development, participants explained that their teaching practice could only improve if they actually felt the need to improve it (van Driel et al., 2012; van Veen et al., 2010; Vescio et al., 2008). In this way, shared leadership behavior could help create conditions necessary for teacher learning, which are also conditional for increased student performance and improved job satisfaction (Guskey, 2002b).

In addition to shared leadership, this study also revealed links between vertical leadership, and the process, and thus the outcomes. Participants explained that vertical leadership was needed to provide structure, focus and quality in the TDT process. For example, vertical leadership could contribute to clarity regarding the team goals and the activities. This was also found in other studies (Allen \& Penuel, 2015; Johnson et al., 2014). Additionally, the team coach's expert knowledge could bring the design process to a higher level, which was also shown in other studies (Becuwe et al., 2016; Huizinga et al., 2014). In this way, vertical leadership indirectly fostered the TDTs' outcomes.

These answers to the second research question pointed to both shared and vertical leadership behaviors as key elements that can be influenced to support the functioning of TDTs. However, how to provide a mix of shared and vertical leadership is not self-evident, and is sometimes even described as paradoxical (Binci et al., 2016; Elloy, 2006; Meirink et al., 2010)

\subsubsection{Intervention}

The third research question that was addressed in this dissertation was: What are the characteristics of an intervention to support TDTs based on these key elements? This question was central to chapter 4 . The notion that shared and vertical leadership are key elements in the TDTs' process was used as a starting point for developing an intervention. 
In this study, the features associated with productive TDT processes were summarized and literature about teacher teams and about management and organization was used to identify specific shared and vertical leadership behaviors that could foster these process features. As such, three guidelines for shared leadership behavior were distinguished: a shared process of defining team goals, a shared process of defining and enacting plans, and stimulating each other to share ideas and experiences. Furthermore, seven guidelines for vertical leadership behavior were defined: explicitly expressing team goals, expressing plans, bringing in expert knowledge, engaging all participants in the discussions, providing direction for the discussions, organizing the team meetings and following a fixed method during the meetings.

Subsequently, an intervention was developed to stimulate these ten leadership behaviors. The nine-step method that was developed was inspired by agile product development (Highsmith, 2010; Schwaber, 1997; Sliger, 2006). TDTs that follow this method work in small, rapid iterations, which stimulates participants to be creative, bring in ideas and formulate clear plans on a planning board. On the one hand, this method provides a clear structure for the teams' collaboration. TDTs that follow this method take explicit time to discuss their goals, tasks and plans during every meeting. Therefore, crucial aspects such as developing a shared vision cannot be overlooked, which sometimes is the case in TDTs (Huizinga et al., 2013). On the other hand, the design process is flexible, as it uses an iterative strategy in which participants only plan ahead for one meeting. In this way, there is room to respond to new ideas and new insights (Highsmith, 2010).

\subsubsection{Enactment}

The fourth research question was: How does enacting this intervention support TDT processes? This question was addressed in chapter 5. In this study, the nine-step method was applied by two TDTs, which were monitored over the course of a year. We obtained data by observing the meetings, collecting logbooks and interviewing participants and coaches.

This study provided insight into how shared and vertical leadership behaviors were exhibited in TDTs and how they supported the process. Findings revealed how the three previously defined shared leadership behaviors were exhibited while enacting the nine-step method. These shared leadership behaviors ensured that the educational materials the TDTs designed were relevant and meaningful for all participants. This is in line with previous studies that indicated that teachers' active participation in defining goals and plans is helpful to ensure that these goals and plans are aligned with teachers' practice, which is an important condition supporting teachers' professional development 
(Garet et al., 2001; Guskey, 2003; Kennedy, 2016; Penuel et al., 2007; van Veen et al., 2010). Furthermore, the study showed that participants' shared leadership behaviors promoted their sense of responsibility and that openly sharing ideas accelerated the design process. These findings all support the notion that shared leadership is crucial in teacher teams (Admiraal et al., 2015; Nappi, 2014; Scribner et al., 2007; Wageman, 2001). By revealing how specific types of shared leadership behavior supported the process, this study made a unique contribution to the existing literature.

Furthermore, chapter 5 indicated how the seven previously defined vertical leadership behaviors were exhibited. These vertical leadership behaviors ensured that the goals and tasks remained clear for all participants and they contributed to the quality of the activities. In this way, vertical leadership behaviors supported the TDTs' progress in designing materials. This finding underlines the importance of external support or coaching when designing educational materials in TDTs (Becuwe et al., 2016; Huizinga et al., 2013; Svihla, Reeve, Sagy, \& Kali, 2015). The study reported in chapter 5 also indicated that the vertical leader could provide access to expert knowledge and relevant information, which created learning opportunities for the participants. This is also consistent with other studies that have indicated that facilitators or coaches play an important role in teachers' professional development (Kennedy, 2016; McKenney et al., 2016; van Veen et al., 2010). Additionally, vertical leadership behavior could ensure that all participants were engaged in the team process and not only the most extroverted participants. For example, the team coaches engaged participants in the planning process by making suggestions for dividing up tasks, or by proposing active working methods during the enacting phase. In this way, the study also contributed to theory about leadership by showing how specific types of vertical leadership could support the process.

The study reported in chapter 5 also indicated two remaining leadership challenges. The first is consistent with research that has indicated that goal-setting in teacher teams is not a given (Kippers et al., 2017; Van Gasse et al., 2016). Even though the nine-step method has a strong emphasis on defining goals and tasks, and making plans, this proved challenging. Although both TDTs defined goals and tasks, and they perceived the goals to be shared, participants and coaches struggled with defining concrete formulations and with recognizing potential tasks during the conversations. Therefore, we concluded that providing the nine-step method is a step in the right direction, but that additional specific support is needed to enable teams to complete this challenging task. 
Second, although all participants volunteered to participate in the TDT, not all participants felt intrinsically committed. Therefore, not all participants shared their ideas and experiences openly and not all participants were willing to volunteer for tasks. This was also found in other studies, which suggested that teachers are often individually occupied with everyday issues, and they may find it difficult to completely commit themselves to the team (Bouwmans et al., 2017; Vangrieken et al., 2015).

These insights about the enactment of shared and vertical leadership behaviors were summarized in an overview (table 5.2). This overview strengthens our understanding about how shared and vertical leadership can be combined, without being perceived as paradoxical or conflicting, as was the case in other studies (Binci et al., 2016; Elloy, 2006; Meirink et al., 2010). Furthermore, this overview can help TDTs' practice in three ways: (1) by looking at examples from practice, they can see how vertical and shared leadership can be combined, (2) it can raise awareness about how both vertical and shared leadership behavior support the TDT's process and (3) examples of the leadership difficulties can help them to avoid potential pitfalls.

\subsection{Reflecting on the methods}

To answer the overarching research question, various research methods were used. The three empirical studies, which were described in chapters 2, 3 and 5, took place within the naturalistic context of TDTs that were already organized by the University of Twente. In the first study, which was described in chapter 2 , a mixed methods research design was applied to explore the essential inputs, processes and outcomes of these TDTs. The questionnaire provided opportunities to obtain general insight into the functioning of TDTs, whereas the interviews could be used to further explain this general insight. The studies reported in chapters 3 and 5 aimed to zoom in further on the relevant factors for TDTs, in particular the leadership behaviors. Therefore, in these studies qualitative approaches including interviews, observations and logbooks were applied, as these could provide in-depth insight. The theoretical study that was described in chapter 4 served to recapitulate what was known about the functioning of TDTs, and to merge this with theory about leadership. This strategy provided opportunities to develop theory-based leadership guidelines and a practical nine-step method for TDTs. In this way, the concept of TDTs could be brought to the next level. 


\subsubsection{Limitations}

Due to the predominantly qualitative nature of the empirical studies, the generalizability of the findings is limited. However, in-depth understandings about the processes within TDTs could be relevant for TDTs in other settings, though the degree to which these cases provide relevant information for other settings must be determined locally by case-tocase transfer (Firestone, 1993). Furthermore, a limiting factor in the empirical studies is that the research was mainly based on self-report. However, as various sources of evidence in terms of data and methods were used (i.e., interviews, observations, logbooks), potential bias was reduced (Poortman \& Schildkamp, 2011). To ensure the reliability of the qualitative data, in all empirical studies an external researcher double-coded part of the data and inter-rater reliability was calculated, and was sufficient to good in all studies.

In chapters 3 and 5, TDTs' processes were monitored over the course of a school year. Therefore, the researcher attended the meetings and collected data. In the study reported in chapter 3 , the researcher was only present in the role of an observer, and did not interfere with the team interactions. However, in the study reported in chapter 5, the researcher had an active role as technical chair, pointing out the steps in the nine-step method. As the researcher also conducted the interviews - which were partly aimed at reflecting on this nine-step method - it is possible that the answers from the participants were (unconsciously) influenced. To minimize bias, the interview respondents were invited to be open and that both positive and negative answers were welcome. Furthermore, triangulation through various instruments such as logbooks and meeting observations also helped put respondent answers into perspective.

\subsubsection{Recommendations for future research}

While this research showed how the implementation of TDTs could be supported, additional research is still needed. First, a more complete picture of the functioning of TDTs in other contexts would be useful. Doing so with the descriptive framework that was developed in chapter 2 might reveal important differences and similarities with the TDTs in the present study. For example, the roles of shared and vertical leadership might be experienced differently in school-based TDTs, as the participating teachers in school-based TDTs are direct colleagues, who depend on each other in their daily teaching practice.

Second, the findings discussed in chapter 5 suggest that the nine-step method could be refined. Particularly important would be bolstering support for helping TDTs more actively with defining concrete team goals. After that, the refined method could be implemented 
and studied again. Additionally, to extend the generalizability of the findings, and further refine the approach, the nine-step method could be tested and studied in various settings.

Third, TDT participants in this study explained that they gained new knowledge and skills due to their engagement with the TDT. However, they only provided limited examples of how their schools benefited as a result. To sustain the benefits of professional development, a major challenge for TDTs is to transfer the new knowledge from individual teachers to colleagues from their schools. Further research is needed to understand how schools can facilitate the transfer of TDT-created knowledge. For example, research could focus on the potential effects of knowledge-sharing events within schools, where TDT participants can share their insights with colleagues. Alternatively, the potential benefits of organizing school-based professional learning communities, in which teachers actively share knowledge and experiences that they gained in networked TDTs, could be explored with an eye toward knowledge sharing within a school. These efforts could contribute to understanding how TDT benefits can be shared with others outside the TDTs.

Fourth, the present study focused on the processes of TDTs. To obtain a complete picture of 'TDTs' functioning, future research should incorporate systematic measurements of TDT outcomes. For example, this could involve including pre- and post-test of teachers' professional development, assessing the quality of the designed materials and measuring the outcomes for students. In this way, conclusions could be drawn about the effectiveness of TDT functioning for professional development. Additionally, further insight into the effectiveness of the nine-step method that was developed in this study could be obtained.

\subsection{Recommendations for practice and policy}

Section 6.1 described how the implementation of TDTs could be supported to promote their functioning. In line with this, the main recommendations from this dissertation are aimed at organizers of TDTs. First, this study offers valuable insights that can help organizers understand the functioning of TDTs. Organizers can benefit from using the results of this study to raise their awareness that the implementation of TDTs is not automatically successful, and what kinds of support are needed. Furthermore, organizers could use the descriptive framework discussed in chapter 2 to target their support of TDT processes. Second, since findings indicate that the nine-step method described in chapter 4 is a useful practical tool for structuring the process of TDTs, organizers could apply this approach to helping TDTs to combine shared and vertical leadership. Third, the overview 
of leadership behaviors from chapter 5 could help participants and coaches to become aware of their leadership behavior. These tools can directly support the implementation of TDTs.

While these tools provide useful supports, long-term and shared benefits of TDTs require more than frameworks and tools for organizers. Therefore, this section zooms out to provide recommendations for practice that move beyond the TDT meetings, and elaborate on requirements for departments for teacher training, secondary schools and national policy.

\subsubsection{Ensure team coaches develop competencies to lead TDTs}

Chapter 5 revealed that, while using the nine-step method, a blend of shared and vertical leadership behaviors was exhibited. Although participants and team coaches explained that this blend supported the TDT process, remaining leadership challenges were identified. First, it was found that the participants as well as the coaches struggled with defining concrete goals and tasks, and they often asked for help from the technical chair to provide clear formulations. It was concluded that thinking about goals and tasks was self-evident neither for TDT participants, nor for TDT coaches. Second, the team coaches' efforts to engage all participants in the TDT process were not always successful It seems plausible that team coaches may not always know how to actively address participants' intrinsic engagement in the meetings. This is particularly important for TDTs such as chapter 5's TDT 2, which have very large tasks, assigned from the outside, and extending beyond the personal teaching practice of the participants

With these remaining leadership challenges, one can conclude that providing TDTs with a method that integrates shared and vertical leadership behavior might not be enough. In order to effectively support TDTs, team coaches should be supported in further developing their own curriculum design expertise and their leadership skills. In this way, team coaches can become more aware of their role and tasks in terms of vertical leadership, and the roles and tasks of the participants in terms of shared leadership.

\subsubsection{Stimulate improvement and use of infrastructures to share material}

Designing educational materials is increasingly considered to be a core aspect of teachers' work (Carlgren, 1999; Cober et al., 2015; Koehler \& Mishra, 2005). This is also reflected in national educational policies. For example, the Dutch government has recently communicated the ambition to give teachers a substantial role in developing educational materials to support current national reforms (Platform Onderwijs2032, 2016). 
Chapters 2, 3 and 5 showed that the TDT participants did develop educational materials, which in some cases were implemented in practice; however, these outcomes stayed with individual teachers, as they provided limited examples of how they shared the designed materials with other teachers. To move the outcomes in terms of the designed materials beyond the level of individual teachers, distribution of educational materials must be facilitated. This can be achieved, for example, by using an online infrastructure for sharing educational materials with other teachers. In this way, innovative educational materials are easily accessible for all teachers, which can contribute to actual educational change. However, this infrastructure will only work if teachers have the opportunity to modify the materials to keep them up-to-date and to adapt them to their own needs.

This type of infrastructure already exists, for example WikiWijs or TeachersPayTeachers.com. These are online platforms to find, share and adapt educational materials. Although these infrastructures are promising for sustaining educational change, participants in this study indicated that they are not yet well known among Dutch teaching colleagues. Therefore, efforts could be made to familiarize TDT participants and other teachers with such platforms (Kreijns, Van Acker, Vermeulen, \& van Buuren, 2013). Furthermore, as research has indicated that teachers' curating skills are crucial while using these platforms (McGreal, Kinuthia, Marshall, \& McNamara, 2013), teachers should be supported in how to use them, by further developing their skills for identifying, adapting or managing existing materials. In this way, these platforms have the potential to grow, and to become a core part of teachers' efforts. In addition, external efforts to organize, curate and update these platforms should be on-going (Kramer, Ocenar, \& Yamasaki, 2016).

\subsubsection{Encourage teachers to use their professional leeway}

In the introduction, the context of this dissertation was described by explaining that we live in a 'knowledge society' that is subject to continuing change. Therefore, in the revised examination programs for science subjects in the Netherlands, teachers are encouraged to address present-day topics and to keep adapting their teaching practice. It was described that these revised examination programs leave room for teachers to make their own choices, as there are no prescribed textbooks, or teaching methods. Compared to other countries, schools in the Netherlands are characterized by great autonomy regarding curriculum planning and assessment (OECD, 2014). And increasingly in the Netherlands, experts and professionals are calling for attention to (supporting teachers in) making active use of their professional leeway (Onderwijsraad, 2016). 
In chapters 2, 3 and 5, it was noted that the designed educational materials were not always implemented in practice. Participants explained that they did not always have time to implement their own materials, as they first needed to address the compulsory components of the examination program. So although teachers in the Netherlands are free to use their own educational materials, and the revised examination program aimed to encourage teachers to address present-day topics, in practice, teachers struggle with addressing innovative topics of their own choice, in addition to the list of compulsory examination topics. Many teachers perceive this as paradoxical. Therefore, they often prefer to hold on to existing textbooks, because they are more confident that this will ensure that all compulsory topics and concepts are addressed.

Designing and incorporating innovative teaching practices that move beyond standard textbooks could contribute to teachers' professional development (Desimone, 2009), which indirectly leads to increased job satisfaction (Guskey, 2002b). Furthermore, specifically for science education, innovative teaching practices can contribute to students' positive attitude towards science (Aikenhead, 2009), and can give students a more realistic view of what science entails (Kolst $\varnothing, 2001$ ). Therefore, to increase the likelihood that TDT participants do actually implement the innovative materials they design in TDTs, teachers require support in identifying and leveraging the productive overlap between their own ideas for teaching and learning and the compulsory examination topics. Increasing the room for elective topics may also help.

\subsubsection{Incorporate time for designing and professional development}

Many TDT participants in this study explained that participating in a TDT contributed to their professional development and that exchanging experiences with teachers from other schools made their teaching job more attractive. However, they also realized that the available time and resources would would not be enough for them to keep participating in the TDT forever. As the world keeps changing, education continuously needs to adapt and teachers need continuing professional development. While there may only be limited long-term effects of participating in a TDT for one or two years, those effects are drastically at risk if teachers are not granted sufficient time to fully engage with the TDT.

Moreover, this study only focused on teachers who chose to participate in TDTs. There are also many teachers who are not actively participating in TDTs or another type of PLC to promote their professional development. To ensure that teachers keep improving their teaching practice and keep learning, PLC engagement should be an explicit aspect of teacher job performance. But this requires that teachers have dedicated time to invest (e.g., in designing materials and in their own professional development). 


\subsection{Closing considerations: educational change continues}

The first chapter of this dissertation indicated that the speed of changes and innovations is increasing. As a result, education constantly needs to adapt. For example, in 2013, when this project started, Dutch secondary school science teachers were preparing for the revised examination programs for science subjects.

Now, four years later, educational change has continued, as a new large-scale revision of the curriculum has been announced in the Netherlands (Coördinatiegroep curriculumherziening, 2017). The revised curriculum will include a basic foundation of knowledge and skills for primary and secondary education, which will enable students to progress into higher forms of education, and to function effectively in society. Therefore, there will be a new 'core curriculum' that is restricted in scope and content, and an 'elective curriculum' that will give teachers more time and opportunities to address individual needs and ambitions. To develop the building blocks for this revised curriculum, networked TDTs will be established, consisting of teachers from various schools, school leaders and curriculum design experts.

Knowing that TDTs can contribute to teachers' professional development and to the design of educational materials, networked TDTs like the ones in the Netherlands do indeed stand to have advantages in the context of educational change. However, this study showed that successful functioning of TDTs requires care and maintenance. By developing and applying a descriptive framework for TDTs, we found that leadership plays a key role, but providing adequate leadership is challenging. In this regard, a practical nine-step method and detailed leadership guidelines were developed. Insight from applying these in practice contributed to a theoretical and practical foundation that defines and explains successful implementation of TDTs. Other TDTs, such as those established in the context of the new curriculum, can benefit from the tools and insights presented here. 


\section{REFERENCES}

Admiraal, W., Kruiter, J., Lockhorst, D., Schenke, W., Sligte, H., Smit, B., ... de Wit, W. (2015). Affordances of teacher professional learning in secondary schools. Studies in continuing education, 38(3), 281-298. doi:10.1080/0158037X.2015.1114469

Aikenhead, G. (2009). Research into STS science education. Revista brasileira de pesquisa em educacao em ciencias, $9(1)$.

Aikenhead, G., Orpwood, G., \& Fensham, P. (2011). Scientific literacy for a knowledge society. In C. Linder, L. Ostman, D. Roberts, P. O. Wickman, G. Erickson, \& A. MacKinnon (Editors), Exploring the landscape of scientific literacy (Pages 28-44). New York.

Allen, C. D. \& Penuel, W. R. (2015). Studying teachers' sense making to investigate teachers' responses to professional development focused on new standards. Journal of teacher education, 66(2), 136-149. doi:10.1177/0022487114560646

Avalos, B. (2011). Teacher professional development in Teaching and Teacher Education over ten years. Teaching and teacher education, 27(1), 10-20. doi:10.1016/j.tate.2010.08.007

Avey, J. B., Avolio, B. J., Crossley, C. D., \& Luthans, F. (2009). Psychological ownership: theoretical extensions, measurement and relation to work outcomes. Journal of organizational behavior, 30(2), 173-191. doi:10.1002/job.583

Bakah, M. A. B., Voogt, J. M., \& Pieters, J. M. (2012a). Updating polytechnic teachers' knowledge and skills through teacher design teams in Ghana. Professional development in education, 38(1), 7-24. doi:10. 1080/19415257.2011.576265

Bakah, M. A. B., Voogt, J. M., \& Pieters, J. M. (2012b). Advancing perspectives of sustainability and large-scale implementation of design teams in Ghana's polytechnics: Issues and opportunities. International journal of educational development, 32(6), 787-796. doi:10.1016/j.ijedudev.2011.11.002

Becuwe, H., Pareja Roblin, N., van Braak, J., Tondeur, J., Castelein, E., \& Thys, J. (2015). Condities voor de succesvolle implementatie van leergemeenschappen: de casus van Teacher educator Design Teams voor ICT-integratie. Tijdschrift voor lerarenopleiders, 36(4), 5-16.

Becuwe, H., Tondeur, J., Pareja Roblin, N., Thys, J., \& Castelein, E. (2016). Teacher design teams as a strategy for professional development: The role of the facilitator. Educational research and evaluation, 22(3-4), 141-154.

Bergman, J. Z., Rentsch, J. R., Small, E. E., Davenport, S. W., \& Bergman, S. M. (2012). The shared leadership process in decision-making teams. The journal of social psychology, 152(1), 17-42. doi:10 . 1080 / 00224545.2010 .538763

Binci, D., Cerruti, C., \& Braganza, A. (2016). Do vertical and shared leadership need each other in change management? Leadership \& organization development journal, 37(5), 558-578. doi:10.1108/LODJ - 082014-0166

Boersma, K. T., Kamp, M. J. A., Oever, L., \& van den Schalk, H. H. (2010). Naar actueel, relevant en samenhangend biologieonderwijs. Utrecht: CVBO. 
Bolam, R., McMahon, A., Stoll, L., Thomas, S., \& Wallace, M. (2005). Creating and sustaining effective professional earning communities. Bristol: University of Bristol.

Borg, T. (2012). The evolution of a teacher community of practice: identifying facilitating and constraining factors. Studies in continuing education, 34(3), 301-317. doi:10.1080/0158037X.2011.622717

Borko, H. (2004). Professional Development and Teacher Learning: Mapping the Terrain. Educational researcher, 33(8), 3-15. doi:10.3102/0013189X033008003

Borko, H., Jacobs, J., Seago, N., \& Mangram, C. (2014). Facilitating video-based professional development: Planning and orchestrating productive discussions. In Y. Li, E. A. Silver, \& S. Li (Editors), Transforming mathematics instruction (Pages 259-281). Cham: Springer International Publishing. doi:10.1007/978-3-319-04993-9_16

Boschman, F., McKenney, S., Pieters, J. M., \& Voogt, J. (2016). Exploring the role of content knowledge in teacher design conversations. Journal of computer assisted learning, 32(2), 157-169. doi:10.1111/jcal. 12124

Boschman, F., McKenney, S., \& Voogt, J. (2015). Exploring teachers' use of TPACK in design talk: The collaborative design of technology-rich early literacy activities. Computers \& education, 82(100), 250-262. doi:10.1016/j.compedu.2014.11.010

Bouwmans, M., Runhaar, P., Wesselink, R., \& Mulder, M. (2017). Fostering teachers' team learning: An interplay between transformational leadership and participative decision-making? Teaching and teacher education, 65, 71-80. doi:10.1016/j.tate.2017.03.010

Bryk, A. S., Gomez, L. M., \& Grunow, A. (2011). Getting ideas into action: Building networked improvement communities in education. In M. T. Hallinan (Editor), Frontiers in sociology of education (Pages 127162). Dordrecht: Springer Netherlands. doi:10.1007/978-94-007-1576-9_7

Buchem, I. (2012). Psychological ownership and personal learning environments: Do sense of ownership and control really matter? In Personal learning environments (ple) conference. Aveiro, Portugal.

Carlgren, I. (1999). Professionalism and teachers as designers. Journal of curriculum studies, 31(1), 43-56. doi:10.1080/002202799183287

Carson, J. B., Tesluk, P. E., \& Marrone, J. A. (2007). Shared leadership in teams: An investigation of antecedent conditions and performance. Academy of management journal, 50(5), 1217-1234.

Chapman, C. (2014). From within- to between- and beyond-school improvement: A case of rethinking roles and relationships? In International congress for school effectiveness and improvement. Yokyakarta, Indonisia.

Cober, R., Tan, E., Slotta, J., So, H.-J., \& Könings, K. D. (2015). Teachers as participatory designers: two case studies with technology-enhanced learning environments. Instructional science, 43(2), 203-228. doi:10.1007/s11251-014-9339-0

Coenders, F. G. M., Terlouw, C., Dijkstra, S., \& Pieters, J. M. (2010). The effects of the design and development of a chemistry curriculum reform on teachers' professional growth: a case study. Journal of science teacher education, 21, 535-557. doi:10.1007/s10972-010-9194-z

Commissie vernieuwing Natuurkundeonderwijs havo vwo. (2010). Nieuwe natuurkunde, Advies-examenprogramma's voor havo en vwo. Amsterdam: Nederlandse Natuurkundige Vereniging.

Conley, S., Fauske, J., \& Pounder, D. G. (2004). Teacher Work Group Effectiveness. Educational administration quarterly, 40(5), 663-703. doi:10.1177/0013161X04268841

Coördinatiegroep curriculumherziening. (2017). Herziening van het curriculum in het primair en voortgezet onderwijs. 
Cordingley, P., Bell, M., Rundell, B., \& Evans, D. (2003). The impact of collaborative continuing professional development (CPD) on classroom teaching and learning. In Research evidence in education library. London.

Creswell, J. W. (2013). Research design: Qualitative, quantitative, and mixed methods approaches. Sage publications.

Crow, G. M. \& Pounder, D. G. (2000). Interdisciplinary teacher teams: Context, design, and process. Educational administration quarterly, 36(2), 216-254. doi:10.1177/0013161X00362004

Cviko, A., McKenney, S., \& Voogt, J. (2013). The teacher as re-designer of technology integrated activities for an early literacy curriculum. Journal of educational computing research, 48(4), 447-468. doi:10. 2190/EC.48.4.C

DeBoer, G. E. (2000). Scientific literacy: Another look at its historical and contemporary meanings and its relationship to science education reform. Journal of research in science teaching, 37(6), 582-601.

Desimone, L. M. (2009). Improving Impact Studies of Teachers' Professional Development: Toward Better Conceptualizations and Measures. Educational researcher, 38(3), 181-199. doi:10 . 3102 / 0013189X08331140

Desimone, L. M., Porter, A. C., Garet, M. S., Yoon, K. S., \& Birman, B. F. (2002). Effects of Professional Development on Teachers' Instruction: Results from a Three-year Longitudinal Study. Educational evaluation and policy analysis, 24(2), 81-112. doi:10.3102/01623737024002081

Desimone, L. M., Smith, T. M., \& Philips, K. P. (2013). Linking student achievement growth to professional development participation and changes in instruction: A longitudinal study elementary students and teachers in Title I schools. Teachers and teaching, 115(5), 1-46.

Dickerson, C., Jarvis, J., \& Levy, R. (2014). Learning through projects: identifying opportunities for individual professional learning and development. Professional development in education, 40(1), 17-35. doi:10.1080/19415257.2013.794747

Elizondo-Montemayor, L., Hernández-Escobar, C., Ayala-Aguirre, F., \& Aguilar, G. M. (2008). Building a sense of ownership to facilitate change: the new curriculum. International journal of leadership in education, 11(1), 83-102. doi:10.1080/13603120701663486

Elloy, D. F. (2006). Superleader behaviors and self-managed work teams: Perceptions of supervisory behaviors, satisfaction with growth, and team functions. Journal of business \& economics research, 4(12), 97-102.

Ensley, M. D., Hmieleski, K. M., \& Pearce, C. L. (2006). The importance of vertical and shared leadership within new venture top management teams: Implications for the performance of startups. The leadership quarterly, 17(3), 217-231. doi:10.1016/j.leaqua.2006.02.002

Erickson, G., Minnes Brandes, G., Mitchell, I., \& Mitchell, J. (2005). Collaborative teacher learning: Findings from two professional development projects. Teaching and teacher education, 21(7), 787-798. doi:10. 1016/j.tate.2005.05.018

Ermeling, B. A. (2010). Tracing the effects of teacher inquiry on classroom practice. Teaching and teacher education, 26(3), 377-388. doi:10.1016/j.tate.2009.02.019

Firestone, W. A. (1993). Alternative Argumentsfor Generalizing From Data as Applied to Qualitative Research. Educational researcher, 22(4), 16-23.

Fisher, G. \& Sugimoto, M. (2006). Supporting self-directed learners and learning communities with sociotechnical environments. Research and practice in technology enhanced learning, 1(1), 31-64.

Fishman, B. J., Marx, R. W., Best, S., \& Tal, R. T. (2003). Linking teacher and student learning to improve professional development in systemic reform. Teaching and teacher education, 19(6), 643-658. doi:10. 1016/S0742-051X(03)00059-3 
Forbes, C. T. \& Davis, E. A. (2010). Curriculum design for inquiry: Preservice elementary teachers' mobilization and adaptation of science curriculum materials. Journal of research in science teaching, 47(7), 820-839. doi:10.1002/tea.20379

Fullan, M. G. (1993). Why teachers must become change agents. Educational leadership, 50(6), 12-17.

Fullan, M. (2007). The new meaning of educational change (4th). London: Routledge.

Garet, M. S., Porter, A. C., Desimone, L. M., Birman, B. F., \& Yoon, K. S. (2001). What Makes Professional Development Effective? Results From a National Sampleof Teachers. American educational research journal, 38(4), 915-945.

Gast, I., Schildkamp, K., \& van der Veen, J. T. (2017). Team-based professional development interventions in higher education: A systematic review. Review of educational research. doi:10 . 3102 / 0034654317704306

Geijsel, F., Sleegers, P., van den Berg, R., \& Kelchtermans, G. (2001). Conditions fostering the implementation of large-scale innovation programs in schools: Teachers' perspectives. Educational administration quarterly, 37(1), 130-166. doi:10.1177/00131610121969262

Gendole, A. A., Coenders, F. G. M., Voogt, J. M., \& Pieters, J. M. (2015). Factors supporting or hindering continuation of a collaborative professional development program for communicative language teaching. African journal of teacher education, 4(1).

Gorozidis, G. \& Papaioannou, A. G. (2014). Teachers' motivation to participate in training and to implement innovations. Teaching and teacher education, 39, 1-11. doi:10.1016/j.tate.2013.12.001

Green, E. L. (1980). The independent learning in science model of school-based curriculum development. In J. Eggelston (Editor), (Pages 14-40). London: Routledge \& Kegan Paul.

Gregory, A. (2010). Teacher learning on problem-solving teams. Teaching and teacher education, 26(3), 608615. doi:10.1016/j.tate.2009.09.007

Gronn, P. (2009). From distributed to hybrid leadership in practice. In A. Harris (Editor), Distributed leadership. Dordrecht: Springer Netherlands. doi:DOI10.1007/978-1-4020-9737-911

Gronn, P. (2008). The future of distributed leadership. Journal of educational administration, 46(2), 141-158. doi:10.1108/09578230810863235

Grossman, P., Wineburg, S., \& Woolworth, S. (2001). Toward a theory of teacher community. The teachers college record, 103(6), 942-1012

Guskey, T. (2002a). Does it make a difference? Educational leadership, 59(6), 45-51.

Guskey, T. (2002b). Professional development and teacher change. Teachers and teaching: theory and practice, 8(3), 381-391. doi:10.1080/135406002100000512

Guskey, T. (2003). What makes professional development effective? Phi delta kappan, 84(10), 748-750.

Hampden-Thompson, G. \& Bennett, J. (2013). Science teaching and learning activities and students' engagement in science. International journal of science education, 35(8), 1325-1343. doi:10 . 1080 / 09500693.2011.608093

Handelzalts, A. (2009). Collaborative curriculum development in teacher design teams (Doctoral dissertation, University of Twente).

Hardré, P. L., Ge, X., \& Thomas, M. K. (2006). An Investigation of Development Toward Instructional Design Expertise. Performance improvement quarterly, 19(4), 63-90.

Hardré, P. L., Ling, C., Shehab, R. L., Nanny, M. A., Nollert, M. U., Refai, H., ... Wollega, E. D. (2013). Teachers in an interdisciplinary learning community: Engaging, integrating, and strengthening K-12 education. Journal of teacher education, 64(5), 409-425. doi:10.1177/0022487113496640

Hargreaves, A. (2003). Teaching in the Knowledge Society. Education in the age of insecurity. New York: Teacher College Press. 
Hargreaves, A. \& Fullan, M. (2012). Professional capital: Transforming teaching in every school. New York: Teachers College Press.

Hargreaves, A. \& O'Connor, M. T. (2017). Cultures of professional collaboration: their origins and opponents. Journal of professional capital and community, 2(2), 74-85. doi:10.1108/JPCC-02-2017-0004

Havnes, A. (2009). Talk, planning and decision-making in interdisciplinary teacher teams: a case study. Teachers and teaching, 15(1), 155-176. doi:10.1080/13540600802661360

Highsmith, J. (2010). Agile project management: creating innovative products (2nd ed.) Boston: Pearson Education, Inc.

Hoch, J. E. (2013). Shared leadership and innovation: The role of vertical leadership and employee integrity. Journal of business and psychology, 28(2), 159-174. doi:10.1007/s10869-012-9273-6

Hoch, J. E., Pearce, C. L., \& Welzel, L. (2010). Is the most effective team leadership shared? Journal of personnel psychology, 9(3), 105-116. doi:10.1027/1866-5888/a000020

Hoegl, M. \& Gemuenden, H. G. (2001). Teamwork quality and the success of innovative projects: A theoretical concept and empirical evidence. Organization science, 12(4), 435-449.

Hofman, R. H. \& Dijkstra, B. J. (2010). Effective teacher professionalization in networks? Teaching and teacher education, 26(4), 1031-1040. doi:10.1016/j.tate.2009.10.046

Hord, S. M. (2004). Learning together, leading together. Changing Schools Through Professional Learning Communities. New York: Teachers College Press.

Huizinga, T., Handelzalts, A., Nieveen, N., \& Voogt, J. (2014). Fostering teachers' design expertise in teacher design teams: conducive design and support activities. Curriculum journal, 26(1), 137-163. doi:10 . 1080/09585176.2014.990395

Huizinga, T., Handelzalts, A., Nieveen, N., \& Voogt, J. M. (2013). Teacher involvement in curriculum design: Need for support to enhance teachers' design expertise. Journal of curriculum studies, 46(1), 33-57. doi:10.1080/00220272.2013.834077

Hunzicker, J. (2011). Effective professional development for teachers: a checklist. Professional development in education, 37(2), 177-179. doi:10.1080/19415257.2010.523955

Jackson, D. \& Temperley, J. (2007). From Professional Learning Community to Networked Learning Community. In L. Stoll \& K. S. Louis (Editors), Professional learning communities. divergence, depth and dillemas (Pages 45-62). New York: Open University Press.

Johnson, N. A. (1993). Reconsidering curriculum development: A framework for co-operation. Interchange, 24(4), 409-433. doi:10.1007/BF01435197

Johnson, R., Severance, S., Leary, H., \& Miller, S. (2014). Mathematical tasks as boundary objects in design-based implementation research. In The international conference of the learning sciences icls (Pages 1127-1131). Boulder, CO: Learning and becoming in practice: The International Conference of the Learning Sciences (ICLS) 2014.

Kafyulilo, A., Fisser, P., \& Voogt, J. (2014). Teacher design in teams as a professional development arrangement for developing technology integration knowledge and skills of science teachers in Tanzania. Education and information technologies, 21(2), 301-318. doi:10.1007/s10639-014-9321-0

Karhatsu, H., Ikonen, M., Kettunen, P., Fagerholm, F., \& Abrahamsson, P. (2010). Building blocks for self-organizing software development teams. In International conference on software technology engineering (Pages 297-304). San Juan, USA.

Katz, S. \& Earl, L. (2010). Learning about networked learning communities. School effectiveness and school improvement, 21(1), 27-51. doi:10.1080/09243450903569718

Kennedy, M. M. (2016). How does professional development improve teaching? Review of educational research, 86(4), 945-980. doi:10.3102/0034654315626800 
Kippers, W. B., Poortman, C. L., Schildkamp, K., \& Visscher, A. J. (2017). Data literacy: what do educators learn and struggle with during a data use intervention? Manuscript submitted for publication.

Kirkpatrick, D. L. \& Kirkpatrick, J. D. (2006). Evaluating training programs: The four levels (3rd ed.) San Francisco: Berret-Koehler Publishers.

Koehler, M. J. \& Mishra, P. (2005). What happens when teachers design educational technology? The development of technological pedagogical content knowledge. Journal of educational computing research, 32(2), 131-152. doi:10.2190/0EW7-01WB-BKHL-QDYV

Kolst $\varnothing$, S. D. (2001). Scientific literacy for citizenship: Tools for dealing with the science dimension of controversial socioscientific issues. Science education, 85(3), 291-310. doi:10.1002/sce.1011

Kramer, J., Ocenar, J., \& Yamasaki, J. (2016). Crowdteaching: Online crowdsourcing in education. In Teaching, colleges \& community conference. Honolulu, Hawaii.

Kreijns, K., Van Acker, F., Vermeulen, M., \& van Buuren, H. (2013). What stimulates teachers to integrate ICT in their pedagogical practices? The use of digital learning materials in education. Computers in human behavior, 29(1), 217-225. doi:10.1016/j.chb.2012.08.008

Kruse, S. D. \& Louis, K. S. (1997). Teacher teaming in middle schools: Dilemmas for a schoolwide community. Educational administration quarterly, 33(3), 261-289. doi:10.1177/0013161X97033003002

Kuusisaari, H. (2014). Teachers at the zone of proximal development - Collaboration promoting or hindering the development process. Teaching and teacher education, 43, 46-57. doi:10.1016/j.tate. 2014.06.001

Lee, J. \& Suh, A. (2015). How do virtual community members develop psychological ownership and what are the effects of psychological ownership in virtual communities? Computers in human behavior, 45(100), 382-391. doi:10.1016/j.chb.2014.12.002

Levinsen, K. T. \& Nielsen, J. (2011). Innovating design for learning in the networked society. In Exploring the theory, pedagogy and practice of networked learning (Pages 237-256). New York: Springer New York. doi:10.1007/978-1-4614-0496-5_14

Little, J. (1990). The persistence of privacy: Autonomy and initiative in teachers' professional relations. The teachers college record, 91(4), 509-536.

Little, J. W. (2002). Locating learning in teachers' communities of practice: opening up problems of analysis in records of everyday work. Teaching and teacher education, 18, 917-946.

Little, J. W. (2006). Professional Community and Professional Development in the Learning-Centered School. Washington DC: National Education Association.

Loucks-Horsley, S., Stiles, K. E., Mundry, S., Love, N., \& Hewson, P. W. (2009). Designing Professional Development for Teachers of Science and Mathematics. Thousand Oaks, CA: SAGE.

McDermott, L. P. (2016). Teacher design teams: Building capacity for learner-centered course development. Asean journal of open distance learning, 8(2), 24-32.

McGreal, R., Kinuthia, W., Marshall, S., \& McNamara, T. (2013). Open educational resources: Innovation, research and practice. Vancouver: Commonwealth of Learning and Athabasca University.

McKenney, S., Boschman, F., Pieters, J., \& Voogt, J. (2016). Collaborative design of technology-enhanced learning: What can we learn from teacher talk? Techtrends, 60, 385-391. doi:10.1007/s11528-0160078-8

McKenney, S., Kali, Y., Markauskaite, L., \& Voogt, J. (2015). Teacher design knowledge for technology enhanced learning: an ecological framework for investigating assets and needs. Instructional science, 43(2), 181-202. doi:10.1007/s11251-014-9337-2

Meirink, J. A., Imants, J., Meijer, P. C., \& Verloop, N. (2010). Teacher learning and collaboration in innovative teams. Cambridge journal of education, 40(2), 161-181. doi:10.1080/0305764X.2010.481256 
Meyers, E. M., Erickson, I., \& Small, R. V. (2013). Digital literacy and informal learning environments: an introduction. Learning, media and technology, 38(4), 355-367. doi:10.1080/17439884.2013.783597

Moe, N. B., Dingsoyr, T., \& Kvangardsnes, O. (2009). Understanding shared leadership in agile development: A case study. In 42nd hawaii international conference on systems sciences. Honolulu, Hawaii.

Mohrman, S. A., Cohen, S. G., \& Morhman Jr, A. M. (1995). Designing team-based organizations: New forms for knowledge work.

Mooney Simmie, G. (2007). Teacher Design Teams (TDTs)-building capacity for innovation, learning and curriculum implementation in the continuing professional development of in-career teachers. Irish educational studies, 26(2), 163-176. doi:10.1080/03323310701295914

Nappi, J. S. (2014). The teacher leader: Improving schools by building social capital through shared leadership. Principals research review, 9(6).

Nicolaides, V. C., LaPort, K. A., Chen, T. R., Tomassetti, A. J., Weis, E. J., Zaccaro, S. J., \& Cortina, J. M. (2014). The shared leadership of teams: a meta-analysis of proximal, distal and moderating relationships. The leadership quarterly, 25(5), 923-942. doi:10.1016/j.leaqua.2014.06.006

OECD. (2014). Education policy outlook: Netherlands.

Onderwijsraad. (2016). Een ander perspectief op professionele ruimte in het onderwijs. Den Haag: Onderwijsraad.

Osborne, J., Simon, S., \& Collins, S. (2003). Attitudes towards science: A review of the literature and its implications. International journal of science education, 25(9), 1049-1079. doi:10 . 1080 / 0950069032000032199

Park, V. \& Datnow, A. (2009). Co-constructing distributed leadership: district and school connections in data-driven decision-making. School leadership \& management, 29(5), 477-494. doi:10 . 1080 / 13632430903162541

Pearce, C. L. (2004). The future of leadership: Combining vertical and shared leadership to transform knowledge work. Academy of management executive, 18(1), 47-57.

Pearce, C. L., Sims Jr, H. P., Cox, J. F., Ball, G., Schnell, E., Smith, K. A., \& Trevino, L. (2003). Transactors, transformers and beyond. Journal of management development, 22(4), 273-307. doi:10 . 1108 / 02621710310467587

Pearce, C. L. \& Sims, H. P. J. (2002). Vertical versus shared leadership as predictors of the effectiveness of change management teams: An examination of aversive, directive, transactional, transformational, and empowering leader behaviors. Group dynamics: theory, research, and practice, 6(2), 172-197. doi:10.1037//1089-2699.6.2.172

Penuel, W. R., Fishman, B. J., Yamaguchi, R., \& Gallagher, L. P. (2007). What makes professional development effective? Strategies that foster curriculum implementation. American educational research journal, 44(4), 921-958. doi:10.3102/0002831207308221

Platform Onderwijs2032. (2016). Ons onderwijs2032 Eindadvies. Den Haag.

Poortman, C. L. \& Schildkamp, K. (2011). Alternative quality standards in qualitative research? Quality \& quantity, 46(6), 1727-1751. doi:10.1007/s11135-011-9555-5

Potvin, P. \& Hasni, A. (2014). Interest, motivation and attitude towards science and technology at K-12 levels: a systematic review of 12 years of educational research. Studies in science education, 50(1), 85-129. doi:10.1080/03057267.2014.881626

Ritchie, R. \& Woods, P. A. (2007). Degrees of distribution: towards an understanding of variations in the nature of distributed leadership in schools. School leadership \& management, 27(4), 363-381. doi:10. 1080/13632430701563130 
Ryan, R. M. \& Deci, E. L. (2000). Self-determination theory and the facilitation of intrinsic motivation, social development, and well-being. American psychologist, 55(1), 68-78.

Schildkamp, K., Poortman, C. L., \& Handelzalts, A. (2016). Data teams for school improvement. School effectiveness and school improvement, 27(2), 228-254. doi:10.1080/09243453.2015.1056192

Schwaber, K. (1997). SCRUM Development Process. Business object design and implementation, 117-134.

Scribner, J. P., Sawyer, R. K., Watson, S. T., \& Myers, V. L. (2007). Teacher teams and distributed leadership: A study of group discourse and collaboration. Educational administration quarterly, 43(1), 67-100. doi:10. 1177/0013161X06293631

Shawer, S. (2010). Classroom-level teacher professional development and satisfaction: teachers learn in the context of classroom-level curriculum development. Professional development in education, 36(4), 597-620. doi:10.1080/19415257.2010.489802

Sliger, M. (2006). A project manager's survival guide to going agile. Boulder, CO: Rally Software Development Corporation.

SLO. (2010). Scheikunde inde dynamiekvan de toekomst. Enschede: SLO.

Smylie, M. A., Lazarus, V., \& Brownlee-Conyers, J. (1996). Instructional outcomes of school-based participative decision making. Educational evaluation and policy analysis, 18(3), 181-198.

Stenhouse, L. (1975). An introduction to curriculum research and development. London: Heinemann Educational Books.

Stolk, M. J., Bulte, A. M. W., de Jong, O., \& Pilot, A. (2009). Towards a framework for a professional development programme: empowering teachers for context-based chemistry education. Chemistry education research and practice, 10(2), 164. doi:10.1039/b908255g

Stolk, M. J., Jong, O., Bulte, A. M. W., \& Pilot, A. (2010). Exploring a framework for professional development in curriculum innovation: Empowering teachers for designing context-based chemistry education. Research in science education, 41(3), 369-388. doi:10.1007/s11165-010-9170-9

Stoll, L. (2010). Connecting learning communities: Capacity building for systemic change. In A. Hargreaves, A. Lieberman, M. Fullan, \& D. Hopkins (Editors), Second international handbook of educational change (Pages 469-484). Dordrecht: Springer Netherlands. doi:10 .1007/ 978 - 90 - 481 2660-6_28

Stoll, L., Bolam, R., McMahon, A., Wallace, M., \& Thomas, S. (2006). Professional learning communities: A review of the literature. Journal of educational change, 7(4), 221-258. doi:10.1007/s10833-006-0001-8

Svihla, V., Reeve, R., Sagy, O., \& Kali, Y. (2015). A fingerprint pattern of supports for teachers' designing of technology-enhanced learning. Instructional science, 43(2), 283-307. doi:10.1007/s11251-014-9342-5

Tata, J. \& Prasad, S. (2004). Team Self-management, Organizational Structure, and Judgments of Team Effectiveness. Journal of mangerial issues, 16(2), 248-265.

Thomas, G., Wineburg, S., Grossman, P., Myhre, O., \& Woolworth, S. (1998). In the company of colleagues. Teaching and teacher education, 14(1), 21-32. doi:10.1016/S0742-051X(97)00058-9

Thousand, J. S. \& Villa, R. A. (1993). Collaborative teams: A powerful tool to school restructuring. In R. A. Villa, J. S. Thousand, W. Steinback, \& S. Steinback (Editors), Restructuring for caring and effective education an administrative guide to creating heterogeneous schools (Pages 73-108). Baltimore: Brookes Baltimore.

Van Gasse, R., Vanlommel, K., Vanhoof, J., \& Van Petegem, P. (2016). Teacher collaboration on the use of pupil learning outcome data: A rich environment for professional learning? Teaching and teacher education, 60(100), 387-397. doi:10.1016/j.tate.2016.07.004 
van Driel, J. H., Meirink, J. A., van Veen, K., \& Zwart, R. C. (2012). Current trends and missing links in studies on teacher professional development in science education: a review of design features and quality of research. Studies in science education, 48(2), 129-160. doi:10.1080/03057267.2012.738020

van Tuijl, C. \& Walma van der Molen, J. (2016). Study choice and career development in STEM fields: an overview and integration of the research. International journal of technology and design education, 26(2), 159-183.

van Veen, K., Zwart, R. C., Meirink, J. A., \& Verloop, N. (2010). Professionele ontwikkeling van leraren. Leiden: ICLON.

Vangrieken, K., Dochy, F., Raes, E., \& Kyndt, E. (2015). Teacher collaboration: A systematic review. Educational research review, 15(100), 17-40. doi:10.1016/j.edurev.2015.04.002

Vangrieken, K., Meredith, C., Packer, T., \& Kyndt, E. (2017). Teacher communities as a context for professional development: A systematic review. Teaching and teacher education, 61(100), 47-59. doi:10.1016/j.tate.2016.10.001

Verhoef, N. C., Coenders, F., Pieters, J. M., van Smaalen, D., \& Tall, D. O. (2015). Professional development through lesson study: teaching the derivative using GeoGebra. Professional development in education, 41(1), 109-126.

Vermunt, J. D. (2003). The power of learning environments and the quality of student learning. In E. de Corte, L. Verschaffel, N. Entwistle, \& J. van Merriënboer (Editors), Powerful learning environments unraveling basic components and dimensions. Pergamon/Elsevier Science Ltd.

Vescio, V., Ross, D., \& Adams, A. (2008). A review of research on the impact of professional learning communities on teaching practice and student learning. Teaching and teacher education, 24(1), 80-91. doi:10.1016/j.tate.2007.01.004

Visser, T. C., Coenders, F. G. M., Terlouw, C., \& Pieters, J. M. (2012). Design of a model for a professional development programme for a multidisciplinary science subject in the Netherlands. Professional development in education, 38(4), 679-682. doi:10.1080/19415257.2012.669393

Voogt, J., Westbroek, H., Handelzalts, A., Walraven, A., McKenney, S., Pieters, J. M., \& de Vries, B. (2011). Teacher learning in collaborative curriculum design. Teaching and teacher education, 27(8), 12351244. doi:10.1016/j.tate.2011.07.003

Voogt, J., Laferrière, T., Breuleux, A., Itow, R. C., Hickey, D. T., \& McKenney, S. (2015). Collaborative design as a form of professional development. Instructional science, 43(2), 259-282. doi:10.1007/s11251-0149340-7

Wageman, R. (1997). Critical success factors for creating superb self-managing teams. Organizational dynamics, 26(1), 49-61.

Wageman, R. (2001). How leaders foster self-managing team effectivenes: Design choices versus handson coaching. Organization science, 12(5), 559-577.

Wikeley, F., Stoll, L., Murillo, J., \& De Jong, R. (2005). Evaluating effective school improvement: Case studies of programmes in eight European countries and their contribution to the effective school improvement model. School effectiveness and school improvement, 16(4), 387-405. doi:10 . 1080 / 09243450500234617

Yin, R. K. (2013). Case study research - Design and methods (5th). Sage Publications Inc.

Yukl, G. (2012). Effective leadership behavior: What we know and what questions need more attention. Academy of management perspectives, 26(4), 66-85. doi:10.5465/amp.2012.0088

Yukl, G., Gordon, A., \& Taber, T. (2002). A hierarchical taxonomy of leadership behavior: Integrating a half century of behavior research. Journal of leadership and organizational studies, 9(1), 15-32. 


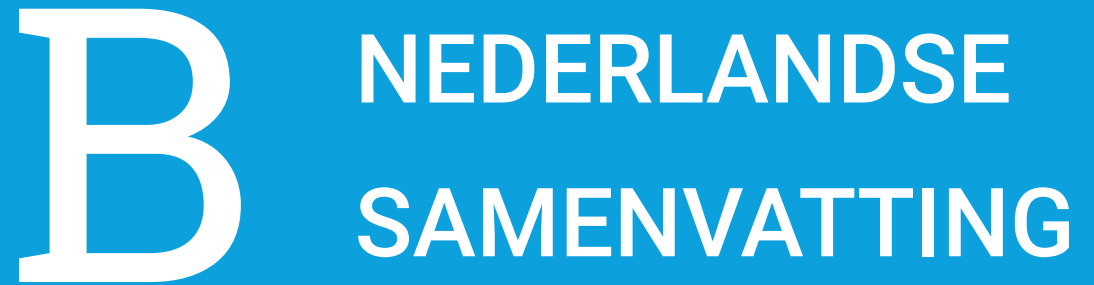

\section{B.1 Vernieuwingen in bètavakken: de rol van docenten}

Vernieuwingen en innovaties in de wereld van wetenschap en techniek volgen elkaar in snel tempo op. Om het voortgezet onderwijs toekomstbestendig te houden moet het curriculum daar voortdurend op inspelen. In Nederland zijn er daarom voor de bètavakken de afgelopen jaren nieuwe examenprogramma's voor havo en vwo ingevoerd.

Bij deze vernieuwde examenprogramma's wordt veel gebruik gemaakt van contexten die aansluiten bij de belevingswereld van leerlingen. Daarnaast wordt de samenhang tussen de verschillende bètavakken zichtbaar gemaakt, en is er aandacht voor de ontwikkeling van de wetenschappelijke geletterdheid van leerlingen. Door deze vernieuwingen wordt het curriculum aantrekkelijker voor leerlingen, wat zou kunnen bijdragen aan hun enthousiasme voor wetenschap en techniek.

Docenten spelen een belangrijke rol bij de invoering van vernieuwingen in het onderwijs. Zij zijn immers degenen die het in de praktijk moeten brengen in de klas. Daarom is het belangrijk om docenten actief te betrekken bij de invoering van de vernieuwingen.

Daarnaast is het belangrijk dat docenten goed op de hoogte zijn van de onderwijsvernieuwingen. Zij moeten voldoende gelegenheden krijgen om zich de vernieuwingen eigen te maken. Met andere woorden: aandacht voor de professionele ontwikkeling van docenten is cruciaal bij de implementatie van onderwijsvernieuwingen.

\section{B.2 Docent Ontwikkel Teams}

In een context van onderwijsvernieuwing is het enerzijds van belang om docenten actief te betrekken bij de vernieuwing. Anderzijds moet er aandacht zijn voor hun professionele ontwikkeling. Docent Ontwikkel Teams (DOTs) zijn professionaliseringsprogramma's waarbij docenten gezamenlijk aan de slag gaan met het (her)ontwerpen van vernieuwend lesmateriaal. 
Voorgaand onderzoek heeft aangetoond dat DOTs veel kunnen opleveren. In de eerste plaats kunnen DOTs concreet lesmateriaal opleveren. Omdat dit materiaal door docenten zelf is gemaakt, is de kans groter dat zij het daadwerkelijk gebruiken in de klas.

Tegelijkertijd kunnen DOTs bijdragen aan de professionele ontwikkeling van docenten. Door samen te werken aan concreet materiaal ontwikkelen ze bijvoorbeeld inhoudelijke kennis over hun vakgebied, vaardigheden met het ontwerpen van onderwijs en een waardevol netwerk van collega's en wetenschappers. Als zij deze nieuwe kennis en vaardigheden toepassen in de klas kunnen niet alleen de docenten, maar ook de leerlingen daarvan profiteren.

De DOTs in dit onderzoek werden georganiseerd vanuit de Universiteit Twente, en vonden plaats tussen 2010 en 2016. In deze DOTs kwamen docenten van verschillende scholen maandelijks bij elkaar onder begeleiding van een vakdidacticus. De deelnemende docenten kozen vaak zelf een onderwerp, bijvoorbeeld nieuwe onderwerpen in de examenprogramma's, moderne wetenschappelijke ontwikkelingen in het vakgebied, of innovatieve instructiemethoden. Bij sommige DOTs stond het onderwerp van tevoren vast, maar er was altijd ruimte voor docenten om hier zelf een precieze invulling aan te geven. Vervolgens verzamelden ze informatie over dit onderwerp, nodigden ze experts uit om hierover te vertellen en ontwikkelden ze samen relevante opdrachten of experimenten voor leerlingen.

\section{B.3 Doel van de studie en onderzoeksvragen}

Ondanks deze veelbelovende opbrengsten, gaat het effectief samenwerken en samen leren in een DOT niet vanzelf. De effectiviteit van DOTs hangt sterk af van de de manier warop de DOTs geïmplementeerd zijn. Er is echter nog geen theoretische en praktische basis voor de succesvolle implementatie van DOTs. De overkoepelende onderzoeksvraag in deze studie was daarom: Hoe kan de implementatie van DOTs ondersteund worden?

Om deze vraag te kunnen beantwoorden, moest eerst het functioneren van DOTs in kaart gebracht worden. Dit zorgde voor inzicht in welke factoren beïnvloed kunnen worden om het functioneren van DOTs te ondersteunen. 
Deze inzichten zijn gebruikt om een interventie te ontwikkelen, die vervolgens is toegepast in de praktijk. De volgende vier onderzoeksvragen stonden centraal:

1 Hoe kunnen de kenmerken van DOTs worden vastgelegd in een beschrijvend raamwerk?

2. Welke sleutelfactoren van dit beschrijvende raamwerk kunnen beïnvloed worden om DOTs te ondersteunen?

3. Wat zijn de kenmerken van een interventie om DOTs te ondersteunen, die gericht is op deze sleutelelementen?

4 Hoe kan het toepassen van deze interventie de processen in DOTs bevorderen?

\section{B.4 Resultaten}

\section{Beschrijvend raamwerk}

Het startpunt van hoofdstuk 2 was een theoretische verkenning van de factoren die kunnen bijdragen aan de effectiviteit van DOTs. Dit resulteerde in een conceptueel raamwerk, bestaande uit drie stadia: input, proces en uitkomsten. Vervolgens zijn zowel kwantitatieve als kwalitatieve data uit de praktijk gebruikt om het conceptuele raamwerk te evalueren en aan te scherpen tot een geïntegreerd beschrijvend raamwerk. Het resulterende raamwerk bestond uit negen categorieën van factoren die relevant geacht werden.

Voor het input-stadium zijn twee categorieën onderscheiden: (1) Individuele (docent) kenmerken en (2) contextuele (school) kenmerken. Hoofdstuk 2 toonde bijvoorbeeld aan dat docenten die niet uit zichzelf gemotiveerd waren om te participeren, ook minder positief waren over het proces en de uitkomsten. Het proces-stadium omvatte vijf categorieën: (3) team interactie, (4) gezamenlijke doelen, (5) activiteiten, (6) DOT-organisatie en (7) leiderschap van de team coach. Met name die laatste bleek een belangrijke rol te spelen, omdat de handelingen van de teamcoach altijd gericht waren op één van de andere procesfactoren. De coaches hadden bijvoorbeeld invloed op hoe de team interactie verliep, en ze speelden een rol in het opstellen van de teamdoelen. Daarom is het leiderschap van de teamcoach centraal gezet in het beschrijvende raamwerk. Tot slot zijn er twee categorieën van uitkomsten gedefinieerd: (8) professionele ontwikkeling en (9) het ontworpen materiaal. Het beschrijvende raamwerk is weergegeven in afbeelding B.1. 


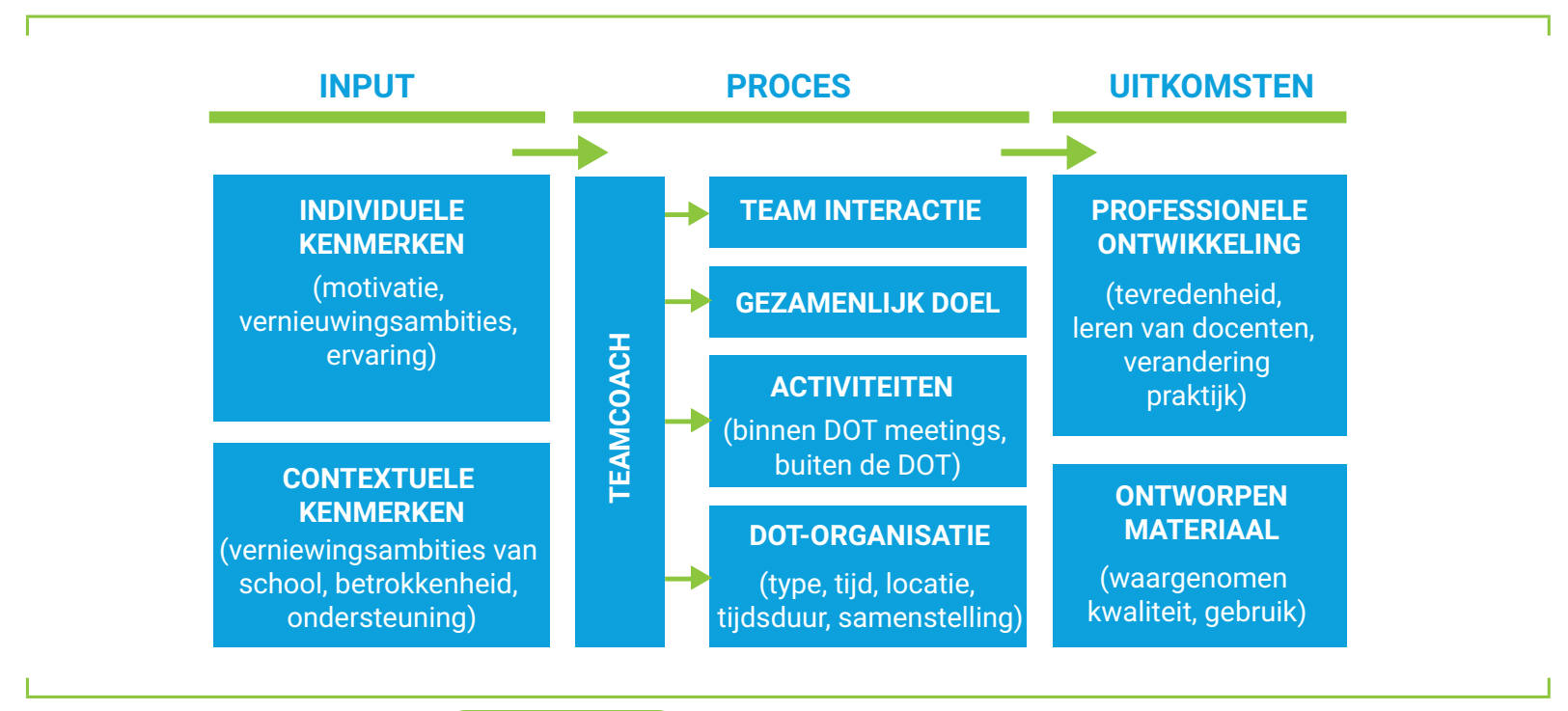

afbeelding B.1 Beschrijvend raamwerk voor DOTs

Dit beschrijvende raamwerk kan gebruikt worden door onderzoekers om het functioneren van DOTs te beschrijven en analyseren. Omdat het raamwerk is gebaseerd op zowel theorie als praktijk kan het bovendien worden gezien als een fundamentele eerste stap in de ontwikkeling van een theoretische en praktische basis voor de succesvolle implementatie van DOTs.

\section{Sleutelfactoren}

In hoofdstuk 3 is het beschrijvende raamwerk gebruikt om het functioneren van drie DOTs een jaar lang te volgen. Hierbij lag de focus op het proces en de uitkomsten. Aan de hand van kwalitatieve data - zoals observaties, logboeken en interviews - hebben we in kaart gebracht hoe de DOTs functioneerden en welke sleutelfactoren beïnvloed kunnen worden om het functioneren te bevorderen.

De resultaten toonden aan dat de waargenomen opbrengsten van de DOTs wisselend waren. Daarnaast hebben we verschillende links tussen de processen en de uitkomsten gevonden. We vonden bijvoorbeeld een link tussen gedeeld leiderschap en eigenaarschap: deelnemers die het gevoel hadden dat ze richting konden geven aan het proces en beslissingen konden maken voor het team, hadden een sterker gevoel van eigenaarschap. Dit gevoel van eigenaarschap was vervolgens weer gelinkt aan de uitkomsten. Hoewel alle deelnemers aangaven dat er onderwijsmateriaal was ontworpen, werd dit materiaal niet altijd gebruikt in de praktijk. Alleen de deelnemers met een sterk gevoel van eigenaarschap waren van plan de ontworpen materialen voor langere tijd in de lespraktijk 
te gebruiken, om zo hun onderwijs te verbeteren. Als we deze redeneerlijn volgen, kunnen we dus concluderen dat gedeeld leiderschap indirect de uitkomsten in termen van het ontworpen materiaal van DOTs kan bevorderen.

Daarnaast gaven deelnemers aan dat gedeeld leiderschap nodig was om ervoor te zorgen dat de leerdoelen waren afgestemd op hun behoeften. Zij gaven aan dat hun lespraktijk alleen zou kunnen verbeteren als zij daadwerkelijk de behoefte voelden om het te verbeteren. Op die manier kan gedeeld leiderschap dus ook bijdragen aan de uitkomsten in termen van professionele ontwikkeling.

Maar niet alleen gedeeld leiderschap bleek essentieel. In hoofdstuk 3 vonden we ook connecties tussen verticaal leiderschap, het proces en de uitkomsten. Deelnemers legden uit dat dit verticaal leiderschap nodig was om structuur, focus en kwaliteit in het DOTproces te brengen. Verticaal leiderschap kan er bijvoorbeeld voor zorgen dat de doelen en activiteiten voor iedereen duidelijk zijn. En de expertkennis van de teamcoach kan het ontwerpproces op een hoger niveau brengen. Op deze manier kan verticaal leiderschap ook bijdragen aan de uitkomsten van DOTs.

Als antwoord op de tweede onderzoeksvraag kunnen we daarom concluderen dat gedeeld leiderschap en verticaal leiderschap beide sleutelfactoren zijn die het functioneren van DOTs kunnen bevorderen. Het combineren van gedeeld leiderschap en verticaal leiderschap is echter niet vanzelfsprekend en wordt soms zelfs gezien als paradoxaal.

\section{Interventie}

Het doel van hoofdstuk 4 was om een interventie te ontwikkelen die het functioneren van DOTs kan ondersteunen. De notie dat gedeeld leiderschap en verticaal leiderschap beide sleutelfactoren zijn voor het functioneren van DOTs was hierbij het uitgangspunt.

In dit hoofdstuk zijn de effectieve procesfactoren voor DOTs eerst nog eens samengevat. Vervolgens hebben we literatuur over docententeams en over management en organisatie gebruikt om te identificeren welke leiderschapsgedragingen kunnen bijdragen aan deze procesfactoren. Dit resulteerde in een lijst van tien leiderschapsrichtlijnen. Drie daarvan waren richtlijnen voor gedeeld leiderschap: gezamenlijk doelen opstellen, gezamenlijk plannen opstellen en uitvoeren, en elkaar stimuleren om ideeën en ervaringen te delen. Daarnaast definieerden we zeven richtlijnen voor verticaal leiderschap: expliciet maken doelen, expliciet maken plannen, expertkennis inbrengen, alle deelnemers betrekken bij discussies, richting geven aan discussies, het organiseren van de bijeenkomsten en het volgen van een vaste werkwijze binnen de bijeenkomsten. 


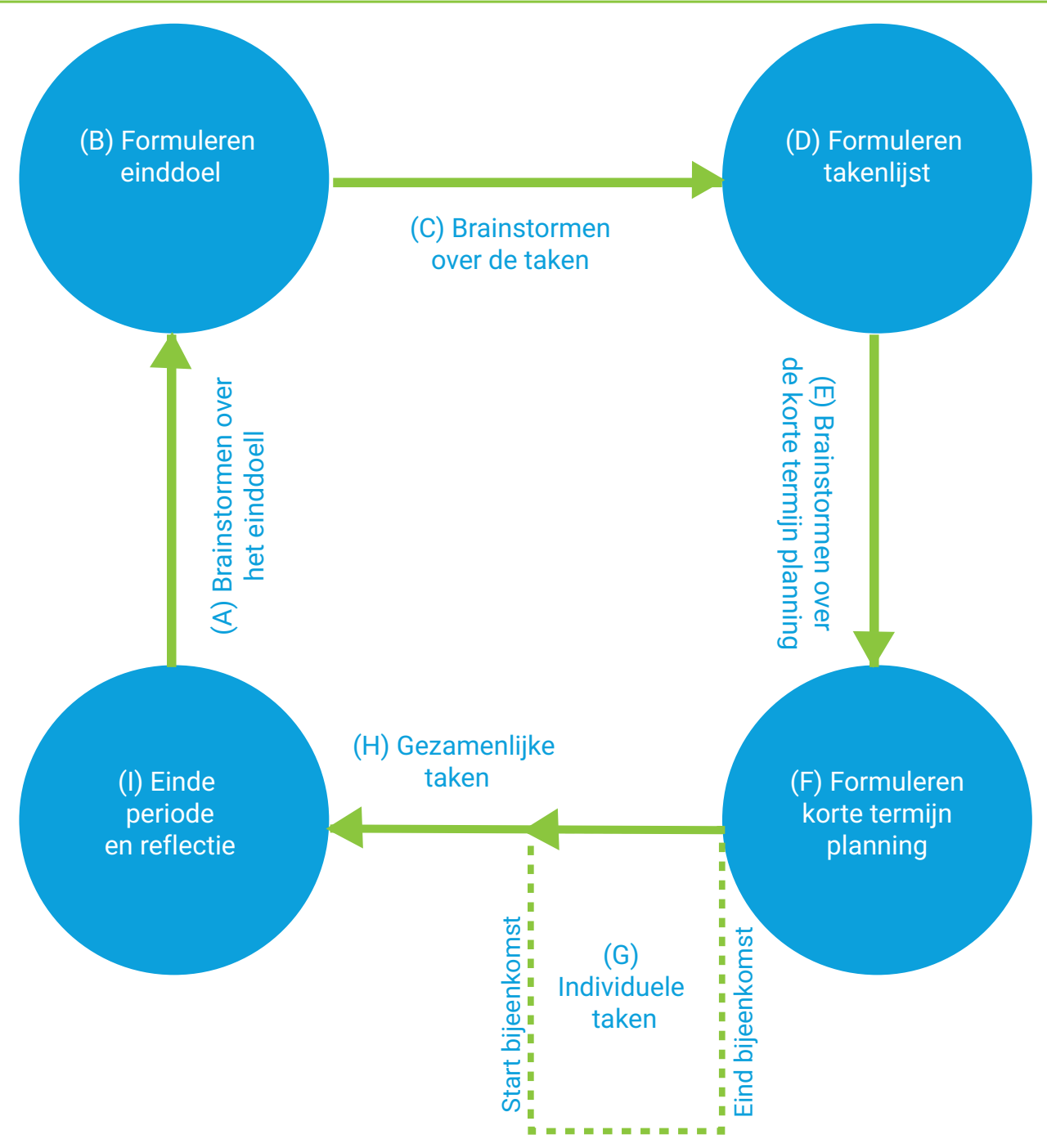

afbeelding B.2 Model van de stapsgewijze werkwijze voor DOTs

Vervolgens hebben we een stapsgewijze werkwijze ontwikkeld die deze tien leiderschapsgedragingen kan stimuleren. Deze werkwijze was geïnspireerd op agile productontwikkeling. Dit is een methode die vaak wordt gebruikt bij het ontwikkelen van complexe software. DOTs die deze werkwijze gebruiken, werken in korte iteraties. Dit kan deelnemers stimuleren om creatief te zijn en eigen ideeën in te brengen. Omdat de doelen en plannen worden geformuleerd op een planbord, ontstaat er duidelijkheid en focus. De stapsgewijze werkwijze is weergegeven in afbeelding B.2, en zal hieronder kort worden toegelicht. 
De stapsgewijze werkwijze start met een gezamenlijke brainstorm over de einddoelen (afbeelding B.2, A). Tijdens deze brainstorm kunnen deelnemers hun eigen ideeën in visie inbrengen. Als de deelnemers het eens worden over het einddoel, wordt het duidelijk geformuleerd door het op te schrijven op het planbord dat voor iedereen zichtbaar is (afbeelding B.2, B). Vervolgens gaan de deelnemers brainstormen over welke activiteiten of taken er gedaan moeten worden om dit einddoel te bereiken (afbeelding B.2, C). Deze taken worden ook opgeschreven op het planbord, wat resulteert in een takenlijst (afbeelding B.2, D). Daarna gaan de deelnemers nadenken over een subdoel voor de komende bijeenkomst, en selecteren zij welke taken van de takenlijst ze de komende periode willen gaan uitvoeren (afbeelding B.2, E). Nadat het plan voor de korte termijn is opgeschreven op het planbord (afbeelding B.2, F), eindigt de bijeenkomst. Tussen de twee bijeenkomsten hebben deelnemers tijd om aan de individuele taken te werken, die ze zelf gekozen hebben (afbeelding B.2, G). Als de volgende bijeenkomst start, kunnen deelnemers toelichten hoe ze de individuele taken hebben uitgevoerd en vervolgens gaan ze aan de slag met de gezamenlijke taken (afbeelding B.2, H). Als einde van de periode reflecteert het team over het proces door terug te kijken op het korte termijnplan (afbeelding B.2, I).

Nadat stap I is afgerond begint de werkwijze weer opnieuw bij stap A. Eerst kijkt het team of het geformuleerde doel nog steeds relevant is. Wanneer dat nodig is, kan het doel worden aangepast of aangescherpt. Daarna kijkt het team naar de takenlijst, en maakt aanpassingen waar nodig. Vervolgens kan het team weer een planning maken voor de volgende periode.

\section{Toepassen}

In hoofdstuk 5 is de stapsgewijze werkwijze een jaar lang door twee DOTs toegepast in de praktijk. Net als in hoofdstuk 3, hebben we kwalitatieve data verzameld door middel van observaties, logboeken en interviews.

Deze studie gaf inzicht in hoe gedeeld leiderschap en verticaal leiderschap tot uiting kwamen, en hoe ze het proces bevorderden. De bevindingen lieten zien dat de drie richtlijnen voor gedeeld leiderschap allemaal tot uiting kwamen tijdens het toepassen van de werkwijze. Dit gedeelde leiderschap zorgde ervoor dat de ontworpen materialen relevant en betekenisvol waren voor alle deelnemers. Daarnaast gaven de deelnemers aan dat het gedeelde leiderschap ervoor zorgde dat ze zich verantwoordelijk voelden om de taken uit te voeren zoals afgesproken. Bovendien legden ze uit dat het openlijk delen van ideeën het ontwerpproces versnelde. 
Daarnaast hebben we laten zien dat alle zeven richtlijnen voor verticaal leiderschap tot uiting zijn gekomen bij het toepassen van de stapsgewijze werkwijze. Dit verticale leiderschap zorgde ervoor dat de doelen en taken altijd duidelijk waren voor de deelnemers. Bovendien droeg het verticale leiderschap bij aan de kwaliteit van de ontwerpactiviteiten. Op deze manier speelde verticaal leiderschap een belangrijke rol in de voortgang in het ontwerpproces van de DOTs. Daarnaast zorgde verticaal leiderschap ervoor dat deelnemers toegang kregen tot expertkennis en relevante informatie. Dit creëerde leermogelijkheden voor de docenten.

In hoofdstuk 5 hebben we ook twee resterende leiderschapsuitdagingen gevonden. De resultaten lieten zien dat zowel deelnemers als coaches het lastig vonden om doelen en taken concreet te formuleren. Bovendien werden mogelijke taken niet als zodanig herkend tijdens de conversaties. Deze bevindingen geven aan dat het een uitdaging is om te denken in doelen en taken. De tweede uitdaging heeft te maken met de intrinsieke betrokkenheid van de deelnemers. Hoewel deelnemers uit eigen motivatie hebben gekozen om mee te doen, bleek dat niet alle deelnemers even actief betrokken waren bij de DOTs. Omdat samen brainstormen en samen planningen maken centraal staat bij de stapsgewijze werkwijze, brengt het extra moeilijkheden met zich mee als enkele deelnemers minder betrokken zijn. Dit kan de motivatie van de andere deelnemers schaden. Dit werd deels opgelost door verticaal leiderschap van de teamcoach, die de deelnemers actief probeerde te betrekken bij de conversaties en bij het uitvoeren van taken.

De inzichten over hoe gedeeld en verticaal leiderschap tot uiting kwamen en hoe ze het proces bevorderden zijn samengevat in een overzichtelijke tabel. Dit overzicht draagt bij aan het inzicht in hoe gedeeld en verticaal leiderschap gecombineerd kunnen worden, zonder dat ze gezien worden als conflicterend of paradoxaal. Daarnaast kan dit overzicht de praktijk van DOTs op drie manieren ondersteunen: (1) door te kijken naar voorbeelden uit de praktijk ziet men hoe gedeeld en verticaal leiderschap gecombineerd kunnen worden, (2) het kan zorgen voor bewustwording over hoe zowel gedeeld als verticaal leiderschap het proces van DOTs kunnen bevorderen en (3) de voorbeelden van leiderschapsuitdagingen kunnen ervoor zorgen dat mogelijke valkuilen vermeden worden.

\section{B.5 Conclusies}

De overkoepelende onderzoeksvraag in deze studie was: Hoe kan de implementatie van DOTs ondersteund worden? 
De resultaten laten allereerst zien dat het waardevol is om het functioneren van DOTs in kaart te brengen. Dit zorgt voor bewustwording dat het implementeren van DOTs niet automatisch succesvol is. Het beschrijvende raamwerk dat in hoofdstuk 2 is ontwikkeld kan inzicht geven in welke factoren een sleutelrol spelen bij het functioneren van DOTs. Het raamwerk is daarom nuttig voor onderzoekers en organisatoren van DOTs.

Daarnaast laten de resultaten zien dat de stapsgewijze werkwijze een praktisch instrument is om het proces van DOTs vorm te geven, omdat het DOTs helpt om gedeeld en verticaal leiderschap te combineren. Bovendien dragen de bevindingen uit hoofdstuk 5 bij aan de theorie over het combineren van gedeeld en verticaal leiderschap in docententeams. Omdat deze bevindingen zijn samengevat in een overzichtelijke tabel, kan het deelnemers en coaches in de praktijk helpen om bewust te worden van hun leiderschapsgedrag.

In 2013, toen dit project startte, waren bètadocenten in Nederland zich aan het voorbereiden op de vernieuwde examenprogramma's voor de bètavakken. Nu, vier jaar later is een nieuwe curriculumherziening al aangekondigd. Er zullen DOTs gevormd worden, bestaande uit docenten, schoolleiders en medewerkers van Stichting Leerplanontwikkeling (SLO), die de bouwstenen voor deze curriculumherziening gaan ontwikkelen.

Omdat DOTs kunnen bijdragen aan de professionele ontwikkeling van docenten en aan het ontwerpen van onderwijsmaterialen, kunnen DOTs inderdaad voordelen hebben in de context van deze onderwijsvernieuwing. Dit proefschrift toonde echter aan dat een succesvolle implementatie van DOTs niet vanzelf gaat. De DOTs die opgezet gaan worden in het kader van de nieuwe curriculumherziening kunnen daarom gebruik maken van de theoretische en praktische basis voor de succesvolle implementatie van DOTs die in dit proefschrift gelegd is. 


\section{CONTRIBUTIONS}

Refereed journals

Binkhorst, F., Handelzalts, A., Poortman, C.L. and van Joolingen, W.R. (2015). Understanding Teacher Design Teams - A mixed methods approach to developing a descriptive framework. Teaching and Teacher Education, 51(C), 213-224. doi:10.1016/j.tate.2015.07.006.

Binkhorst, F., Poortman, C.L, and van Joolingen, W.R. (under review). A qualitative analysis of Teacher Design Teams: in-depth insights into their process and links with their outcomes.

Binkhorst, F., Poortman, C.L., McKenney, S. and van Joolingen (under review). Teacher Design Teams for professional development: Guidelines and a nine-step method for coaches.

Binkhorst, F. Poortman, C.L., McKenney, S., and van Joolingen, W.R. (under review). Revealing the balancing act of vertical and shared leadership in Teacher Design Teams.

\section{Conference presentations}

Binkhorst, F., Handelzalts, A. and van Joolingen, W.R. (2014, July). A retrospective view on Teacher Design Teams. Poster presented at the Conference for JUnior REsearchers of EARLI, Nicosia, Cyprus.

Binkhorst, F., Handelzalts, A. and van Joolingen, W. (2014, November). Understanding the workings of Teacher Design Teams as a tool for professional development and educational renewal. Poster presented at the ICO International Fall School, Blankenberge, Belgium.

Binkhorst, F., Handelzalts, A., Poortman, C.L. and van Joolingen, W.R. (2015, June). Hoe werken Docentontwerpteams? De ontwikkeling van een beschrijvend raamwerk. Paper presented at the Onderwijs Research Dagen, Leiden, The Netherlands. 
Binkhorst, F., Handelzalts, A., Poortman, C.L. and van Joolingen, W.R. (2015, August). Professional development and educational innovation in Teacher Design Teams. Paper presented at the European Association for Research on Learning and Instruction (EARLI) conference, Limassol, Cyprus.

Binkhorst, F., Poortman, C.L. and van Joolingen, W.R. (2015, November). The links between leadership style, process-design, ownership and perceived outcomes in Teacher Design Teams. Paper presented at the ICO National Fall School, Utrecht, The Netherlands.

Binkhorst, F., Poortman, C.L. and van Joolingen, W.R. (2016, January). A qualitative analysis of Teacher Design Teams: Links between leadership, process-design, ownership and perceived outcomes. Paper presented at the International Congress of School Effectiveness and Improvement (ICSEI), Glasgow, Schotland. Awarded with the Professional Development in Education Best Paper Award.

Binkhorst, F., Poortman, C.L., McKenney, S. and van Joolingen W.R. (2016, May). Effectief leiderschap in docentontwikkelteams: Het ontwerpen van een vernieuwde werkwijze. Paper presented at the Onderwijs Research Dagen, Rotterdam, The Netherlands.

Binkhorst, F., Poortman, C.L., McKenney, S., van Joolingen, W.R. (2017, January). Balancing shared and vertical leadership: Evaluating a procedure that supports team coaches to lead Teacher Design Teams. Paper presented at the International Congress of School Effectiveness and Improvement (ICSEI), Ottawa, Canada.

Binkhorst, F., Poortman, C.L., McKenney, S., van Joolingen, W.R. (2017, June). Effectieve Docentontwikkelteams: Evaluatie van een vernieuwde werkwijze. Paper presented at the Onderwijs Research Dagen, Antwerp, Belgium.

\section{Workshops and invited lectures}

Binkhorst, F. (2015, June). Wat maakt DOTs effectief? Invited lecture at: DO's en DON'Ts van DOTs, NVON uitwisselingsbijeenkomst, Utrecht, The Netherlands.

Binkhorst, F. (2016, May). Docentprofessionalisering en vakvernieuwing in Docentontwikkelteams: Hoe kunnen we de opbrengsten optimaliseren? Workshop at the ECENT/ELWIER conference, Utrecht, The Netherlands.

Binkhorst, F. (2016, June). De opbrengsten van DOTs voor professionele ontwikkeling en schoolontwikkeling. Workshop at the DOT Symposium Radboud Docenten Academie, Nijmegen, The Netherlands. 
Verhoef, N., Coenen, T., Binkhorst, F., Behnen, F., Lensink, H., Poortman, C., Wietsma, J.J. (2017, May) PLG onderzoek en praktijk: proces, begeleiding en uitkomsten. Presentation at the ELAN Symposium, Enschede, The Netherlands.

\section{Other publications}

Binkhorst, F. and Poortman, C. (2017). Connecting the DOTs. Een praktische werkwijze voor het coachen van Docent Ontwikkel Teams. Deventer: TechYourFuture.

Binkhorst, F. (2017). Zelfsturend met hulp. Didactief, 47(8).

Binkhorst, F. (in press). Balancing self-regulation and top-down support: A case study of a Teacher Design Team in transition to a new approach. In C. Brown and C.L. Poortman (Eds.), Networks for learning: effective collaboration for teacher, school and system improvement. London: Routledge. 
In the ICO Dissertation Series dissertations are published of graduate studentsfrom faculties and institutes on educational research within the ICO Partner Universities: Eindhoven University of Technology, Leiden University, Maastricht University, Open University of the Netherlands, University of Amsterdam, University of Twente, Utrecht University, VU University Amsterdam, and Wageningen University, and formerly University of Groningen (until 2006), Radboud University Nijmegen (until 2004), and Tilburg University (until 2002). The University of Groningen, University of Antwerp, University of Ghent, and the Erasmus University Rotterdam have been 'ICO 'Network partner' in 2010 and 2011. From 2012 onwards, these ICO Network partners are full ICO partners, and from that period their dissertations will be added to this dissertation series.

326. Lucieer, S.M. (06-01-2016). Selecting Students for Medical Education: Exploring Novel Approaches. Rotterdam: Erasmus University Rotterdam.

327. Ouwehand, K.H.R. (15-01-2016). Effects of Observing and Producing Deictic Gestures on Memory and Learning in Different Age Groups. Rotterdam: Erasmus University Rotterdam.

328. Bogert, N.J. van der (21-01-2016). On teachers' visual perception and interpretation of classroom events using eye tracking and collaborative tagging methodologies. Eindhoven: Eindhoven University of Technology.

329. Wolff, C. (16-02-2016). Revisiting 'withitness': Differences in teachers' representations, perceptions, and interpretations of classroom management. Heerlen: Open University of the Netherlands.

330. Kok, E.M. (01-04-2016). Developing visual expertise; from shades of grey to diagnostic reasoning in radiology. Maastricht: Maastricht University.

331. De Beer, H.T. (11-05-2016). Exploring Instantaneous Speed in Grade Five: A Design Research. Eindhoven: Eindhoven University of Technology. 
332. Ebbeler, J. (12-05-2016). Implementing data use in schools: effects on the professional development of educators and the role of school leaders in data teams. Enschede: University of Twente.

333. Draaijer, S. (10-06-2016). Supporting Teachers in Higher Education in Designing Test Items. Amsterdam: Vrije Universiteit Amsterdam.

334. Bos, L.T. (15-06-2016). Moving Beyond Words. Supporting Text Processing Using a Situation Model approach. Amsterdam: Vrije Universiteit Amsterdam.

335. Vrugte, J. ter (16-06-2016). Serious support for serious gaming. Enschede: University of Twente.

336. Kock, Z.D.Q.P. (23-06-2016). Toward physics education in agreement with the nature of science: Grade 9 electricity as a case. Eindhoven: Eindhoven University of Technology.

337. Trinh Ba, T. (28-6-2016) Development of a course on integrating ICT into inquiry-based science education. Amsterdam: Vrije Universiteit Amsterdam.

338. Gerken, M. (29-06-2016). How do employees learn at work? Understanding informal learning from others in different workplaces. Maastricht: Maastricht University.

339. Louws, M.L. (06-07-2016) Professional learning: what teachers want to learn. Leiden: Leiden University.

340. Geel, M.J.M. van, \& Keuning T. (08-07-2016). Implementation and Effects of a Schoolwide DataBased Decision Making Intervention: a Large-Scale Study. Enschede: University of Twente.

341. Bouwer, I.R., \& Koster, M.P. (02-09-2016) Bringing writing research into the classroom: The effectiveness of Tekster, a newly developed writing program for elementary students. Utrecht: Utrecht University.

342. Reijners, P.B.G. (02-09-2016.) Retrieval as a Cognitive and Metacognitive Study Technique to Learn from Expository Text. Heerlen: Open University of the Netherlands.

343. Hubers, M.D. (08-09-2016). Capacity building by data team members to sustain schools' data use. Enschede: University of Twente.

344. Hsiao, Y.P. (23-09-2016). Peer Support to Facilitate Knowledge Sharing on Complex Tasks. Heerlen: Open University of the Netherlands.

345. Scheer, E.A. (23-09-2016). Data-based decision making put to the test. Enschede: University of Twente. 
346. Bohle Carbonell, K. (28-9-2016). May I ask you....? The influence of Individual, Dyadic, and Network Factors on the Emergence of Information in Exchange Teams. Maastricht: Maastricht University.

347. Claessens, L.C.A. (30-09-2016). Be on my side, I'll be on your side: Teachers' perceptions of teacher-student relationships. Utrecht: Utrecht university.

348. Jansen in de Wal, J. (18-11-2016). Secondary school teachers' motivation for professional learning. Heerlen: Open University of the Netherlands.

349. Kock, W.D. de. (24-11-2016). The effectiveness of hints during computer supported word problem solving. Groningen: University of Groningen.

350. Oonk, C. (07-12-2016). Learning and Teaching in the Regional Learning Environment: Enabling Students and Teachers to Cross Boundaries in Multi-Stakeholder Practices'. Wageningen: Wageningen University.

351. Beckers, J. (09-12-2016). With a little help from my e-portfolio; supporting students' self directed learning in senior vocational education. Maastricht: Maastricht University.

352. Osagie, E.R. (14-12-2016) Learning and Corporate Social Responsibility. A study on the role of the learning organization, individual competencies, goal orientation and the learning climate in the CSR adaptation process. Wageningen: Wageningen University. 


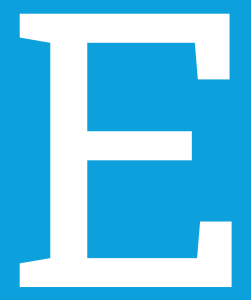

\section{DANKWOORD}

Allereerst wil ik mijn promotoren en copromotor bedanken. De afgelopen vier jaar heb ik ontzettend veel van jullie kunnen leren. Wouter van Joolingen, jij hebt me enthousiast gemaakt over dit onderwerp en je hebt het proces vanaf het begin tot eind meegemaakt. Je hield altijd de grote lijnen in de gaten en je zorgde ervoor dat het onderzoek de kant op bleef gaan zoals het oorspronkelijk bedoeld was. Susan McKenney, aangezien jij er later bij kwam kon je een frisse blik op het project werpen. Door jouw expertise, je positieve en scherpe inbreng kreeg het onderzoek weer een nieuwe impuls. Cindy Poortman, ook jij kwam er later bij, al heb ik het gevoel dat je er al vanaf het begin bij was. Door jouw gedetailleerde feedback en gestructureerde werkwijze, kon het onderzoek gestaag voortgang boeken. En daarnaast - ook niet onbelangrijk - zorgde je voor veel gezelligheid bij de vele (dans)avonden bij conferenties. Ook Adam Handelzalts, mijn begeleider tijdens het eerste jaar van het onderzoek, verdient hier een bijzondere vermelding. Jij hebt ervoor gezorgd dat het project vanaf het begin een duidelijke structuur kreeg, waar we de jaren daarna nog veel van hebben geprofiteerd.

Ook wil ik TechYourFuture bedanken voor het mogelijk maken van dit project, met name Jos Brunninkhuis en Maria Hendriks. Bedankt voor jullie betrokkenheid de afgelopen vier jaar.

Mijn dank is ook groot aan alle respondenten in dit onderzoek. Allereerst de deelnemende docenten, bedankt dat ik jullie DOT-deelname mocht volgen en dat jullie bereid waren om tijd vrij te maken voor mijn vragenlijsten en interviews. En natuurlijk alle teamcoaches, voor het meewerken aan interviews en het invullen van de vele logboeken. Hierbij wil ik vooral Fer Coenders en Jan Jaap Wietsma bedanken, voor het meedenken aan de vernieuwde werkwijze en de bereidheid om deze toe te passen in hun DOTs.

Daarnaast dank ik ook alle andere collega's van ELAN. Door aan de ene kant de inhoudelijke colloquia, onderzoeksoverleggen en PEP-bijeenkomsten en aan de andere kant de gezellige koffiepauzes, lunches en wandelingen over de campus bleef het voor mij vier jaar lang de moeite waard om heen en weer te reizen tussen Nijmegen en Enschede. 
En volgens mij is het schrijven van een proefschrift onmogelijk zonder vrienden die je kunnen ondersteunen en afleiden met leuke dingen zoals etentjes, snowboardvakanties, festivals, stedentrips, spelletjesavonden, speciaalbierproeverijen, wijnproeverijen, andere proeverijen of gewoon een goed gesprek. Bedankt vrienden, jullie maakten mijn promotietraject een stuk gezelliger!

Lieve familie en schoonfamilie, jullie vormen een belangrijke uitvalbasis. Jullie hebben het hele promotietraject op de voet gevolgd en leefden mee met elke hobbel en met elk succes. In het bijzonder wil ik mijn ouders Aad en Nora bedanken. Jullie hebben me altijd gestimuleerd om te doen wat ik leuk vind, zonder me een bepaalde kant op te pushen.

Tot slot, lieve Bernard, dankjewel dat je er altijd voor me bent. Bij jou voel ik me thuis en kan ik zijn wie ik ben. Met jou kan ik lachen, gek doen, huilen en serieuze gesprekken voeren. Wij zijn een hecht team, en samen kunnen we de hele wereld aan! 